\title{
EXTRACELLULAR INVESTIGATION OF ACTIVE HEARING AND INTRACELLULAR INVESTIGATION OF AUDITORY PROCESSING IN NOCTUID MOTHS
}

by

Scott M. Whitehead, B.Sc.H

A thesis submitted to the Faculty of Graduate Studies and Research in partial fulfillment of the requirements for the degree of

Master of Science

Biology Department

Ottawa-Carleton Institute of Biology

Carleton University

Ottawa, Ontario

December 1, 2008

(C) Copyright, 2008 


$\begin{array}{ll}\begin{array}{l}\text { Library and } \\ \text { Archives Canada }\end{array} & \begin{array}{l}\text { Bibliothèque et } \\ \text { Archives Canada }\end{array} \\ \begin{array}{l}\text { Published Heritage } \\ \text { Branch }\end{array} & \begin{array}{l}\text { Direction du } \\ \text { Patrimoine de l'édition }\end{array} \\ \begin{array}{l}\text { 395 Wellington Street } \\ \text { Ottawa ON K1A 0N4 } \\ \text { Canada }\end{array} & \begin{array}{l}\text { 395, rue Wellington } \\ \text { Ottawa ON K1A 0N4 } \\ \text { Canada }\end{array}\end{array}$

Your file Votre référence ISBN: 978-0-494-47538-6

Ourfile Notre référence

ISBN: 978-0-494-47538-6

NOTICE:

The author has granted a nonexclusive license allowing Library and Archives Canada to reproduce, publish, archive, preserve, conserve, communicate to the public by telecommunication or on the Internet, loan, distribute and sell theses worldwide, for commercial or noncommercial purposes, in microform, paper, electronic and/or any other formats.

The author retains copyright ownership and moral rights in this thesis. Neither the thesis nor substantial extracts from it may be printed or otherwise reproduced without the author's permission.
AVIS:

L'auteur a accordé une licence non exclusive permettant à la Bibliothèque et Archives Canada de reproduire, publier, archiver, sauvegarder, conserver, transmettre au public par télécommunication ou par l'Internet, prêter, distribuer et vendre des thèses partout dans le monde, à des fins commerciales ou autres, sur support microforme, papier, électronique et/ou autres formats.

L'auteur conserve la propriété du droit d'auteur et des droits moraux qui protège cette thèse. $\mathrm{Ni}$ la thèse ni des extraits substantiels de celle-ci ne doivent être imprimés ou autrement reproduits sans son autorisation.
In compliance with the Canadian Privacy Act some supporting forms may have been removed from this thesis.

While these forms may be included in the document page count, their removal does not represent any loss of content from the thesis.
Conformément à la loi canadienne sur la protection de la vie privée, quelques formulaires secondaires ont été enlevés de cette thèse.

Bien que ces formulaires aient inclus dans la pagination, il n'y aura aucun contenu manquant.

\section{Canada}


ABSTRACT

A recent study by Windmill et al. (2006) suggested that the noctuid moth, Noctua pronuba, is capable of actively tuning its membrane in order to be more sensitive to the higher echolocation frequencies used by bats. This occurs in response to high intensity auditory stimulation and is hysteretic lasting for an average of 7.5 minutes. Windmill et al. (2006) proposed that the moth is doing this in order to more accurately detect the bat should it return. The first chapter of this thesis tests Windmill's hypothesis. Linear regression analysis showed no significant change in afferent response as a function of time for Noctua pronuba, Noctua pronuba that had transected auditory afferents, Acronicta americana, Xestia dolosa, or Catocala ultronia. Amphipyra pyramidiodes showed significantly reduced sensitivity. The second chapter of this thesis used intracellular recording techniques to identify auditory afferents and additional auditory interneurons and deduce whether or not they are making direct connections with flight motorneurons. Two cells are described: (1) The possible B-cell gave an average instantaneous spike rate of $30.78 \pm 1.29 \mathrm{~Hz}$ and closely resembled the B-cell morphology suggested in Surlykke and Miller (1982). (2) The possible motorneuron showing auditory influence was constantly spiking at an average rate of $46.75 \pm 4.91 \mathrm{~Hz}$. Presentation of an auditory stimulus increased firing rate to an average of $94.72 \pm$ $15.56 \mathrm{~Hz}$. 


\section{ACKNOWLEDEDGEMENTS}

First and foremost, I would like to thank Dr. Jeff Dawson for both inspiring me and allowing me the opportunity to pursue graduate level studies. Through flourishing times and times of stress your guidance as both a mentor and a friend will not be forgotten.

I would like to thank the Dawson team/Insect Flight Group, Amanda, Lauren, Ryan, Katharina and Trish for their friendly advice and their willingness to lend a helping hand throughout the course of my graduate career, also, thanks to Allison for the surprise snacks and "free" coffees. Thanks to the Yack Lab, Jackie, AJ, and Katie and the Lewis Lab for your friendship and advice and a big thank you to Dr. Gerald Pollack for giving me the opportunity to learn intracellular recording techniques first hand.

I would like to thank Dr. James Fullard (University of Toronto), Matt Jackson and Navdeep Asi for their advice concerning my research and their friendly accommodation during my many visits to their lab at the Queen's University Biology Station.

Thank you to my thesis advisors, Dr. Jayne Yack and Dr. John Lewis, for your guidance, constructive comments and patient attitude towards an ambitious and constantly changing project. Allowing me to pursue multiple research interests/physiological techniques has definitely left me richer for the experience.

Thanks to the entire Carleton University Biology Department and to all the new friends I have made since coming to Ottawa. Because of you I will always be able to look back fondly at my time spent here.

This thesis was made possible by generous equipment loans from Dr. James Fullard, Dr. John Lewis and Dr. Susan Bertram. I am also grateful for funding from the School of 
Graduate Studies and Research at Carleton. This project was funded by grants from NSERC and the Faculty of Science awarded to Dr. Dawson. 


\section{TABLE OF CONTENTS}

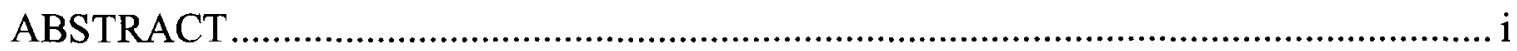

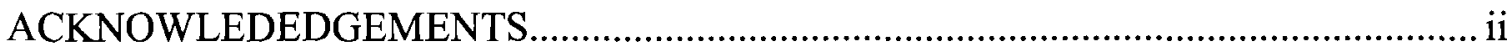

TABLE OF CONTENTS ......................................................................................... iv

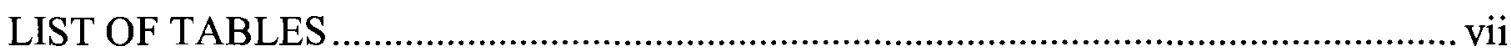

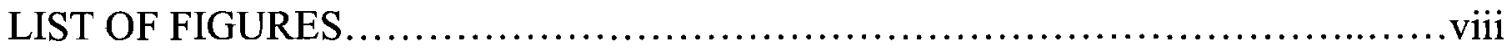

\section{CHAPTER 1}

General Introduction and Literature Review ............................................................... 11

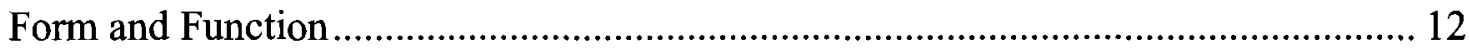

Physical Constraints on Sound Reception in Insects. ............................................... 15

Active Mechanisms in Insect Hearing ................................................................. 20

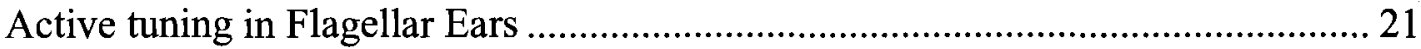

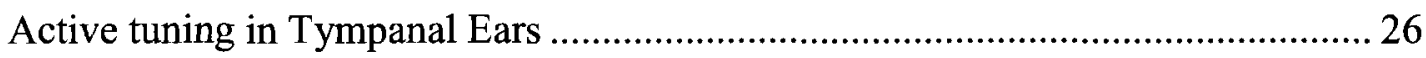

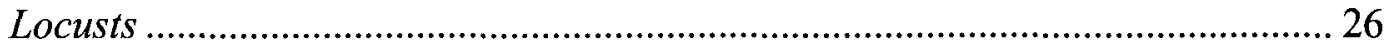

Moths

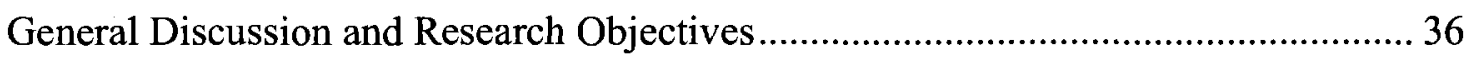

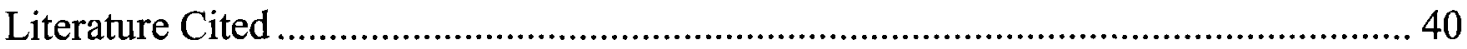




\section{CHAPTER 2}

Extracellular Investigation of Active Hearing in the noctuid Moth, Noctua pronuba ..... 46

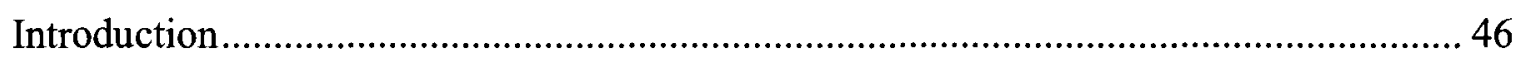

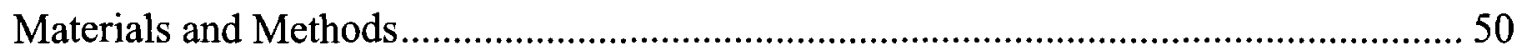

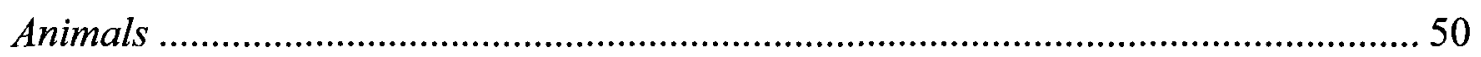

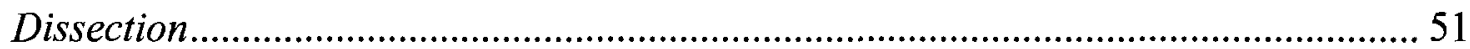

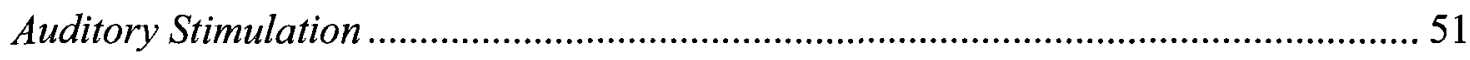

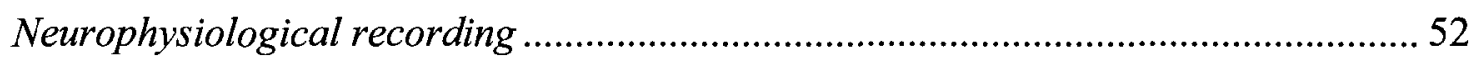

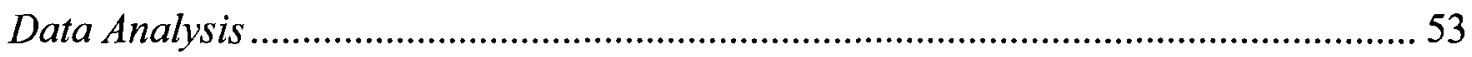

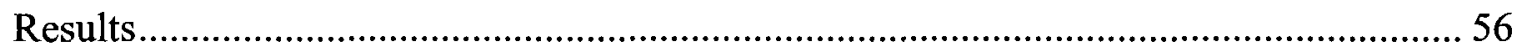

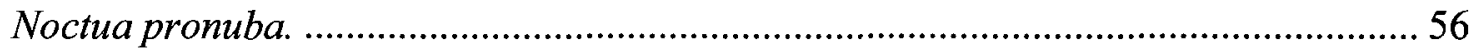

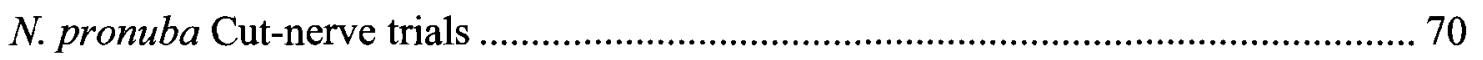

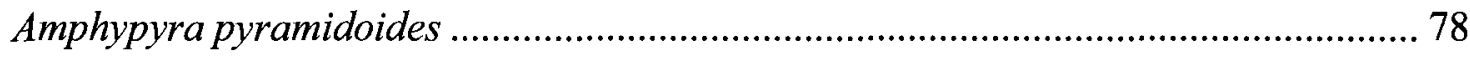

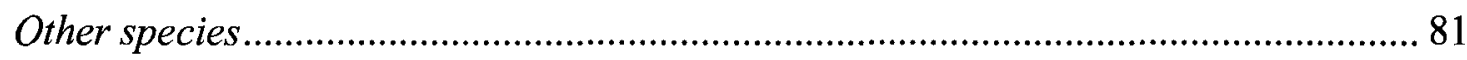

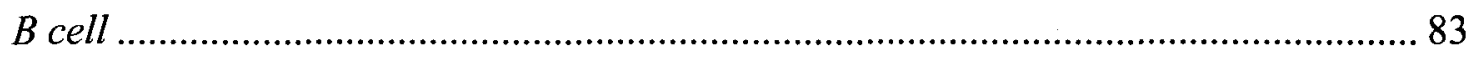

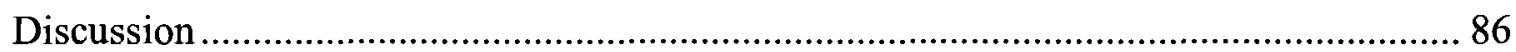

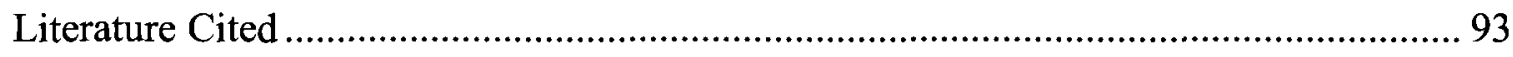




\section{CHAPTER 3}

Intracellular Investigation of Auditory Processing in the noctuid Moth ...................... 97

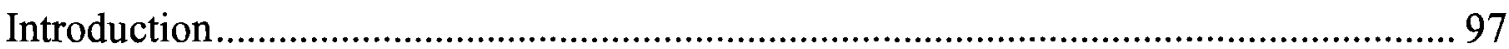

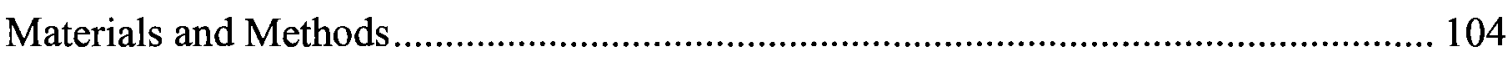

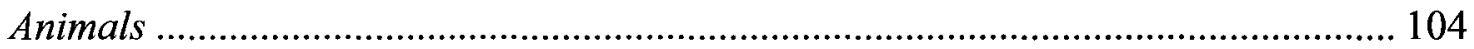

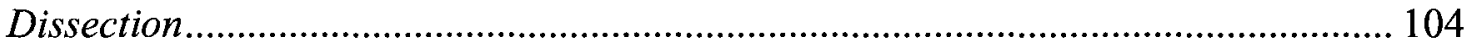

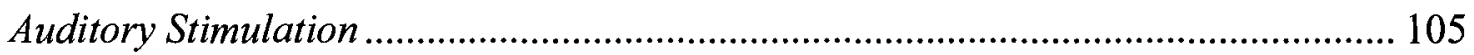

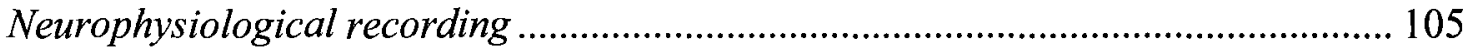

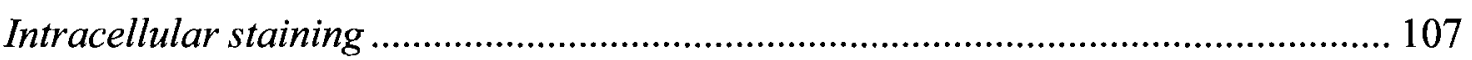

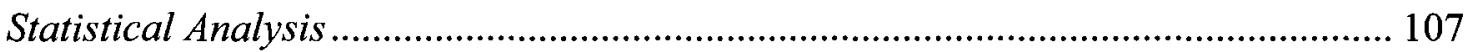

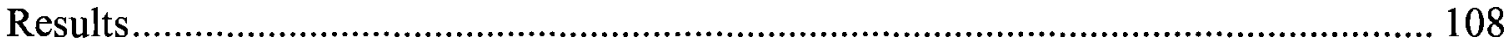

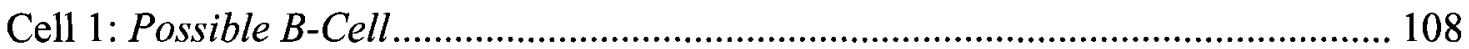

Cell 2: Motor neuron showing auditory influence .............................................. 116

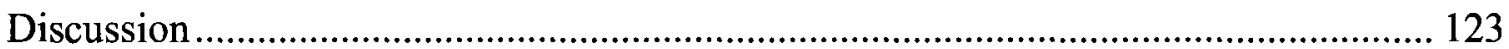

Neuron 1: Possible B-Cell ..................................................................................... 123

Neuron 2: Motor neuron showing auditory influence ......................................... 124

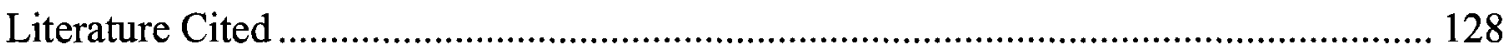

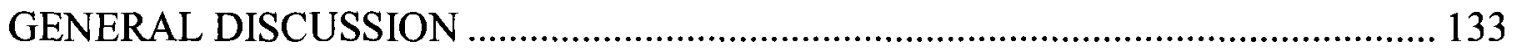

APPENDIX 1

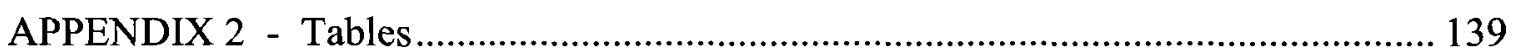

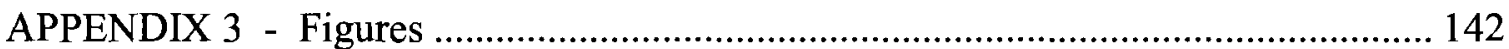




\section{LIST OF TABLES}

Table 1. T-statistics and $p$ values given for Early vs. Late, Early vs. Re and Late vs. Re comparisons. This table includes both N. pronuba and N. pronuba CUT trials. Yellow boxes indicate a statistically significant result.

Table 2. Regression statistics for $N$. pronuba indicating both the F-statistic and $p$ values. Binom column gives Binomail test statistic as the likelihood of achieving Xnumber of significant values across the total sample size. 68

Table 3. Regression statistics for $N$. pronuba CUT indicating both the F-statistic and $p$ values. Binom column gives Binomail test statistic as the likelihood of achieving $\mathrm{X}$-number of significant values across the total sample size.

Table 4. Regression statistics for $A$. pyramidoides indicating both the F-statistic and $p$ values. Binom column gives Binomail test statistic as the likelihood of achieving $\mathrm{X}$-number of significant values across the total sample size.

Table 5. Regression statistics for A. americana, X. dolosa, and C. ultronia indicating both the F-statistic and $p$ values. Binom column gives Binomail test statistic as the likelihood of achieving X-number of significant values across the total sample size. 


\section{LIST OF FIGURES}

Figure 1. (A) Sound wave represented by a propagating pure tone sine wave. (B) Interaural time difference (ITD) as a function of azimuthal angle $\left[^{\circ}\right]$ for a human and a fly......

Figure 2. Distortion product otoacoustic emissions recorded from the tympanal ear of Locusta migratoria. 28

Figure 3. Frequency spectrum showing both the magnitude of response and phase of response of the tympanum of Noctua pronuba as a result of stimulation with $80 \mathrm{~ms}$ frequency sweeps from $20-80 \mathrm{kHz}$ 34

Figure 4. (A) Neural audiogram from Noctua pronuba. (B) Oscillogram of a typical pursuit sequence for the big brown bat, Eptesicus fuscus. 37

Figure 5. Illustration of stimulus protocol 54

Figure 6. Typical extracellular recording of response to auditory stimulation as seen in $N$. pronuba. 57

Figure 7. Early, Late and RE data compared at $42 \mathrm{kHz}$ and $74 \mathrm{kHz}$ for $N$. pronuba. 61

Figure 8. Time series data for interspike interval in N. pronuba trials plotted over tympanal velocity data from Windmill et al. (2006). 64

Figure 9. Time series data for latency in N. pronuba trials plotted over tympanal velocity data from Windmill et al. (2006) 66

Figure 10. Early, Late and RE data compared at $42 \mathrm{kHz}$ and $74 \mathrm{kHz}$ for $N$. pronuba CUT 
Figure 11. Time series data for spike number in $N$. pronuba CUT trials plotted over tympanal velocity data from Windmill et al. (2006).

Figure 12. Time series data for spike number in $A$. pyramidiodes trials plotted over tympanal velocity data from Windmill et al. (2006)

Figure 13. Instantaneous B-cell firing rate $(\mathrm{Hz})$ given as an average across specific groups of moths.

Figure 14. Pterothorascic ganglion containing possible noctuid moth B-cell stained by ionophoretic injection of Alexa Fluor 488 (A10436) and viewed with a fluorescent microscope..

Figure 15. Intracellular instantaneous firing rate $(\mathrm{Hz})$ for a possible noctuid moth B-Cell.

Figure 16. Intracellular trace of possible noctuid moth B-cell.

Figure 17. Intracellular recording from possible noctuid moth motorneuron showing auditory influence..

Figure 18. Intracellular instantaneous firing rate for a possible noctuid moth motor neuron showing auditory influence

Figure 19. Intracellular latency values for a possible noctuid moth motor neuron showing auditory influence

Figure 20. Time series data for spike number and burst duration in N. pronuba trials plotted over tympanal velocity data from Windmill et al. (2006). 
Figure 21. Time series data for interspike interval, burst duration and latency in $N$. pronuba CUT trials plotted over tympanal velocity data from Windmill et al. (2006)

Figure 22. Time series data for interspike interval, burst duration and latency in $A$. pyramidiodes trials plotted over tympanal velocity data from Windmill et al. (2006)

Figure 23. Time series data for spike number, interspike interval, burst duration and latency in A. americana, $X$. dolosa, and C. ultronia trials plotted over tympanal velocity data from Windmill et al. (2006). 


\section{CHAPTER 1}

\section{General Introduction and Literature Review}

Insects are marvels of evolution. At first glance they may seem to the casual observer quite basic in both form and function, but on closer inspection this is far from the truth. Since their emergence approximately 400 million years ago they have developed into an estimated 5-30 million different species organized into 30 different orders, accounting for as much as $75 \%$ of all known animal life on earth. Only about a million species have been scientifically described to date.

It comes as no surprise that such diversity has brought with it a great variety of structural and sensory specializations allowing insects to exploit many different habitats. Flying dragonflies (Order: Odonata) patrol the skies using a flight system capable of producing aerial maneuvers that even our most advanced aircraft are not capable of. Cicadas (Order: Hemiptera) are capable of producing mating calls that exceed 106 decibels, while crickets (Order: Orthoptera) decipher from which direction a potential mate is chirping using specialized ears located on their legs. Fireflies (Order: Coleoptera) are capable of producing their own bioluminescence to attract mates by employing a controlled chemical reaction in their abdomen. Some moths are even capable of intercepting the ultrasonic chirps of bats using tympanal ears capable of hearing frequencies in excess of $150 \mathrm{kHz}$. Adult humans, in contrast, can only hear frequencies up to about $17 \mathrm{kHz}$.

Considering the amazing processing capabilities of the insect auditory system it is not surprising that in excess of one century's worth of physiological research has been 
devoted to uncovering their underlying mechanisms. Insect ears are thought to have independently evolved at least 17 times (Yack and Dawson, 2008). What scientists have found through years of study is, in most cases, an anatomically less complex auditory system compared to vertebrates, although, it is one that is capable of some magnificent feats of auditory processing while at the same time comprising the most structurally diverse array of hearing apparati known in nature (Yack, 2004). Insects use their auditory systems for much of the same reasons that other animals do. They can be used in intrapersonal communication, which in most cases relates to mating. The mating calls of crickets and cicadas are forms of insect communication that most everyone has had the opportunity upon which to eavesdrop. Insects also use their ears for detecting predators. Many moths use their highly tuned ultrasound sensitive ears to detect the echolocation calls of night flying bats in order to avoid predation (Roeder, 1967). Insects even use their ears to detect sources of prey. Parasitic flies, such as Ormia ocharcea, can listen for the mating calls of their cricket hosts and use them to detect their specific location (Cade, 1975).

\section{Form and Function}

Structurally, insect ears come in two forms; flagellar and tympanal. Flagellar ears are near field sound detectors that consist of an antennal shaft connected to a sensory organ at the base, commonly referred to as Johnston's organ (Johnston, 1855). Near field sound receivers detect and encode the particle movement component of sound as they move from side to side in response to an impinging sound wave. Johnston's organ can 
vary quite extensively in size, function and complexity between species. Surprisingly, the mosquito flagellar ear may be the most complex of all insect ears. The culicid mosquitoes Johnston's organ packs about 15,000 scolopidial (sensory) cells, or the approximate number of hair cells found in the human cochlea, into a space about one hundred thousand times smaller (Boo and Richards, 1975).

Tympanal ears can be found almost anywhere on the insect body (Yack and Fullard, 1993) and consist of three functional parts (Yager, 1999): the tympanum, the trachael air sack, and the tympanal organ. The tympanum consists of a thin piece of cuticle supported by a cuticular rim. This structure is responsible for transducing the pressure component of sound into mechanical vibrations. Tympani can vary in their size, shape, and thickness with all of these characteristics interacting to form the insect's specific mechanical representation of a sound stimulus. A great example of this is seen in the locust whose tympanum is made up of four distinct regions, all of varying thickness and size, which interact to assist in the discrimination of different sound frequencies (Michelsen, 1971; Stephen and Bennet, 1982). Ormia ochracea is another amazing example in that its tympanal membranes are located less than $0.5 \mathrm{~mm}$ apart but are capable of distinguishing submicrosecond differences in the time of arrival of incident sound waves (Robert et al., 1996).

The tracheal air sack is the air pocket located behind the tympanum that houses the tympanal organ. Tracheal air sacks can either act in unison with adjacent ears through direct tracheal connections, as seen in crickets (Larsen and Michelsen, 1978), or 
stand alone in supporting the function of a single ear as seen in the noctuid moth (Roeder and Treat, 1957).

The tympanal organ is a multicellular mechanoreceptive unit responsible for the transduction of mechanical vibrations of the tympanum into neural impulses. Insect mechanoreceptors are commonly referred to as chordotonal organs (Yack and Fullard, 1993; Hoy and Robert; 1996; Yager, 1999; Yack, 2004). A single chordotonal organ is comprised of a group of mechanoreceptive units termed chordotonal sensilla or scolopidia (Field and Matheson, 1998). Each scolopidium consists of four linearly arranged cell types (Yack, 2004) the primary cell type being an arrangement of one to four bipolar sensory neurons. The other three cell types are considered accessory cells which include: (1) A scolopidial cell enclosing dendrites of the primary sensory neurons; (2) attachment cells (one or more) located at the distal region of the sclopidial cell; and (3) a glial sheath cell (one or more) associated with the proximal region of the primary sensory neurons.

After a sound wave is received by either a flagellar or tympanal ear and transduction of the signal into neural energy by the chordotonal organ is completed it is carried to the central nervous system (CNS) by the auditory afferent neurons for further processing.

There are three important features of any auditory stimulus, all, or a combination of which, must be processed in parallel to gain an appropriate picture of the insect's auditory world. These parameters are frequency, intensity and the direction from which the sound is propagated (Pollack, 2000). Different organisms have different hearing 
ranges, referring to the range of sound frequencies that an organism is physiologically capable of recognizing. Humans, for example, are capable of hearing sounds in the range of about $20 \mathrm{~Hz}$ to $17 \mathrm{kHz}$, while noctuid moths are generally capable of hearing sounds from $1 \mathrm{kHz}$ to over $100 \mathrm{kHz}$ with some even capable of hearing sounds in the range of $200 \mathrm{kHz}$ (Robert and Hoy, 2007). Ears require specific sound energy levels to be capable of detecting a sound at a given frequency. How sensitive an ear is refers to its ability to detect low energy sounds. This is commonly referred to as an auditory threshold. A noctuid moth will generally have a best frequency of approximately $20 \mathrm{kHz}$ (See Roeder, 1967 for review) meaning that this is the frequency where the moth can detect sound at the lowest intensity. So, at $50 \mathrm{kHz}$, the moth would need more sound energy to detect the sound than it would at $20 \mathrm{kHz}$ (its threshold at $50 \mathrm{kHz}$ is higher). Directional hearing refers to the insect's ability to localize a sound source in space. This is done by combining time of arrival of the sound at each ear with the perceived intensity at each ear. The closer together an animals ears are the harder it is for that particular animal to perceive the differences in time of arrival and intensity of the sound. So it will come as no surprise that insects have had to evolve some rather creative mechanisms to counteract the limits imposed on their auditory systems by their small body size.

\section{Physical Constraints on Sound Reception in Insects}

The physical properties of a traveling sound wave have different implications on both flagellar (near field) and tympanal ears (far field). Pressure (p) and particle velocity (v) are the two components that make up a sound wave such that $\mathrm{p}=\mathrm{Zv}$, where $\mathrm{Z}$ is the acoustic impedance of the medium through which the sound is traveling in $\mathrm{N} \cdot \mathrm{s} / \mathrm{m}^{3}$. This 
relationship is equivalent to the relationship given for Ohm's law for electricity which states that $V=I R\left(V=\right.$ voltage, $I=$ current, $R=$ resistance). Overall intensity $\left(\mathrm{Wat} / \mathrm{m}^{2}\right)$ of a sound can be represented by I where $I=p v$. The particle velocity component of sound only dominates in very close proximity to the sound source (a few wavelengths) while at greater distances the pressure component dominates.

In studying near field sound reception, Tichner (1953) was first to observe that the male mosquito uses its antennae to detect the buzzing of the females wings during flight. Jackson and Robert (2006) characterized how this sound is attenuated as a function of distance from the female mosquito. As the male mosquito reaches $15-20 \mathrm{~mm}$ in distance from the female there is an almost complete attenuation of the particle velocity component of sound

At greater distances (values for distance depend on wavelength of the sound) a tympanal ear is most efficient. If a sound wave is represented by a sine wave of a constant frequency (pure tone) then it can be said that it consists of 3 specific parameters: amplitude, frequency, and direction. At $20^{\circ}$ Celsius and $20 \%$ relative humidity a sound wave will travel at approximately 343 meters per second. A human standing some distance from a sound source will have the propagating sound wave hit each of their ears at a slightly different time depending on what angle she is standing relative to the source. By processing the difference in the sound's time of arrival at each ear the human can infer from what direction the sound is coming. The ear closest to the sound source is referred to as the ipsilateral ear and the further ear is the contralateral ear. The difference in the sound's time of arrival at each ear is referred to as the interaural time difference 
(ITD) (Fig. 1A). Another useful property of a sound wave to consider is the attenuation of the wave that occurs as it passes around the human's head to reach the contralateral ear. If the ratio of wavelength relative to the size of an interfering solid object (ie. the head of a human) is $10: 1$ or less the sound wave will be diffracted and thereby attenuated before it reaches the contralateral ear. The resulting difference in sound amplitude at the opposing ear is referred to as the interaural intensity difference (IID) (Fig 1A). Azimuthal angle describes at which angle a sound source is located relative to the midline of an animal. If a sound source is $90^{\circ}$ off the midline then the ITD for the particular organism will be at a maximum. In a human this would be equivalent to $500 \mu \mathrm{s}$ ITD and $1.5 \mu \mathrm{s}$ in a fly (Fig 1B). As azimuth is decreased the ITD also decreases. This would mean that for a fly, such as Ormia ocharcea, ITD would become a sub microsecond value at azimuth values below $45^{\circ}$ (Mason et al, 2001). 
Figure 1. (A) A sound wave represented by a propagating pure tone sine wave. Dark and light lines represent physical characteristics of a single wave at the ipsilateral and contralateral ears respectively. As a function of time the peak of the sine wave arrives at the contralateral ear later resulting in an interaural time difference $(\partial t)$. As a function of sound pressure the sound wave is attenuated as it passes around the body of the animal to the contralateral ear resulting in an interaural intensity difference $(\partial A)$. These phenomena combined can be used to elucidate from what direction a sound wave is propagating with the ear ipsilateral to the sound source receiving more intense stimulation (greater amplitude) before the contralateral ear. (B) Interaural time difference (ITD) as a function of azimuthal angle [ $\left.{ }^{\circ}\right]$ for the human and the fly. Azimuthal angle refers to the angle of incidence of a propagating sound wave relative to the midline of the organism. At $0^{\circ}$ ITD is equal to 0 as the sound wave reaches each ear at the same time. As the angle is increased to $90^{\circ}$ the ITD increases to reach a maximum of $500 \mu \mathrm{s}$ in the human and $1.5 \mu \mathrm{s}$ in the fly. (Taken from Robert and Hoy, 2007) 

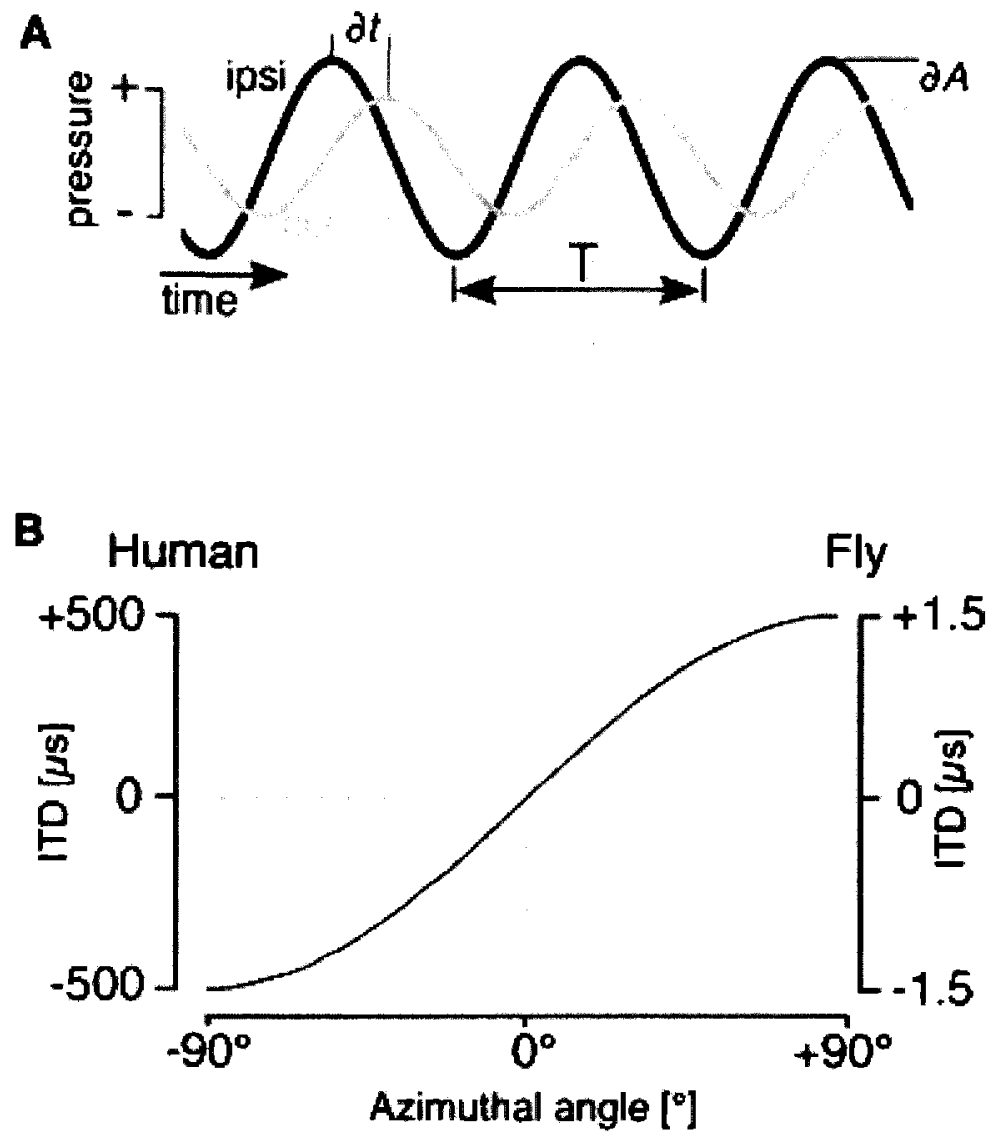


\section{Active Mechanisms in Insect Hearing}

As the study of passive mechanical characteristics of insects ears progressed so did the technology used to isolate them. The laser Doppler vibrometer, for example, is a tool capable of detecting microscale vibrations of both insect antennal and tympanal ears. Göpfert and Robert (2000) were one of the first teams to use the laser Doppler vibrometer to investigate the hearing characteristics of insects. When they first pointed the laser at the antenna of a mosquito, Toxorhynchites brevipalpis, they noticed a conspicuously nonlinear tuning response (Göpfert and Robert, 2001). This suggested that some physiological process was affecting the antenna's ability to vibrate as predicted for a simple (passive) harmonic oscillator. These findings suggested that some insects may be using active mechanics to modify passive characteristics of their auditory systems gaining yet another advantage in their ability to exploit the "would be" limitations of their auditory world. Since the initial work on mosquito antennal receivers (Göpfert et al., 1999; Göpfert and Robert, 2000; 2001) scientists have expanded the investigation of insect active hearing to include moths (Windmill et al., 2006; 2007; Kössl et al., 2007), locusts (Windmill et al., 2005), and Drosophila (Göpfert and Robert, 2003; Göpfert et al., 2005; 2006). This research has given scientists insight into the features necessary for an active hearing system, in addition to developmental, genetic, and physiological constraints on their functioning (Göpfert and Robert, 2007).

The four essential characteristics of active hearing according to Göpfert and Robert (2007) are as follows: (1) there must be a comprehensive nonlinearity in the tuning response of a particular hearing apparatus that serves to condense a wide range of 
stimulus amplitudes into a defined range of mechanical responses, (2) a frequency selectivity effect where the hearing apparatus can actively select and amplify certain frequencies in order to improve sensitivity, (3) the ability to produce self sustained mechanical oscillations, or the presence of otoacoustic emissions (ie. a spontaneous mechanical response of the ear that can be recorded as sound emitted by the ear), and (4) the response must reflect a physiological expenditure of energy, or power gain, that is a necessary component in producing the response. Point number four would imply that any animal capable of active tuning would lose the response under some forms of physiological stress or after death.

Active tuning in Flagellar Ears

As previously mentioned Göpfert and Robert (2001) were the first to notice that stimulating a mosquito with a near field sound and simultaneously recording the oscillations of its antenna with a laser Doppler vibrometer would result in a nonlinear response output. Specifically, they noticed that antennal oscillations would display a maximal response and phase transition that deviated from a linear relationship at the insect's best (resonant) frequency, a finding that would not be expected for a simple (passive) harmonic oscillator. Starting at background room noise and gradually increasing the intensity of their stimulus (carrier frequency of $380 \mathrm{~Hz}$ ) produced an antennal displacement $(\mu \mathrm{m})$ versus sound particle displacement $(\mu \mathrm{m})$ consisting of three distinct regions: (1) as the sound intensity was increased from background noise to about $0.3 \mu \mathrm{m}$ sound particle displacement (SPD), and tip displacement (TD) also increased in a 
linear fashion, (2) as SPD was increased from about $0.3 \mu \mathrm{m}$ to $1.0 \mu \mathrm{m}$, the TD diverged from a linear relationship with SPD and gave higher than expected valued for TD, (3) as SPD approached $1.0 \mu \mathrm{m}$, TD gradually returned to a linear relationship and eventually became compressed (less then expected values for TD).

On closer inspection, Göpfert and Robert (2001) also noticed a distinct sharpening in the frequency tuning of the antennal receiver as the stimulus amplitude was reduced. For both very low and high intensities the antennal receiver showed a broad tuning curve while stimuli at medium intensities showed a tighter tuning curve and increased gain.

When physiological vulnerability was tested their findings were confirmed. Both dead and anesthetized mosquitoes showed no gain effects when stimulated at the previous stimulus intensities (Göpfert and Robert, 2001). Finally, what confirmed the mosquito's auditory system as a true active hearing system was the presence of self sustaining receiver oscillations (Göpfert and Robert, 2001). When the mosquito was given a thoracic injection of dimethyl sulphoxide (DMSO), a chemical known to affect mechanotransduction by chordotonal sensilla, self sustaining oscillations could be readily induced. These oscillations, which were greater than those expected in the presence of background noise, could be suppressed by the presentation of tones of similar frequencies and disappeared with death. Jackson and Robert (2006) were next in adding to the active component of mosquito hearing by isolating and assigning a biologically relevant use to it. The male mosquito's auditory system is designed to detect the characteristic buzzing of the females wing beats during flight. As the sound of a passing female is played to a restrained male mosquito the antennal recordings show a small peak sensitivity shift, or 
increase in antennal response magnitude, that precedes presentation of maximum stimulus intensity. As the female stimulus reaches its maximum intensity the antennal response decreases, after which it again sharply increases to form a maximum peak in sensitivity about one second after peak stimulus intensity.

Considering the data given in Jackson and Robert (2006) it becomes apparent that the male mosquito is effectively increasing the time that it can hear the female mosquito by increasing sensitivity both pre and post peak stimulus presentation. This, in effect, creates an elongated window where the male is capable of detecting the female. This effect is not seen in dead or anesthetized flies. The increased window of opportunity for the male mosquito to detect the female may not seem significant until one considers the severe attenuation that presents itself in the world of near field sound detection. A behavioral study by Gibson and Russel (2006) published about one month prior to the submission of Jackson and Robert (2006) foreshadowed the importance of listening for mates by suggesting that wing beat frequencies play an integral role in mate recognition. Their study first showed that mosquitoes have an average wing beat frequency of about $420 \mathrm{~Hz}$ that routinely varies in the range of about $300 \mathrm{~Hz}$ to $500 \mathrm{~Hz}$. Given this preliminary data they asked: what, if anything, happens behaviorally when a female enters the auditory space of a male? Initial findings indicate that if a male mosquito flying at a $435 \mathrm{~Hz}$ wing beat frequency was probed with a $450 \mathrm{~Hz}$ synthetic stimulus pulse that it will increase its wing beat frequency to match the stimulus frequency. This response was found to be hysteretic in that the male would hold the probed stimulus frequency for a period of time after the removal of the stimulus. The next step was to 
look at what happened to the male's wing beat frequency in the presence of a female mosquito. Two tethered mosquitoes of opposite sexes were brought in close proximity to one another and a similar result occurred: the male would either change its flight frequency to match the female or they would compromise and meet halfway. The flying in tune response would occur in a matter of seconds and, interestingly enough, this is about the same amount of time it takes for gain fluctuations to occur in antennal mechanics as shown by Jackson and Robert (2006). The final experiment in Gibson and Russel (2006) looked at changes in wing beat frequency as a result of bringing two males together. In such cases male mosquitoes tend to diverge in their flight frequencies, the possible result of competition for auditory space. The role of active mechanics in auditory convergence and divergence is an intriguing source of future study.

The next question, considering that the mosquito meets the necessary criteria for active hearing, is where the active process is initiated. Two possible answers exist: (1) either the point of activation for an auditory process lies within the muscles surrounding or within the active structure, or (2) within some other anatomical component of the structure itself. In the case of mosquitoes the antennal structure is known to rotate about the second to proximal antennal segment, a segment which contains no internal musculature (Göpfert and Robert, 2001). This would imply that the active mechanism lies within the chordotonal organ connecting to the base of the segment. Although the cellular origins of active hearing have yet to be explored in mosquitoes, the ears of Drosophila melanogaster offer an ideal system through which to explore these processes. 
Work by Kim et al. (2003) was first to investigate the molecular/genetic identity of the ion channels in dipteran chordotonal sensilla. Findings indicate that, in Drosophila, an ion channel referred to as NOMPC is necessary for the production of receptor potentials in sensory neurons but not for a mechanical response to occur to sound. In addition, Nanchung protein (Nan), a protein similar to the vanilloid receptor related (TRPV) channels found in vertebrates, is exclusively expressed in the sensory cilia of Drosoplila chordotonal organs and is necessary for the production of antennal sound evoked potentials. Göpfert et al. (2006) expanded on this by showing that flies with a NOMPC mutation showed a lack of spontaneously evoked oscillations, while on the other hand, flies with a Nan mutation (Nan protein is a subunit of Nan-Iav channels) showed an increased frequency of spontaneously evoked oscillations. NOMPC/Nan double mutants showed a response somewhere between the single mutant values. It is now assumed that NOMPC and Nan-Iav channels work together to regulate the sensitivity of the Drosophila ear with NOMPC being responsible for the overall amplification process and Nan-Iav being responsible for the amount of gain produced (Robert and Hoy, 2007).

Mosquitoes and Drosophila serve as two excellent examples of how insects with flagellar auditory structures use active mechanical feedback to more precisely tune their ears to relevant stimuli. They each fulfill the four essential characteristics of active hearing given in Göpfert and Robert (2007). While mosquitoes served as an ideal system in which to study both the behavioral and mechanical aspects of active hearing in the near field, Drosophila filled the gap by showing cellular/molecular characteristics of the 
system and its genetic constraints. This data combined gives an excellent picture of active tuning by starting with behavioral context and gradually stripping it down to its mechanical component parts and ultimately its molecular origin. Having such a diverse array of data is advantageous in that it more readily lends itself to both inter- and intraspecies comparisons. The striking similarities between vertebrate hair cells and insect flagellar ears will surely be a popular topic of discussion for researchers in the immediate future.

Active tuning in Tympanal Ears

Work on insect flagellar receivers is nicely contrasted by research being conducted on the tympanal receivers of Locusts and noctuid moths. While mosquito and Drosophila audition takes place at subkilohertz frequencies, some tympanal receivers are capable of detecting sound frequencies over $200 \mathrm{kHz}$.

\section{Locusts}

Preliminary active hearing research on Locusts by Kössl and Boyan $(1998,1998 a)$ revealed that it is possible to record distortion product otoacoustic emissions (DPOAEs) from invertebrates. In mammals that employ tympanate auditory receivers DPOAEs are used to assess the activity of the cochlear amplifier (Frank and Kössl, 1996). Distortion product otoacoustic emissions work on the presumption that if hair cells (in mammals) are actively enhancing incoming sound then output frequencies produced by the mechanical vibrations of the basilar membrane should show a shift, or nonlinearity, when 
input frequency is plotted against output frequency. When assessing DPOAEs two pure tone stimuli, designated $\mathrm{f} 1$ and $\mathrm{f} 2$, are presented simultaneously with $\mathrm{f} 1$ being the lower tone and $\mathrm{f} 2$ being the higher. The two tones should be both close in frequency and presented at either the same amplitude (symmetrical) or at differing amplitudes (asymmetrical) termed $\mathrm{L} 1$ and $\mathrm{L} 2$ respectively. Active processes influencing the mammalian cochlea produce output frequencies which are not present in the input stimuli (distortion products). The most pronounced distortion product found in mammals is located at $2 \mathrm{fl}-\mathrm{f} 2$. The DPOAEs attained in these studies were similar to those attained from mammals in that they also showed peak distortion product levels at $2 \mathrm{fl}-\mathrm{f} 2$ for biologically relevant stimuli (Fig. 2). In these studies $2 \mathrm{fl}$-f2 distortions were measured for stimulus levels ranging between 2 and $70 \mathrm{kHz}$. 
Figure 2. Distortion product otoacoustic emissions recorded from the tympanal ear of Locusta migratoria. Stimulation at $14.95 \mathrm{kHz}(\mathrm{f} 1$ ) and $15 \mathrm{kHz}(\mathrm{f} 2)$ resulted in distortion products being produced with the most prominent being at $2 \mathrm{fl}-\mathrm{f} 2$. The strongest distortion product in vertebrates is also found at 2f1-f2. (Taken from Köss1 and Boyan, 1998a) 


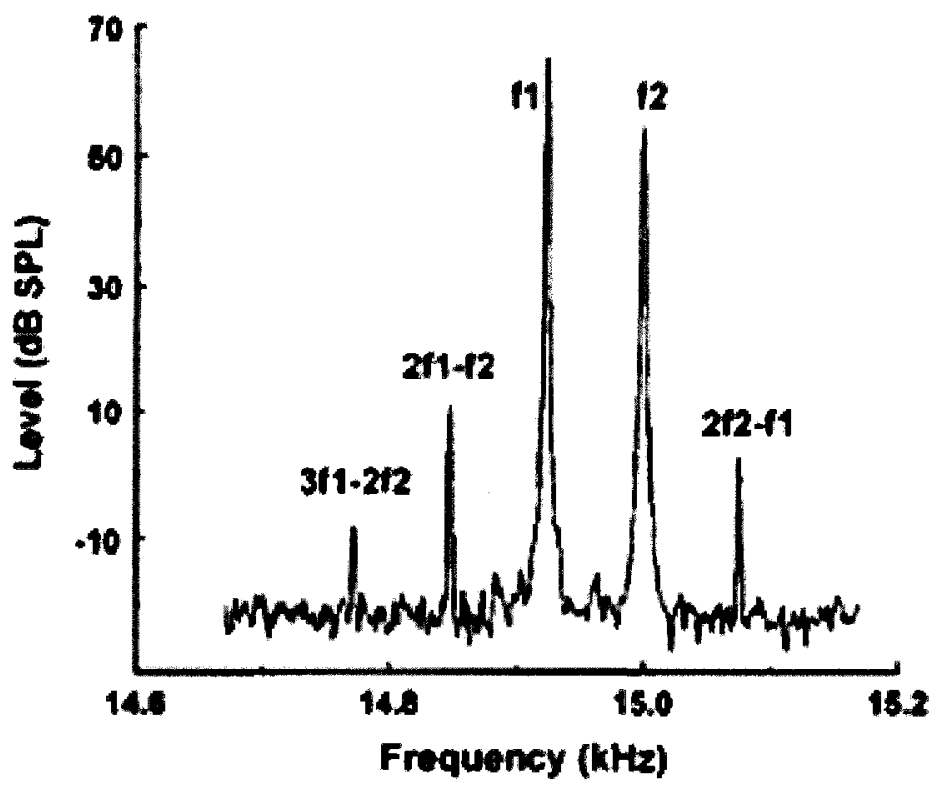


Locusts have about 80 receptor cells divided into four distinct classes labeled: a, b, c, and d (Gray, 1960; Michelsen, 1968). Each of these cell types receives information from a different region of the tympanum which is not of uniform thickness (Michelsen, 1971). Cells a through $\mathrm{c}$ receive information from thicker portions of the membrane (the $\mathrm{b}$ cells are the most sensitive) and respond best to stimulation by frequencies below $10 \mathrm{kHz}$. The $\mathrm{d}$ cells, which are less sensitive than cells a through $\mathrm{c}$ and connect to the thin portion of the tympanic membrane, are responsible for processing frequencies over $10 \mathrm{kHz}$. Results for $2 \mathrm{fl}-\mathrm{f} 2$ threshold curves show peak sensitivity between $3-9 \mathrm{kHz}$ and slow distortion growth (low slope) matching that of the ear's low frequency receptor neurons. $2 \mathrm{f} 1-\mathrm{f} 2$ curves for frequencies over $10 \mathrm{kHz}$ show decreased sensitivity and a steeper distortion threshold slope closely approximating the relationship between $\mathrm{b}$ and $\mathrm{d}$ cells given in Romer (1976). These effects are counteracted by either $\mathrm{CO}_{2}$ induced hypoxia (Kössl and Boyan, 1998) or death. A recent study by Windmill et al. (2005) has given us a very detailed analysis of the mechanical properties of the Locust's tympanic membrane. Using a highly precise laser Doppler vibrometer they mapped out the mechanical characteristics responsible for breaking up incident sound into specific frequency components. The tympanum actually funnels sound energy to different locations on the membrane depending on the frequency characteristics of the receptor cells in that region. The ability of the Locust tympanal membrane to asymmetrically vibrate means that it doesn't act as a simple drum-like oscillator, but instead is responsible for both reception and frequency decomposition of sound waves. There is no difference in how the membrane processes sound waves in living and dead locusts thus 
implying that sound reception and decomposition is a passive process depending on the unique shape of the tympanal membrane.

\section{Moths}

The noctuid moth, Noctua pronuba, has taken the processing system seen in the Locust one step further by being able to actively stiffen its tympanic membrane as a way of increasing its sensitivity to specific frequencies (Windmill et al., 2006).

Ears in Lepidoptera have evolved at least six times (Hoy and Robert, 1996; Yack and Fullard, 2000; Yack and Dawson, 2008) and appear on the head, thorax, abdomen and wings (Roeder et al., 1970; Yack and Fullard, 1993). Other than in sphingids (Waters, 2003) the lepidopteran ear is tympanal.

In noctuid moths the primary purpose of ears is to detect the echolocation calls of insectivorous bats (Fullard and Dawson, 1999). Detecting bats requires the ear to be sensitive to ensure that the bat is detected well before it's within striking range. Nevertheless, if the moth is late in detecting the bat it should be capable of producing a last ditch rapid escape maneuver. In producing a rapid escape maneuver the moth should be able to detect and process information about the bats whereabouts and quickly translate this information into a muscle response. This would imply that the fewer layers of the moth's CNS that the information must travel to produce a motor output the more likely it is that the moth will escape. Considering the sophisticated processing capabilities of the moth ear, in combination with the ears apparent structural simplicity, it is not surprising that recent technological advances have enabled researchers to uncover 
some of the more sophisticated mechanical and physiological processes involved in moth auditory processing.

The noctuid moth tympanic organ is composed of three cells, two auditory cells, $\mathrm{A} 1$ and $\mathrm{A} 2$, and one thought to be nonauditory in function: the B cell (Treat and Roeder, 1959). With so few auditory afferents the noctuid moth is considered tone deaf as single cells are capable of processing a wide range of frequencies (Roeder and Treat, 1961). Both $\mathrm{A} 1$ and $\mathrm{A} 2$ have broad tuning ranges with $\mathrm{A} 1$ being about $20-30 \mathrm{~dB}$ more sensitive in terms of auditory threshold sensitivity (Roeder, 1964). Since the initial work by Roeder the study of auditory processes in noctuid moths has progressed to include single cell studies at the level of the CNS (Boyan and Fullard, 1986,1988; Boyan et al. 1990). The auditory receptor neurons, A1 and A2, activate approximately seven auditory interneurons (Boyan and Fullard, 1986), although this number may be a conservative estimate. Studies showing basic response characteristics of noctuid moth interneurons (Boyan and Fullard, 1988) have yielded clues pertaining to the organization of the auditory system in the thoracic ganglia as a whole (Boyan et al., 1990).

Distortion product otoacoustic emissions have been determined to occur in the noctuid moth, Ascalapha odorata, the arctiid, Empyreuma affinis (Coro and Kössl, 1998; 2001) and in the notodontid, Ptilodon cucullina, which possess only one auditory afferent (Kössl et al., 2007). Moth DPOAE activity is similar to that seen in Locusts except for moth growth functions are steeper and do not show a change in slope at higher frequencies (Coro and Kössl, 1998). DPOAEs disappeared when the moth was treated with ethylether or dead. The reason no slope change occurred with different frequencies 
is most likely due to the moth tympanum being of more uniform thickness and simpler in structure (the tympanic organ only attaches at a single point on the tympanum) when compared to the Locust (Coro and Kössl, 1998). These studies were the first piece of evidence for the possibility of active tuning occurring in moths; Windmill et al. (2006) provided the first mechanical evidence.

When Windmill et al. (2006) presented N. pronuba, the giant yellow underwing, with a high intensity sound stimulus a laser vibrometer showed that the moth was capable of tuning its ear from a best frequency of $42 \mathrm{kHz}$ to $74 \mathrm{kHz}$ by actively altering the mechanics of its tympanic membrane (Fig. 3). The proposed biological significance of this tuning up suggests that, since bats shift the frequencies contained in their echolocation call up as they approach a source of prey, the moth is increasing the sensitivity of its ear to higher frequencies to accommodate for the bat's shift, thereby anticipating its approach and increasing its own chances of escape. Initiation of a tune up in a moth is amplitude dependent and does not depend on spectral composition or pulse structure of the sound stimulus (Windmill et al., 2006). The tuning up response to high amplitude stimuli in $N$. pronuba is also hysteretic in that once the moth is tuned up as a result of high amplitude stimulation it stays tuned up for an average of 7.5 minutes. After 7.5 minutes the moth tympanum returns to the previous resonant frequency where it can be returned to a "tuned up" state upon subsequent high amplitude stimulation. No shifting was found in moths that were dead, decapitated or suffering from $\mathrm{CO}_{2}$ hypoxia. 
Figure 3. Frequency spectrum showing both the magnitude of response (Top) and phase of response (Bottom) of the tympanum of Noctua pronuba as a result of stimulation with $80 \mathrm{~ms}$ frequency sweeps from $20-80 \mathrm{kHz}$. The green curve shows tuning response to low intensity stimuli while the orange curve shows tuning response to high intensity $+35 \mathrm{~dB}$ stimuli. The grey curve depicts the tuning response to high intensity stimulation observed in dead moths. Resonant frequency of the membrane occurs where the membrane vibrates in phase with the stimulus, or crosses the $0^{\circ}$ line on the phase graph. (Taken from Windmill et al. 2006) 


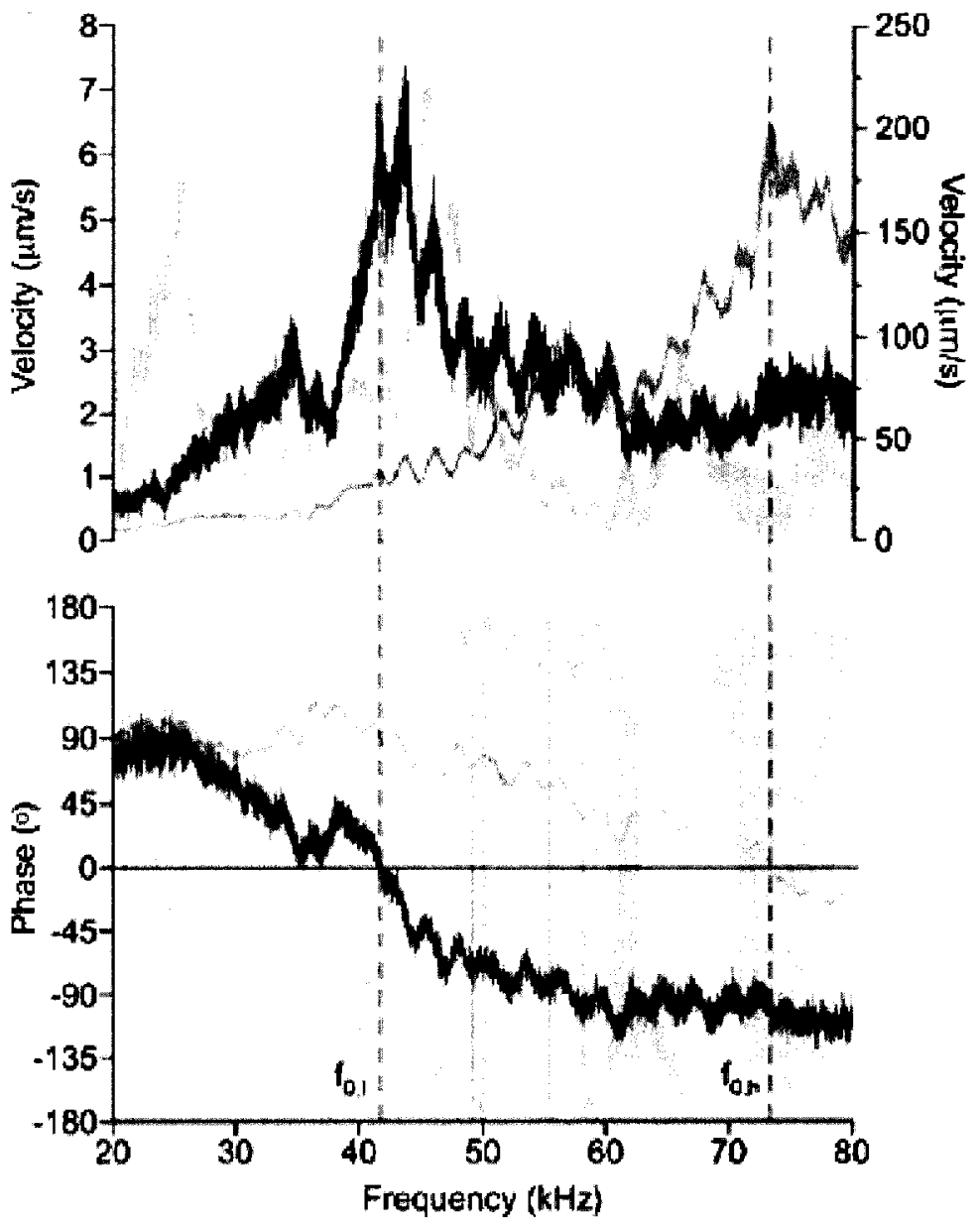


A subsequent study by Windmill et al. (2007) analyzed the vibrational characteristics of the noctuid moth tympana finding that it indeed does not vibrate as expected. The tympanum is shaped like a circular drum head with an opaque zone in the middle, where the receptor cells attach. The attachment site is surrounded by a transparent zone (Rodriguez et al., 2005). When stimulated, only the opaque zone tends to vibrate with the outer transparent zone remaining more or less stationary (Windmill et al., 2007).

\section{General Discussion and Research Objectives}

The existence of active hearing processes in tympanate insects is gaining acceptance from a mechanical perspective, although, aside from the mechanical characteristics disappearing with death, there is little physiological evidence that active tuning is actually taking place. There is a need for more cellular and molecular work to be done in tympanate insects before researchers can conclusively state that they are employing active mechanisms such as those seen in mosquitoes and flies. Active hearing implies some evolutionary need for increased sensitivity. Comparing the spectral analysis for a bat's echolocation call in attack phase (Surlykke and Moss, 2000) to a neural audiogram for N. pronuba (Waters and Jones, 1996) (Fig. 4) raises a number of questions pertaining to the biological need for $N$. pronuba to invest any amount of energy in actively increasing its auditory sensitivity (in Chapter 2: Discussion). This further illustrates the need for physiological confirmation of the tuning up effect in moths. 
Figure 4. (A) Neural audiogram taken as threshold values for eliciting activity in the Al and A2 cells of Noctua pronuba. (Taken from Waters and Jones, 1996). (B) Oscillogram of a typical pursuit sequence for the big brown bat, Eptesicus fuscus (Upper). Asterisks indicate the phase of pursuit in accordance with the oscillograms, spectrograms, and spectra given in sequence below. Initially the bat is in a search phase (S), upon detection of a potential prey source the bat increases the pulse rate of its calls and increases the bandwidth; this phase is referred to as the attack phase (A). As the bat nears the prey source it even further increases the pulse repetition rate of its calls and narrows the bandwidth to complete the terminal buzz which is separated into two phases, Buzz 1 (BI) and Buzz 2 (BII). (Taken from Surlykke and Moss, 2000) 
A

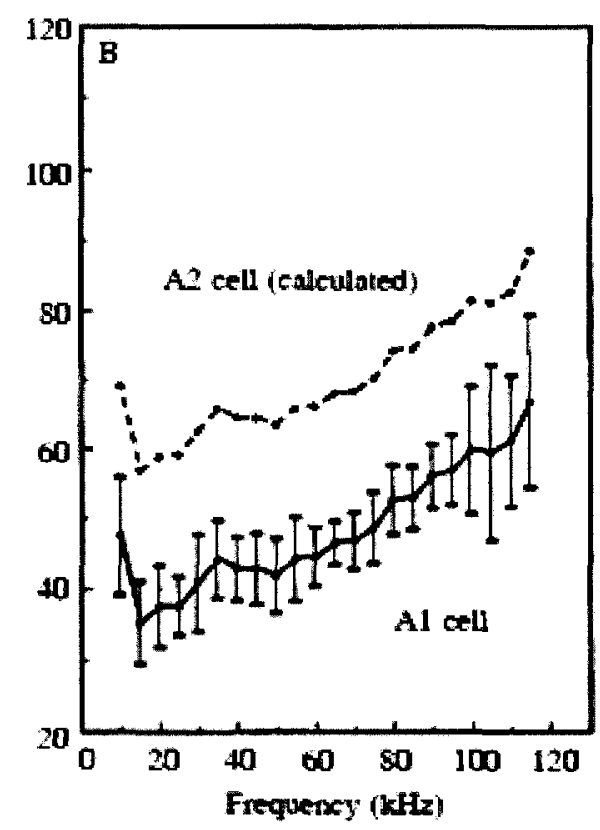

B
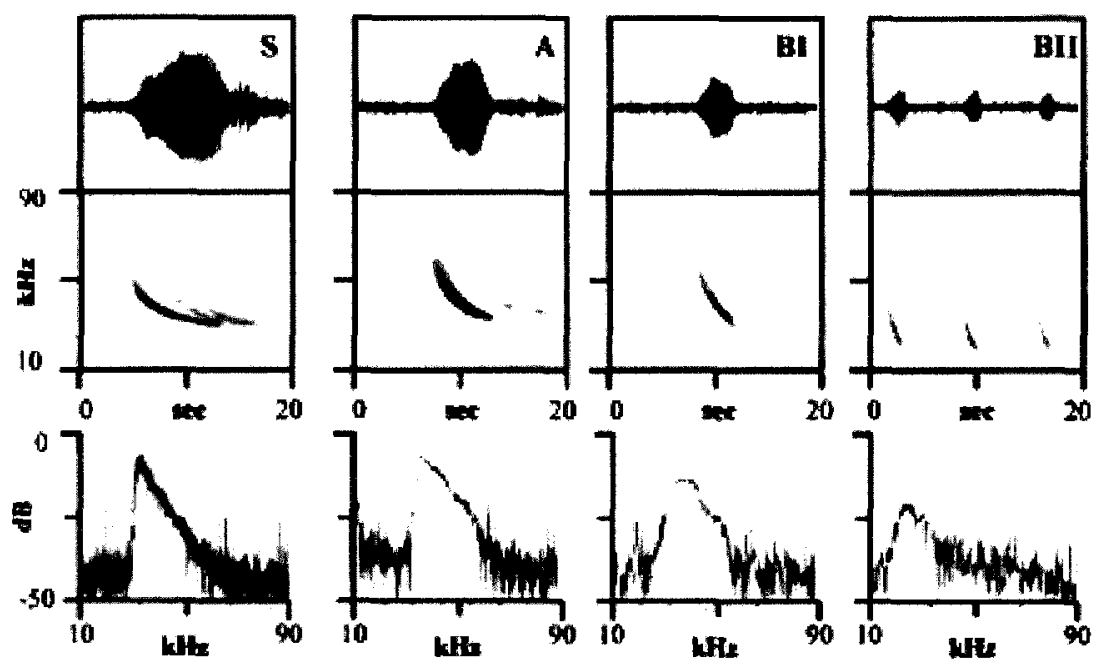
This thesis consists of two chapters. The first chapter investigates the physiological characteristics of active hearing in moths by recording extracellulary from auditory afferents as they respond over time to intense auditory stimulation. The second chapter uses intracellular recording techniques in an attempt to (1) identify and physiologically characterize auditory afferents, and (2) identify and characterize firing properties of auditory interneurons and motorneurons receiving auditory influence in noctuid moths. 
Literature Cited

Boo K.S. and Richards, A.G. (1975). Fine structure of the scolopidia in Johnston's organ of female Aedes aegypti compared with that of male. J. Insect. Physiol. 21: 11291139.

Boyan, G.S. and Fullard, J.H. (1986). Interneurons responding to sound in the tobacco budworm moth Helios virescens (noctuidae): morphological and physiological characteristics. J. Comp. Physiol. A. 190: $581-600$.

Boyan, G.S. and Fullard, J.H. (1988). Information processing at a central synapse suggests a noise filter in the auditory pathway of the noctuid moth. J. Comp. Physiol. A. 164: $251-258$.

Boyan, G.S., Williams, L. and Fullard, J.H. (1990). Organization of the auditory pathway in the thoracic ganglia of noctuid moths. J. comp. Neurol.. 295: $248-267$.

Cade, W. (1975). Acoustically orienting parasitoids: Fly phonotaxis to cricket song. Science. 190: 1312-1313.

Coro, F. and Kössl, M. (1998). Distortion-product otoacoustic emissions from the tympanic organ in two noctuid moths. J. Comp. Physiol. A. 183: 525 - 531.

Coro, F. and Kössl, M. (2001). Components of the 2f1-f2 distortion-product otoacoustic emission in a moth. Hear. Res. 162: 126-133.

Field, L.H. and Matheson, T. (1998). Chordotonal organs of insects. Adv. Insect. Physiol. 27: $1-228$. 
Frank, G. and Kössl, M. (1996). The acoustic two-tone distortions $2 f 12 f 2$ and $f 22 f 1$ and their possible relation to changes in the operating point of the cochlear amplifier. Hearing Res. 98: $104-115$.

Fullard, J.H. and Dawson, J.W. (1999). Why do diurnal moths have ears? Naturwissenschaften. 86: $276-279$.

Gibson, G. and Russell, I. (2006) Flying in tune: sexual recognition in mosquitoes. Curr. Biol. 16: $1311-1316$.

Göpfert, M.C. and Robert, D. (2000). Nanometre-range acoustic sensitivity in male and female mosquitoes. Proc. R. Soc. Lond. B. 267: 453 - 457.

Göpfert, M.C. and Robert, D. (2001). Active auditory mechanics in mosquitoes. Proc. $R$. Soc. Lond. B. 268: $333-339$.

Göpfert, M.C. and Robert, D. (2003). Motion generation by Drosophila mechanosensory neurons. PNAS. 100: $5514-5519$.

Göpfert, M. C. and Robert, D. (2007). Active processes in insect hearing. In Active processes and otoacoustic emissions in hearing (ed. G. A. Manley et al.). Springer Science +Business Media. New York.

Göpfert, M.C., Briegel, H. and Robert, D. (1999). Mosquito hearing: sound-induced antennal vibrations in male and female Aedes aegypti. J. Exp. Biol. 202: 2727 2738.

Göpfert, M.C., Albert, J.T., Nadrowksi, B. and Kamikouchi, A. (2006). Specification of auditory sensitivity by Drosophila TRP channels. Nat. Neurosci. 9: $999-1000$. 
Göpfert, M.C., Humphris, A.D.L., Albert, J.T., Robert, D. and Hendrich, O. (2005). Power gainexhibited by motile mechanosensory neurons in Drosophila ears. Proc. Natl. Acad. Sci. 102: 325 - 330.

Gray, E.G. (1960). The fine structure of the insect ear. Phil. Trans. R. Soc. Lond. B. 243: $75-94$.

Hoy, R.R. and Robert, D. (1996). Tympanal hearing in insects. Ann. Rev. Ent. 41: 433 450.

Jackson, J. C. and Robert, D. (2006). Nonlinear auditory mechanism enhances female sounds for male mosquitoes. PNAS. 103: 16734 - 16739.

Johnston, C. (1855). Auditory apparatus of the Culex mosquito. Q. J. Microsc. Sci. 3: 97102.

Kim, J., Chung, Y.D., Park, D.Y., Choi, S., Shin, D.W., Soh, H., Lee, H.W., Son, W., Yim, J., Park, C.S., Kernan, M.J. and Kim, C. (2003). A TRPV family ion channel required for hearing in Drosophila. Nature. 424: 81 - 84 .

Kössl, M. and Boyan, G.S. (1998). Acoustic distortion products from the ear of a grasshopper. J. Acoust. Soc. Am. 104: 326 - 335.

Kössl, M. and Boyan, G.S. (1998a). Otoacoustic emissions from a nonvertebrate ear. Naturwissenschaften. 85: $124-127$.

Kössl, M., Coro, F., Seyfarth, E-A. and Nässig, W.A. (2007). Otoacoustic emissions from insect ears having just one auditory neuron. J. Comp. Physiol. A. 193: 909-915.

Larsen, O.N. and Michelsen, A. (1978). Biophysics of the ensiferan ear III. The cricket ear as a four-input system. J. Comp. Physiol. A. 123: $217-227$. 
Mason, A.C., Oshinsky, ML. and Hoy, R.R. (2001). Hyperacute directional hearing in a microscale auditory system. Nature. 410: $686-690$.

Middlebrooks, J.C. and Green, D.M. (1991) Sound localization by human listeners. Annu. Rev. Psychol. 42: $135-59$.

Michelsen, A. (1968). Frequency discrimination in the locust ear by means of four groups of receptor cells. Nature. 220: $585-586$.

Michelsen, A. (1971). The physiology of the locust ear. I. Frequency sensitivity of single cells in the isolated ear, II. Frequency discrimination based upon resonances in the tympanum, and III. Acoustical properties of the intact ear. Z. Vergl. Physiologie 71: $49-128$.

Pollack, G. (2000). Who? What? Where? Regognition and localization of acoustic signals by insects Curr. Opin. Neurobiol. 10: $763-767$.

Robert, D. and Hoy, R.R. (2007). Auditory systems in insects. In Insect neurobiology (ed G. North and R. J. Greenspan), pp. 155 - 184. Cold Spring Harbour Laboratory Press, New York.

Robert, D., Miles, R.N. and Hoy, R.R. (1996). Directional hearing and mechanical coupling in the parasitoid fly Ormia ochracea. J. Comp. Physiol. A. 179: 29 - 44.

Rodríguez, R.L., Schul, J., Cocroft, R.B. and Greenfield, M.D. (2005). The contribution of tympanic transmission to fine temporal signal evaluation in an ultrasonic moth. J. Exp. Biol. 208: $4159-4165$.

Roeder, K.D. (1964). Aspects of the noctuid tympanic nerve response having significance in the avoidance of bats. J. Insect. Physiol. 10: $529-546$. 
Roeder, K.D (1967). Nerve cells and insect behavior. Harvard University Press, Cambridge.

Roeder, K.D. and Treat, A.E. (1957). Ultrasonic reception by the tympanic organ of noctuid moths. J. Exp. Zool. 134: $127-157$.

Roeder, K.D. and Treat, A.E. (1961). The detection and evasion of bats by moths. Am. Sci. 49: $135-148$.

Roeder, K.D., Treat, A.E. and Vande Berg, J.S. (1970). Distal lobe of the pilifer: An ultrasonic receptor in choerocampine hawkmoths. Science. 170: 1098-1099.

Romer, H. (1976). Die Informationsverarbeitung tympanaler Rezeptorelemente von Locusta migratoria (Acrididae, Orthoptera). J. Comp. Physiol. A. 109: 101-122.

Stephen, R.O. and Bennet-Clark, H.C. (1982). The anatomical and mechanical basis of stimulation and frequency analysis in the locust ear. J. Exp. Biol. 99: $279-314$.

Surlykke, A. and Moss, C. F. (2000). Echolocation behaviour of big brown bats, Eptesicus fuscus, in the field and laboratory. J. Acoust. Soc. Am. 108: $2419-$ 2429.

Tischner, H. (1953). Über den Gehörsinn von Stechmücken. Acustica. 3: 335 - 343.

Treat, A.E. and Roeder, K.D. (1959). A nervous element of unknown function in the tympanic organs of moths. J. Ins. Physiol. 3: $262-270$.

Waters, D.A. (2003). Bats and moths: what is there left to learn?. Physiol. Entomol. 28: $237-250$. 
Waters, D.A. and Jones, G. (1996). The peripheral auditory characteristics of noctuid moths: responses to the search-phase echolocation calls of bats. J. Exp. Biol. 199: $847-856$.

Windmill, J.F.C., Göpfert, M.C. and Robert, D. (2005). Tympanal travelling waves in migratory locusts. J. Exp. Biol. 208: 157 - 168.

Windmill, J.F.C., Jackson, J.C., Tuck, E.J. and Robert, D. (2006). Keeping up with bats: dynamic auditory tuning in a moth. Curr. Biol. 16: $2418-2423$.

Windmill, J.F.C., Fullard, J.H. and Robert, D. (2007). Mechanics of a simple ear: tympanal vibrations in noctuid moths. J. Exp. Biol. 210: $2637-2648$.

Yack, J.E. (2004). The structure and function of auditory chordotonal organs in insects. Microsc. Res. Tech. 63: 315 - 337.

Yack, J.E., Dawson, J. (2008). Insect Ears. In: (Eds. Basbaum, AI, Kaneko, A, Dallos, Shepherd, GM, and Westheimer, GP) The Senses: A Comprehensive Reference. Audition. Elsevier Inc. 35-53.

Yack, J.E. and Fullard, J.H. (1993) What is an insect ear? Ann. Entomol. Soc. Am. 86: $677-682$.

Yack, J.E. and Fullard, J.H. (2000). Ultrasonic hearing in nocturnal butterflies. Nature. 403: $265-266$.

Yager, D.D. (1999). Structure, development, and evolution of insect auditory systems. Microsc. Res. Tech. 47: $380-400$. 


\section{CHAPTER 2}

Extracellular Investigation of Active Hearing in the Noctuid Moth, Noctua pronuba

\section{Introduction}

The noctuid moth has evolved under constant attack from an invisible threat that stalks it under the cover of night; the bat. As the bat navigates through the night sky searching for its next meal it releases high frequency ultrasonic chirps and listens for their echoes to give it a detailed picture of the landscape that surrounds it. It is the same echolocation calls that the bat uses to navigate that it uses to identify and locate potential prey sources. Evolutionary pressures imposed on moths by predatory bats have resulted in a number of adaptations including the development of highly sensitive tympanal ears capable of detecting and locating high frequency echolocation calls (Fullard and Dawson, 1999; also see review by Fullard, 1998).

The noctuid moth ear is comprised of two auditory cells, or afferents, and one cell thought to be non-auditory in function. These cells are labeled A1, A2, and B respectively (for an extensive review of the pioneering work on noctuid moths see Roeder, 1969). Both $\mathrm{A} 1$ and $\mathrm{A} 2$ have broad tuning ranges with $\mathrm{A} 1$ being about $20-30$ $\mathrm{dB}$ more sensitive in terms of auditory threshold (Roeder, 1964). The discrepancy in threshold sensitivity of $\mathrm{A} 1$ and $\mathrm{A} 2$ has lead researchers to suggest that $\mathrm{A} 1$ is responsible for early detection of far away bats and therefore could initiate negative phonotaxis during flight. The second auditory afferent, A2, is activated when the bat is much closer, and as a result its echolocation calls appear much louder. Researchers have suggested that A2 could be responsible for eliciting last-chance escape maneuvers consisting of loops 
and dives (Roeder, 1962; 1967; 1975). While these cause and effect relationships seem intuitive, researchers have had considerable difficulties determining auditory thresholds necessary to elicit specific aerial maneuvers (Fullard, 1987).

Recently, the concept of active hearing processes has become a hot topic in insect research (Göpfert and Robert, 2007). Active hearing processes are physiological elements of insect hearing that act to increase the insect's sensitivity, or processing ability, in response to an auditory stimulus that would otherwise be very difficult to detect. The four essential characteristics of active hearing according to Göpfert and Robert (2007) are as follows: (1) there must be a comprehensive nonlinearity in the tuning response of a particular hearing apparatus that serves to condense a wide range of stimulus amplitudes into a defined range of mechanical responses, (2) a frequency selectivity effect where the hearing apparatus can actively select and amplify certain frequencies in order to improve sensitivity, (3) the ability to produce self sustained mechanical oscillations, or the presence of otoacoustic emissions (ie. spontaneous mechanical response of the ear that can be recorded as sound emitted by the ear), and (4) the response must reflect a physiological expenditure of energy, or power gain, that is a necessary component in producing the response. Point number four would imply that any animal capable of active tuning would lose the response under some forms of physiological stress or after death.

Pioneering research in insect active hearing has focused on two near field sound detection systems; the mosquito and Drosophila antennal sound receivers (Göpfert and Robert, 2001; 2001a; 2002; Kim et al., 2003; Gopfort et al., 2007; Robert and Hoy, 
2007). Since the initial studies research has expanded to include the far field tympanal receivers of Locusts (Kössl and Boyan, 1998,1998a; Windmill et al., 2005) and moths (Coro and Kössl, 1998, 2001; Windmill et al., 2006, 2007; Kössl et al., 2007, 2008). Early active hearing research on locusts and moths focused on the distortion product otoacoustic emissions (DPOAEs) produced by presenting two pure tones to the ear simultaneously and using a microphone to record the sound produced by the vibrating tympanum. The tympana of these insects was found to be producing frequencies not present in the pure tone stimuli which implied that there may be an active mechanism present that is shifting/amplifying incoming sound. DPOAEs have been successfully recorded from Locusts (Kössl and Boyan, 1998,1998a), noctuid moths (Coro and Kössl, 1998, 2001) and notodontid moths (Kössl et al., 2007) and all of the aforementioned insects require an active metabolism to produce them (Kössl et al., 2008).

Adding to the DPOAE research, a study by Windmill et al. (2006) showed, using laser-Doppler vibrometry, that the noctuid moth, Noctua pronuba, can actively stiffen its tympanic membrane thereby shifting its resonant frequency. They found that membrane stiffening was not dependent on either pulse repetition rate or frequency content (provided the sound is within the applicable hearing range) but is instead exclusively elicited through the presentation of stimuli having appropriately high amplitude. Specifically, Windmill et al. (2006) showed that a moth giving a tympanal resonant frequency of $42 \mathrm{kHz}$ for low intensity stimulation would shift its resonant frequency up to $74 \mathrm{kHz}$ in response to a $87 \mathrm{~dB}$ stimuli presented at $30 \mathrm{kHz}$. They also found that this response was hysteretic, lasting an average of 7.5 minutes, and was not present in dead 
moths. After a "tune up" response the best frequency gradually shifted back to the "tuned down" state $(42 \mathrm{kHz})$ and was capable of being retuned to a "tuned up" state $(74 \mathrm{kHz})$ through presentation of high amplitude stimuli.

For there to be utility in an insect committing some amount of physiological energy to an active hearing system there must be a selective advantage that warrants its development. In addition, there must be a behavioral change as a result that would otherwise not be present in the absence of the active process. The behavioral significance of active hearing in mosquitoes has been described as it relates to identification of sexually compatible conspecifics (Gibson and Russell, 2006; Jackson and Robert, 2006). Windmill et al., (2006) propose that $N$. pronuba is shifting its best frequency, which is between 15 and $25 \mathrm{kHz}$ (Waters and Jones, 1996), up in order to better anticipate the higher echolocation frequencies used by bats upon their return providing that the first attempt at capture was unsuccessful.

Moths have been placed under considerable selective pressure by bats, so it is conceivable that it is to their advantage to develop a highly sensitive auditory system in order to avoid being captured. Although, if in the absence of an active process a moth's auditory system is already sufficiently sensitive to detect bats at great distances, there may not be much utility in investing physiological resources into further increasing its sensitivity. This study will use extracellular neurophysiological recording techniques to assess whether or not the observations in Windmill et al. (2006) are having a physiological effect at the level of the auditory afferents in $N$. pronuba and other noctuid moth species. In this chapter, I use extracellular recordings to assess afferent response to 
high intensity stimuli. Responses will be assessed over time in terms of total number of spikes produced, average interspike interval, average burst duration, and average latency. I predict that if there is an effect at the afferent level we should observe a gradual decrease in both the number of spikes produced and average burst duration and a gradual increase in average interspike interval and average latency over time at both $42 \mathrm{kHz}$ and $74 \mathrm{kHz}$. The gradual decrease in responsiveness should mirror the hysteretic response observed in Windmill et al. (2006), taking an average of 7.5 minutes to return to a "tuned down" state following high intensity stimulation. After the moth has returned to a "tuned down" they should be capable of being returned to a "tuned up" state through intense stimulation. Results will be interpreted in the context of an initial increase in sensitivity to the frequencies $42 \mathrm{kHz}$ and $74 \mathrm{kHz}$ as presented in Windmill et al. (2006).

Materials and Methods

Animals

Wild caught Noctua pronuba (noctuidae) were collected from Ottawa, Ontario, Canada (45.403644,-75.697142) and Winchester, Ontario, Canada (45.090134,75.346373) through the months of June 2008 - August 2008. Wild caught moths were stored in $50 \mathrm{~cm}^{3}$ plastic containers with sheets of wax paper hanging from the inside of the lid to promote oviposition. All adult moths were fed Ad libitum a diet of sugar water ( 3 tablespoons sugar in $300 \mathrm{~mL}$ DI water). Adult wild caught moths were used within two weeks of capture. All neurophysiological recordings were preformed at Carleton University, Ottawa, Ontario, Canada. 


\section{Dissection}

Moths were restrained by laterally pinning the wings to a block of modeling clay using staples, after which the scales were carefully removed from the dorsal portion of the thorax with a fine paintbrush. The moth pterothoracic ganglion (= fused meso- and metathoracic ganglion) was then exposed using a modified dorsal dissection (Roeder and Treat, 1957). After dissection the body cavity was flooded with saline $(7.5 \mathrm{~g} \mathrm{NaCl}, 0.1 \mathrm{~g}$ $\mathrm{KC} 1,0.2 \mathrm{~g} \mathrm{CaCl}, 0.2 \mathrm{~g} \mathrm{NaHCO}$, distilled $\mathrm{H}_{2} \mathrm{O}$ to $1000 \mathrm{ml}$ (modified from Fielden, 1960)). Trachea on or around the auditory nerve was removed with care so as not to stretch or damage the auditory branch (IIIN1). The preparation was then placed in a faraday cage lined with sound attenuating foam (Aurex TM 2" wedges) for neurophysiologal recordings.

\section{Auditory Stimulation}

Auditory stimuli were generated using a waveform generator (Tabor electronics, WW5061) which fed into a pulse shaper (Coulbourn, 584-04) allowing for pulses of varying rise/fall duration, pulse length and interpulse interval. Shaped stimulus pulses were sent to a custom made amplifier (good to $180 \mathrm{kHz}$ ), an oscilloscope, a data acquisition unit, and a speaker (Motorola KSN1078A 2" Cone Tweeter) located within the experimental enclosure.

For each moth auditory threshold was first established at $42 \mathrm{kHz}$ and $74 \mathrm{kHz}$ by visually confirming a response of at least 3 spikes to each of a series of 10 stimulus pulses ( $10 \mathrm{~ms}$ duration, $0.5 \mathrm{~ms}$ rise/fall times). After threshold was detected, and the moth was allowed to sit for 10 minutes post dissection, the moths were then "tuned up" using a 
series of high intensity pulses ( $85 \mathrm{~dB}$ or greater). Each tune up stimulus consisted of three 3 second presentations of high intensity pulse trains consisting of $10 \mathrm{~ms}$ pulses $(0.5 \mathrm{~ms}$ rise/fall times) at $35 \mathrm{kHz}$ separated by a $100 \mathrm{~ms}$ interpulse interval. After the tune up stimulus was presented moths were given alternating $42 \mathrm{kHz}$ and $74 \mathrm{kHz}$ probing pulses, separated by about 30 seconds, at threshold $+5 \mathrm{~dB}$ intensity. Each probe pulse consisted of two $10 \mathrm{~ms}$ pulses ( $1 \mathrm{~ms}$ rise and $1 \mathrm{~ms}$ fall time) with an interpulse interval of 1 second for each frequency. Probe pulses were first presented over a 20 minute period post tune up stimulus after which the moth was given a second tune up stimulus and then re-probed for an additional 5 minutes. See Fig. 5 for a schematic representation of the stimulus protocol.

\section{Neurophysiological recording}

A stainless steel hook electrode referenced to a platinum electrode inserted into the abdomen of the moth was used to record from the auditory nerve, IIIN1b. The recording electrode was connected to an AC pre-amplifier (Grass, P-55). The amplifier output was connected to: (1) a digital oscilloscope (Tektronix, TDS 2014) that was used to monitor extracellularily recorded action potentials from the auditory nerve and the auditory stimulus waveform characteristics during the experiment and, (2) a digital data acquisition unit (Axon Instruments, Digidata 1322A). AxoScope ver. 9.2 software was used to record both the neural activity and auditory stimulus pulses simultaneously for off-line analysis (all waveforms were sampled at $20 \mathrm{kHz}$ ). Cut nerve experiments consisted of moths with the IIIN1 nerve transected just above the point where it fuses 
with the pterothoracic ganglion. All recordings were done in a faraday cage lined with sound attenuating foam (Aurex TM 2" wedges).

\section{Data Analysis}

Spiking responses were analyzed by manually selecting action potential peaks or troughs using AxoScope ver 9.2 software. Moths were first analyzed on an individual basis for approximately the first five minutes post initial tune up (Early), the last five minutes before $2^{\text {nd }}$ tune up (Late) and the $1^{\text {st }}$ five minutes post $2^{\text {nd }}$ tune up (Re-tune) giving three data sets per moth (Fig. 5). Data sets will henceforth be abbreviated as E, L, and $\mathrm{R}$ respectively. Data was averaged within $\mathrm{E}, \mathrm{L}$, and $\mathrm{R}$ recording segments and the resulting averages were averaged across the whole sample of moths for the $E, L$, and $R$ portions. Specific comparisons between data groups will be listed as, for example, EL, where the statistical comparison is Early data versus Late data. A 1-tailed paired sample t-test was employed to test for statistical differences between EL, ER, and LR datasets.

All complete time series data, including B-Cell data, was analyzed for total spike number, average inter-spike-intervals (ISI), average burst duration, and average latency using Spike2 software. Regression analysis was used to test for increasing or decreasing responsiveness in spike number, interspike interval, burst duration, and latency over the first 500 seconds of testing for each moth. A Binomial test was then used to predict statistical significance for regression data compiled across moths for each response parameter. Data was then organized into bins and plotted, for comparison of time-course only, adjacent to the membrane velocity data given in Windmill et al. (2006). 
Figure 5. Illustration of stimulus protocol: Large solid black bars indicate a "tune up" stimulus, small solid black bars are probe stimuli, the Early and Late sections represent the first 5 minutes post initial tune up and last 5 minutes before another tune up stimulus is given. RE refers to the first 5 minutes post 2 nd tune up stimuli. Each complete trial lasts about 25 minutes. 


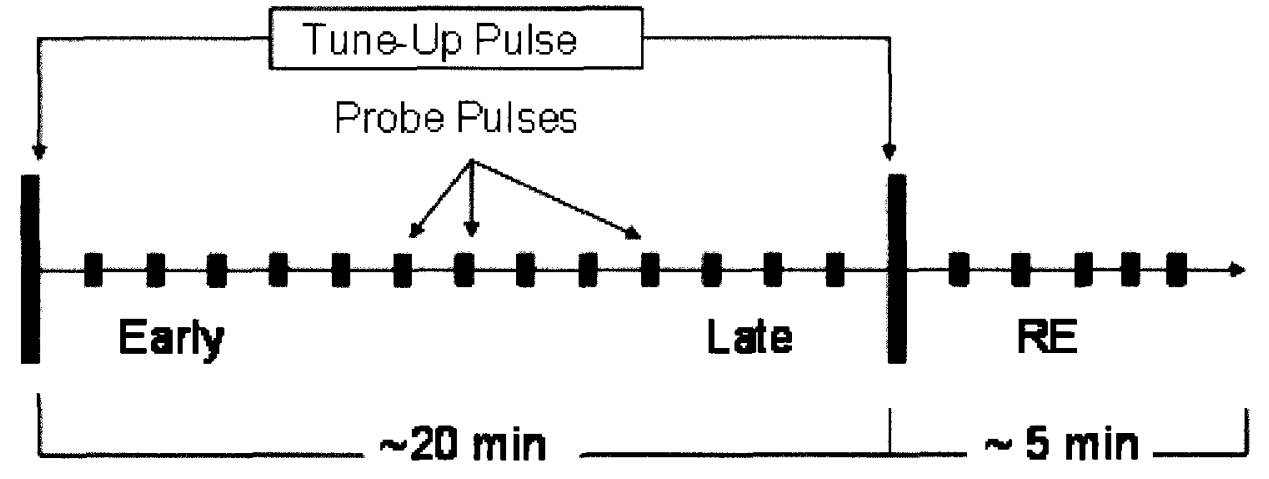


Results

A typical Al response to a probe stimulus is given in Fig. 6.

Noctua pronuba.

For $N$. pronuba $(\mathrm{n}=8)$ EL trials showed significant increases in interspike interval (ISI) (paired t-test, $\mathrm{t}=0.064, \mathrm{p}=0.032$ ) and latency (paired $\mathrm{t}$-test, $\mathrm{t}=0.086, \mathrm{p}=$ 0.043 ) for $74 \mathrm{kHz}$ probe pulses. No significant differences were found for LR trials. In ER trials decreased responsiveness was observed to occur at $42 \mathrm{kHz}$ for average interspike interval of the first three spikes (ISI3) (paired t-test, $\mathrm{t}=0.071, \mathrm{p}=0.036$ ) and at $74 \mathrm{kHz}$ for ISI (paired t-test, $\mathrm{t}=0.003, \mathrm{p}=0.0018$ ) and Latency (paired t-test, $\mathrm{t}=0.068, \mathrm{p}=$ 0.034). Complete sets of statictal values pertaining to $N$. pronuba ELR paired sample ttests are given in Table 1and graphically represented in Fig. 7. 
Figure 6. Typical extracellular recording of response to auditory stimulation as seen in $N$. pronuba. This figure shows (A) typical Al cell response (top) to $42 \mathrm{kHz}$ stimulus pulse (bottom). (B) is the same stimulus response as the highlighted portion in (A) except magnified. This particular response is composed of $7 \mathrm{Al}$ spikes with a burst duration of $0.013 \mathrm{~s}$, latency of $0.00627 \mathrm{~s}$ and an average interspike interval of $0.0019 \mathrm{~s}$. 


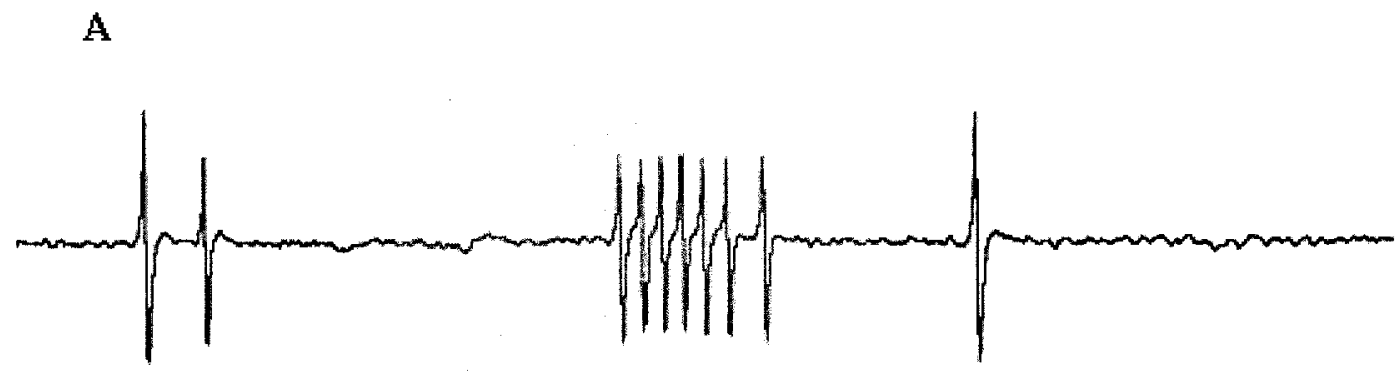

B
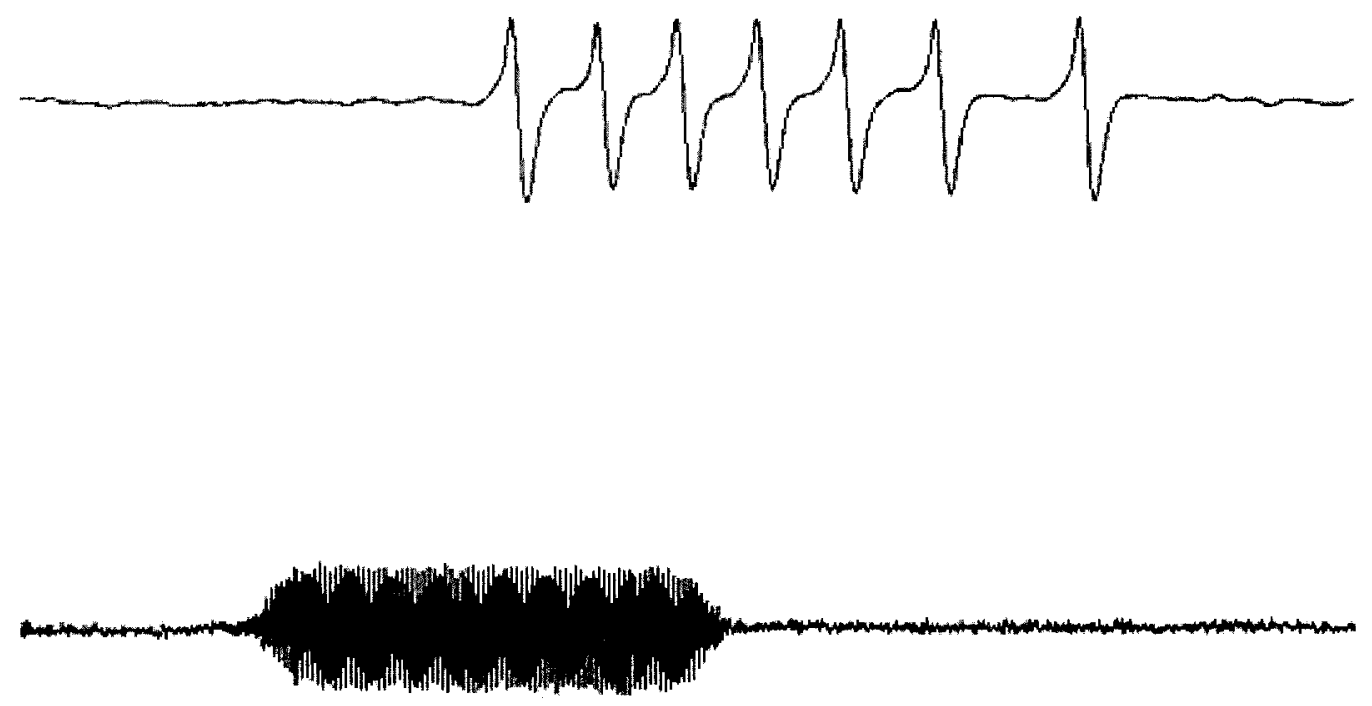

$10 \mathrm{~ms}$ 
Table 1. T-statistics and $p$ values given for Early vs. Late, Early vs. RE and Late vs. RE comparisons. This table includes both $N$. pronuba and $N$. pronuba CUT trials. Yellow boxes indicate a statistically significant result. 


\begin{tabular}{llllllll} 
& \multicolumn{2}{c}{ EvsL } & \multicolumn{2}{c}{ EvsR } & \multicolumn{2}{c}{ Lvs R } \\
\cline { 2 - 7 } NEW & \multicolumn{1}{c}{ 42 } & T-stat & $\mathrm{p}$ & T-stat & $\mathrm{p}$ & T-stat & $\mathrm{p}$ \\
\cline { 2 - 7 } & Spike Cnt & 0.89794 & 0.44897 & 0.657744 & 0.328872 & 0.239473 & 0.119737 \\
ISI (ms) & 0.353122 & 0.176561 & 0.813466 & 0.406733 & 0.318651 & 0.159325 \\
Latency (ms) & 0.404081 & 0.202041 & 0.397088 & 0.198544 & 0.849252 & 0.424626 \\
ISI 1 st 3 (ms) & 0.340391 & 0.170196 & 0.071348 & 0.035674 & 0.488866 & 0.244443
\end{tabular}

74

$\begin{array}{lllllll}\text { Spike Cnt } & 0.487222 & 0.243611 & 0.830454 & 0.415227 & 0.255227 & 0.127614\end{array}$ ISI (ms) $\quad \begin{array}{llllllll}0.063759 & 0.031879 & 0.003697 & 0.001848 & 0.511067 & 0.255533\end{array}$ $\begin{array}{llllllll}\text { Latency (ms) } & 0.086456 & 0.043228 & 0.068474 & 0.034237 & 0.372159 & 0.18608\end{array}$ ISI 1st 3 (ms) $\quad 0.310136 \quad 0.155068 \quad 0.099755 \quad 0.049877 \quad 0.13301 \quad 0.066505$

\begin{tabular}{lrrrrrr}
\hline \multicolumn{1}{c}{42} & T-stat & $p$ & T-stat & $p$ & T-stat & $p$ \\
\hline Spike Cnt & 0.088188 & 0.044094 & 0.115337 & 0.08895 & 0.124546 & 0.062273 \\
ISl (ms) & 0.459531 & 0.229765 & 0.486504 & 0.477126 & 0.623698 & 0.311849 \\
Latency (ms) & 0.775983 & 0.387991 & 0.246543 & 0.160789 & 0.170939 & 0.085469 \\
ISI 1st 3 (ms) & 0.28347 & 0.141735 & 0.457431 & 0.388579 & 0.33995 & 0.169975
\end{tabular}

74

$\begin{array}{lllllll}\text { Spike Cnt } & 0.796306 & 0.398153 & 0.479161 & 0.447611 & 0.139411 & 0.069706\end{array}$ $\begin{array}{llllllll}\mathrm{ISI}(\mathrm{ms}) & 0.519789 & 0.259894 & 0.461143 & 0.39887 & 0.288896 & 0.144448\end{array}$ $\begin{array}{lllllll}\text { Latency (ms) } & 0.718272 & 0.359136 & 0.440692 & 0.385714 & 0.720264 & 0.360132\end{array}$

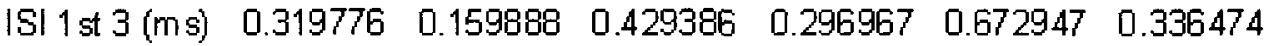


Figure 7. Early, Late and RE data compared at $42 \mathrm{kHz}$ and $74 \mathrm{kHz}$ for $N$. pronuba trials (bars are mean $(+/-\mathrm{SEM})$ ). 

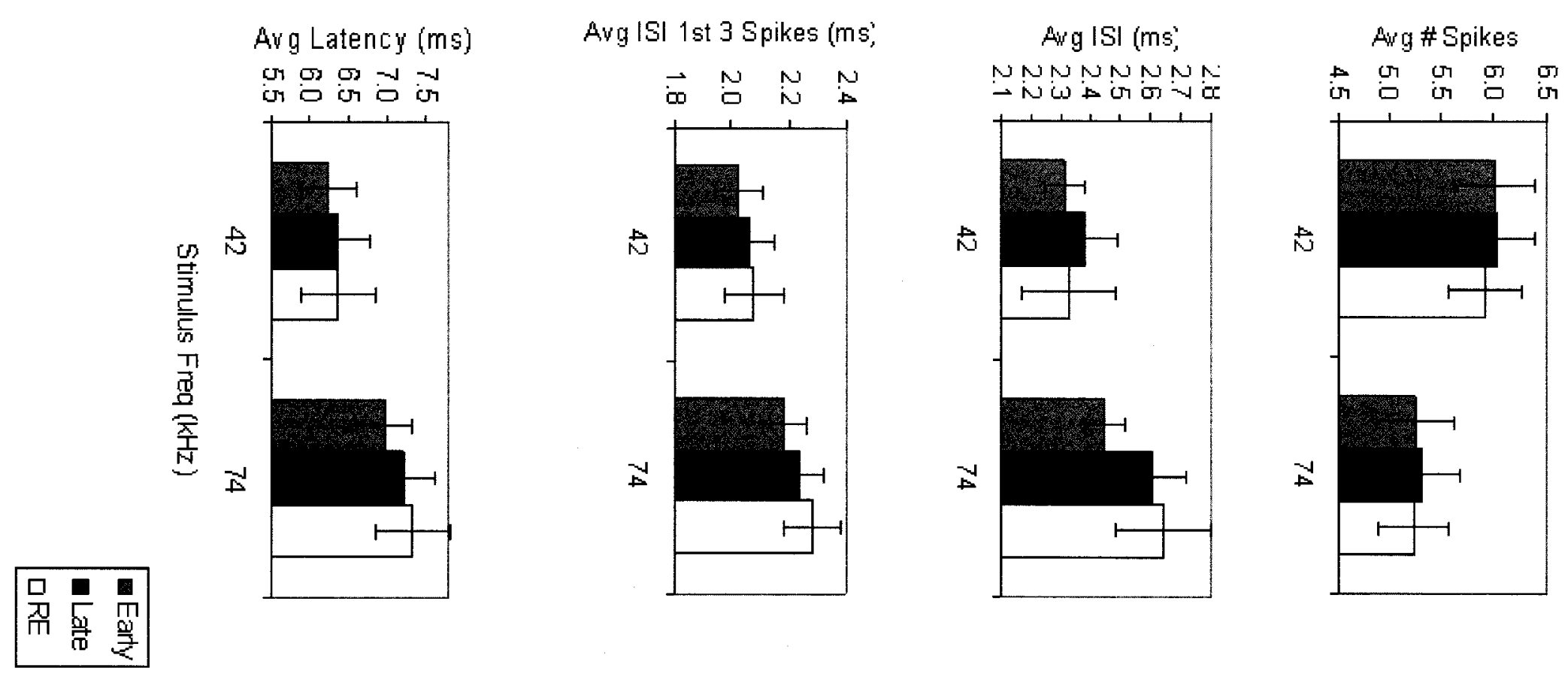
Complete time series data are given as scatterplots to illustrate differences between what values the data tends to fall at $42 \mathrm{kHz}$ and $74 \mathrm{kHz}$. Each scatterplot encompasses all data for a particular moth and across moths. Data at $42 \mathrm{kHz}$ and $74 \mathrm{kHz}$ for total spike number, ISI, burst duration, and latency is organized into 60 second bins and plotted adjacent to data from Windmill et al. (2006) (henceforth referred to as: Windmill) to show differences in the time-course of the responses. Data for Windmill comparison is adjusted to show EL values between 0 and 540 seconds post initial tune up. $R$ values are adjusted so that the second tune up stimulus is always at 1000 seconds resulting in $R$ values ranging between 1000 and 1300 seconds graphically. Graphical representations of ISI and latency are given in Figures 8 and 9 while spike count and burst duration graphs are given in Appendix 3 (Fig. 20).

Linear regressions of spike number, interspike interval, burst duration, and latency for each moth were combined within categories and a binomial test yielded no significant result through the first 500 seconds of testing. Complete linear regression statistics are given in Table 2. 
Figure 8. Time series data for interspike interval in $N$. pronuba trials. Three graphs are given: (A) scatter plot showing probe stimulus responses for all moths at $42 \mathrm{kHz}$ and (B) $74 \mathrm{kHz}$, in addition to times series data $(\mathrm{C})$ placed into 60 second bins and plotted over tympanal velocity data from Windmill et al. (2006) (bars are mean (+/- SD)). Data for $42 \mathrm{kHz}$ and $74 \mathrm{Khz}$ test pulses with time values greater than 1000 seconds account for the $\mathrm{RE}$ portion of the trial. 

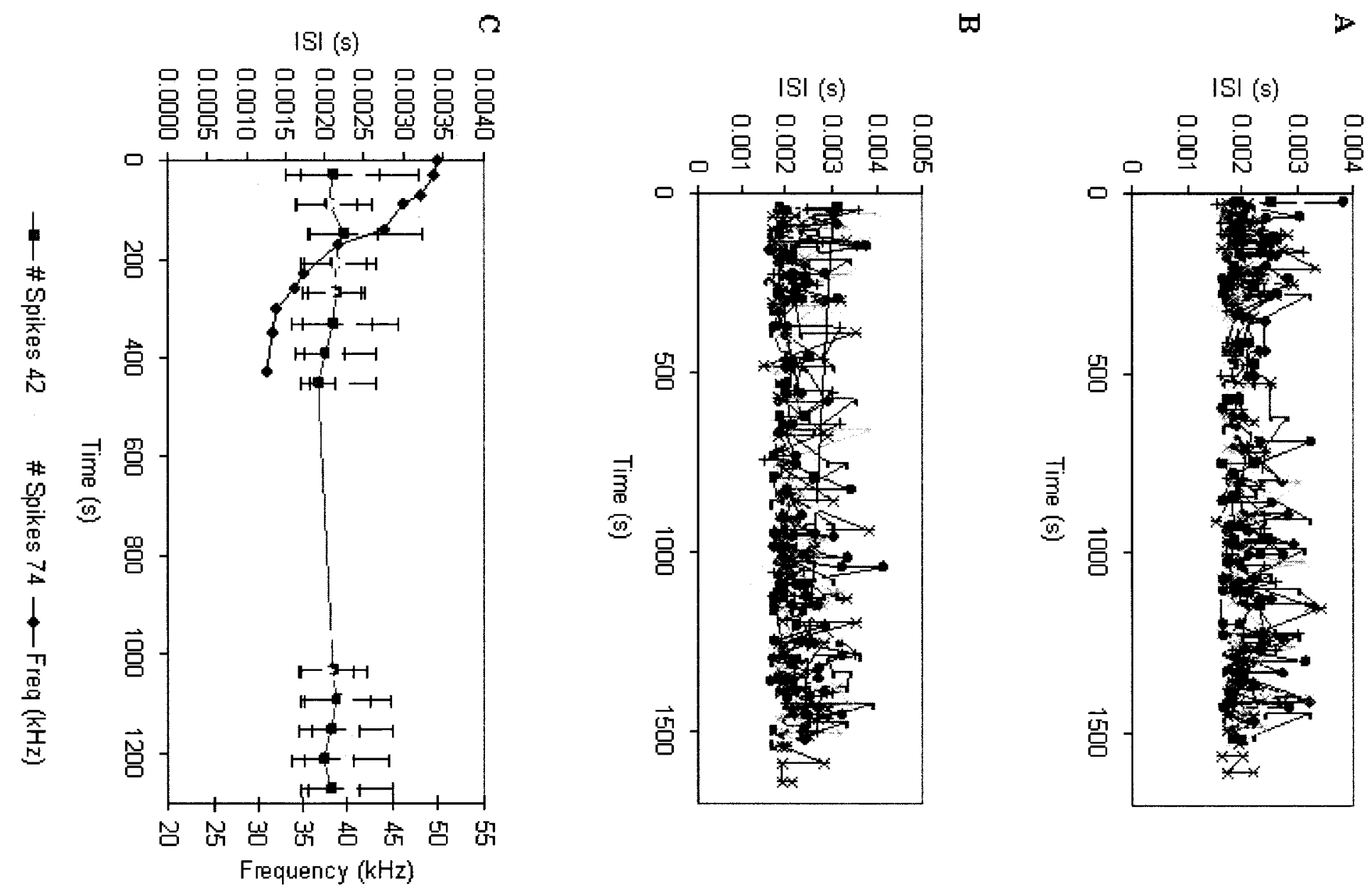
Figure 9. Time series data for latency in N. pronuba trials. Three graphs are given: (A) scatter plot showing probe stimulus responses for all moths at $42 \mathrm{kHz}$ and (B) $74 \mathrm{kHz}$, in addition to times series data (C) placed into 60 second bins and plotted over tympanal velocity data from Windmill et al. (2006) (bars are mean ( $+/-\mathrm{SD})$ ). Data for $42 \mathrm{kHz}$ and $74 \mathrm{kHz}$ test pulses with time values greater than 1000 seconds account for the RE portion of the trial. 

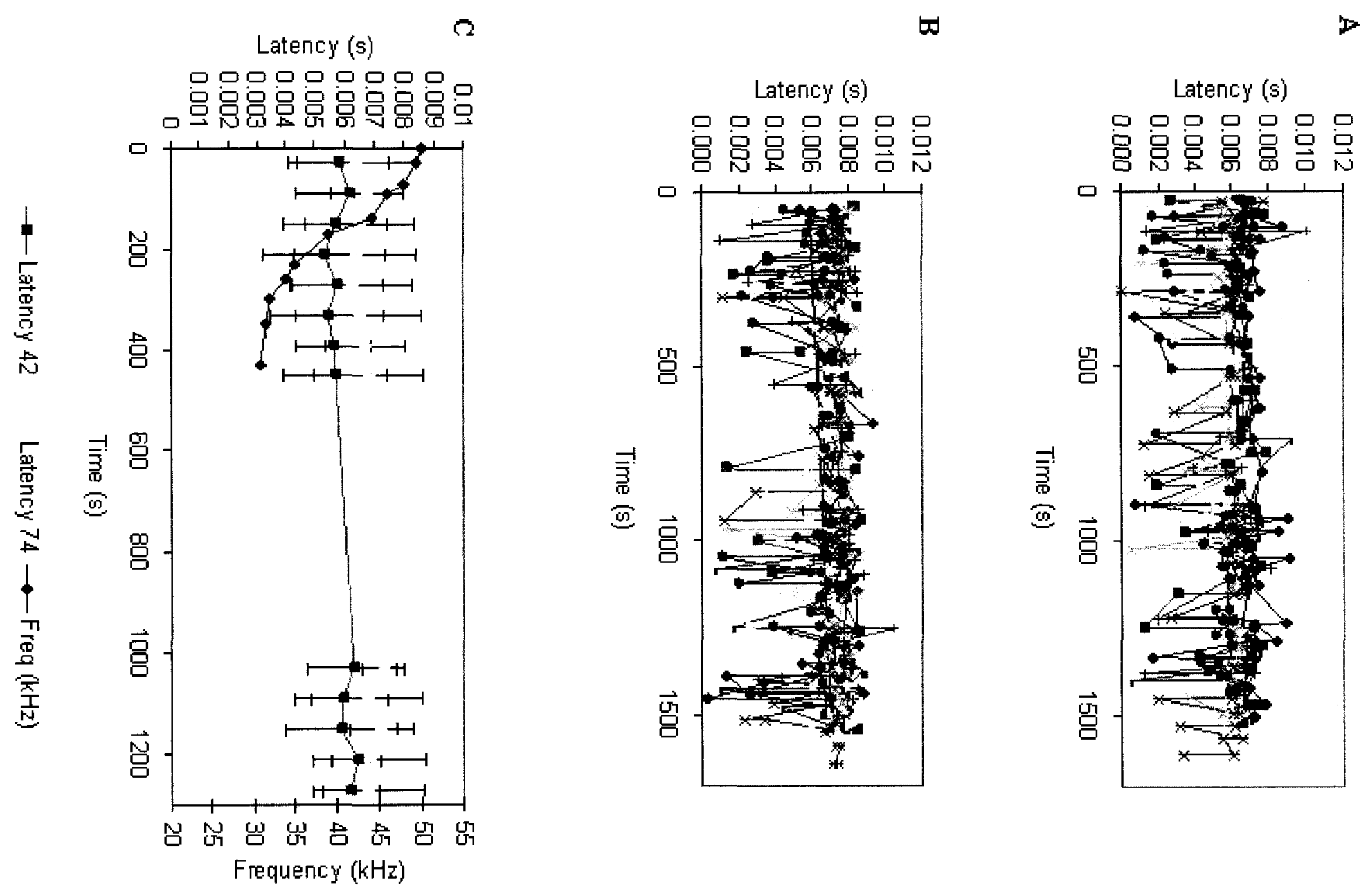
Table 2. Regression statistics for $N$. pronuba indicating both the F-statistic and $p$ values. Yellow boxes indicate statistical significance and the Binom column gives Binomail test statistic as the likelihood of achieving $\mathrm{X}$-number of significant values across the total sample size. 
\# Sig Total Binom

\begin{tabular}{|c|c|c|c|c|c|c|c|c|c|c|c|c|}
\hline \multirow[t]{3}{*}{ Spike \# } & 42 & $\begin{array}{c}F \\
\text { Significance } F\end{array}$ & $\begin{array}{l}0.4624 \\
0.5051\end{array}$ & $\begin{array}{l}0.0773 \\
0.7841\end{array}$ & $\begin{array}{l}4.5638 \\
0.0466\end{array}$ & $\begin{array}{l}0.5070 \\
0.4856\end{array}$ & $\begin{array}{l}3.6609 \\
0.0717\end{array}$ & $\begin{array}{l}4.3279 \\
0.0506\end{array}$ & $\begin{array}{l}0.8709 \\
0.3631\end{array}$ & $\begin{array}{l}0.1047 \\
0.7500\end{array}$ & 1 & 80.0313 \\
\hline & \multirow[t]{2}{*}{74} & $F$ & 0.6211 & 1.0661 & 0.5699 & 0.0890 & 0.4106 & 1.0701 & 4.8692 & 4.3881 & & \\
\hline & & Significance $F$ & 0.4409 & 0.3155 & 0.4601 & 0.7689 & 0.5297 & 0.3133 & 0.0406 & 0.0506 & 1 & 80.0313 \\
\hline \multirow[t]{4}{*}{$|S|$} & \multirow[t]{2}{*}{42} & $F$ & 0.0257 & 1.0252 & 1.2766 & 1.3500 & 0.0044 & 2.3323 & 0.6524 & 1.7877 & & \\
\hline & & Significance $F$ & 0.8744 & 0.3247 & 0.2734 & 0.2605 & 0.9480 & 0.1424 & 0.4298 & 0.1979 & 0 & 80.0039 \\
\hline & \multirow[t]{2}{*}{74} & $F$ & 0.6867 & 0.9605 & 1.3273 & 3.8970 & 0.0052 & 0.0002 & 0.0771 & 0.3235 & & \\
\hline & & Significance $F$ & 0.4175 & 0.3401 & 0.2644 & 0.0639 & 0.9433 & 0.9890 & 0.7844 & 0.5766 & 0 & 80.003 \\
\hline \multirow[t]{4}{*}{ Burst Dur } & \multirow[t]{2}{*}{42} & $F$ & 0.1923 & 0.1429 & 1.9777 & 1.3407 & 0.4398 & 0.2611 & 0.0876 & 0.5498 & & \\
\hline & & Significance $F$ & 0.6662 & 0.7099 & 0.1767 & 0.2620 & 0.5156 & 0.6149 & 0.7707 & 0.4680 & 0 & 80.003 \\
\hline & \multirow[t]{2}{*}{74} & $F$ & 0.9739 & 0.0482 & 1.4800 & 2.1004 & 0.0541 & 0.0620 & 1.5147 & 1.7018 & & \\
\hline & & Significance $F$ & 0.3368 & 0.8287 & 0.2395 & 0.1645 & 0.8187 & 0.8059 & 0.2343 & 0.2085 & 0 & 80.003 \\
\hline \multirow[t]{4}{*}{ Latency } & \multirow[t]{2}{*}{42} & $F$ & 0.6591 & 2.3055 & 0.4567 & 0.2331 & 0.5037 & 0.3029 & 0.0911 & 0.0642 & & \\
\hline & & Significance $F$ & 0.4275 & 0.1463 & 0.5077 & 0.6350 & 0.4870 & 0.5882 & 0.7663 & 0.8029 & 0 & 80.0039 \\
\hline & \multirow[t]{2}{*}{74} & $F$ & 0.4722 & 0.9097 & 9.2649 & 1.1619 & 0.0391 & 0.0003 & 0.1910 & 0.8884 & & \\
\hline & & Siqnificance $F$ & 0.5007 & 0.3528 & 0.0070 & 0.2953 & 0.8455 & 0.9863 & 0.6672 & 0.3584 & 1 & 80.0313 \\
\hline
\end{tabular}


N. pronuba Cut-nerve trials

No significant decreases in spike number, interspike interval, burst duration, or latency was observed for $N$. pronuba $(\mathrm{n}=8)$ with transected auditory nerves (henceforth referred to as: $N$. pronuba CUT). The only significant effect observed in the cut trials was an increase in spike number for EL trials at $42 \mathrm{kHz}$ (paired t-test, $\mathrm{t}=0.088, \mathrm{n}=9, \mathrm{p}$ $=0.044$ ). Complete sets of statistical values pertaining to $N$. pronuba CUT ELR paired sample t-tests are given in Table 1 and graphically represented in Fig. 10. 
Figure 10. Early, Late and RE data compared at $42 \mathrm{kHz}$ and $74 \mathrm{kHz}$ for $N$. pronuba CUT trials (bars are mean (+/- SEM)). 

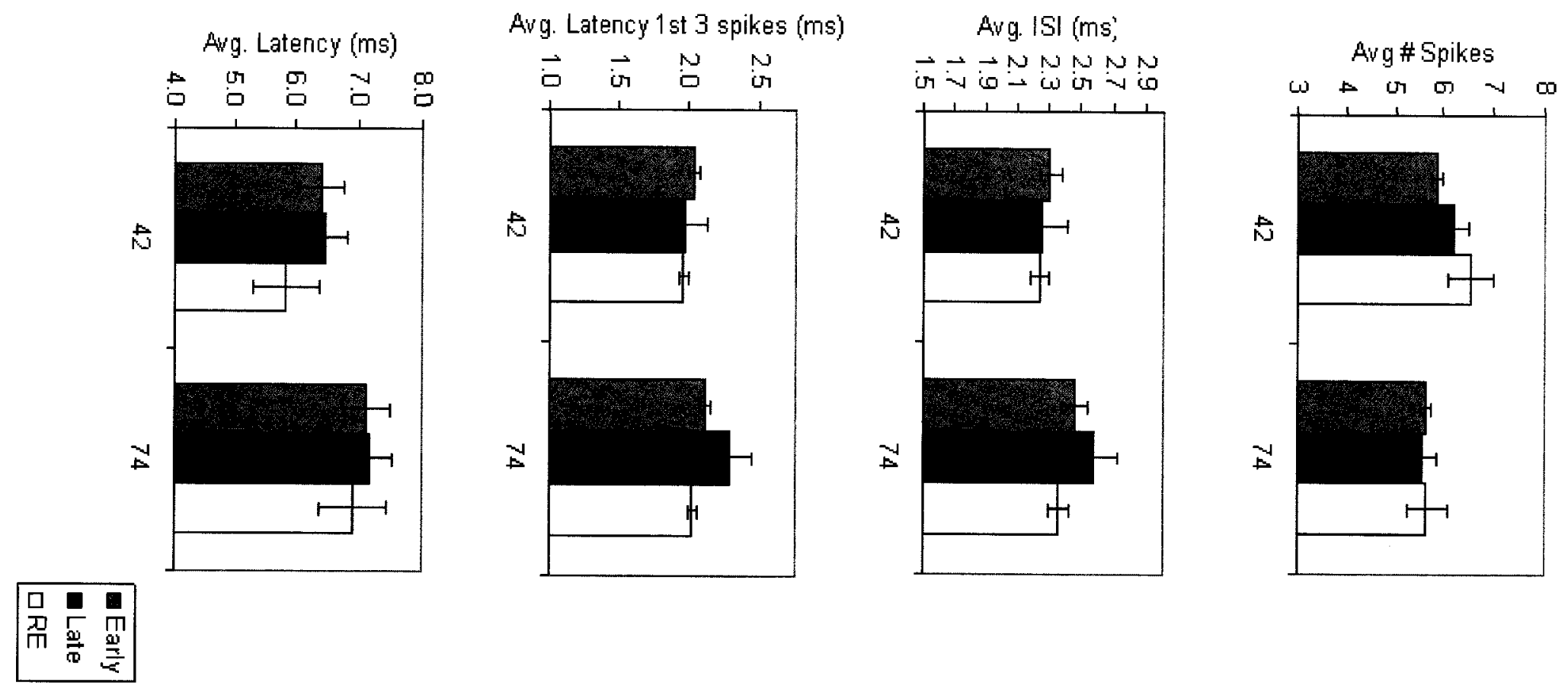
Time series data is again plotted against Windmill. For cut nerve trials the data was adjusted to 100 second bins. Time series data used in the Windmill comparison fell within the range of the scatterplot data. Graphical representation of spike number is given in Fig. 11 (see Appendix 3: Fig. 21).

Linear regressions over the first 500 seconds of testing completed on a per moth basis showed no significant effect for spike number, interspike interval, burst duration, or latency when a binomial test was applied. Complete regression statistics are given in Table 3. 
Figure 11. Time series data for spike number in $N$. pronuba CUT trials. Three graphs are given: (A) scatter plot showing probe stimulus responses for all moths at $42 \mathrm{kHz}$ and (B) $74 \mathrm{kHz}$, in addition to times series data (C) placed into 100 second bins and plotted over tympanal velocity data from Windmill et al. (2006) (bars are mean (+/- SD)). Data for $42 \mathrm{kHz}$ and $74 \mathrm{Khz}$ test pulses with time values greater than 1200 seconds account for the RE portion of the trial. 

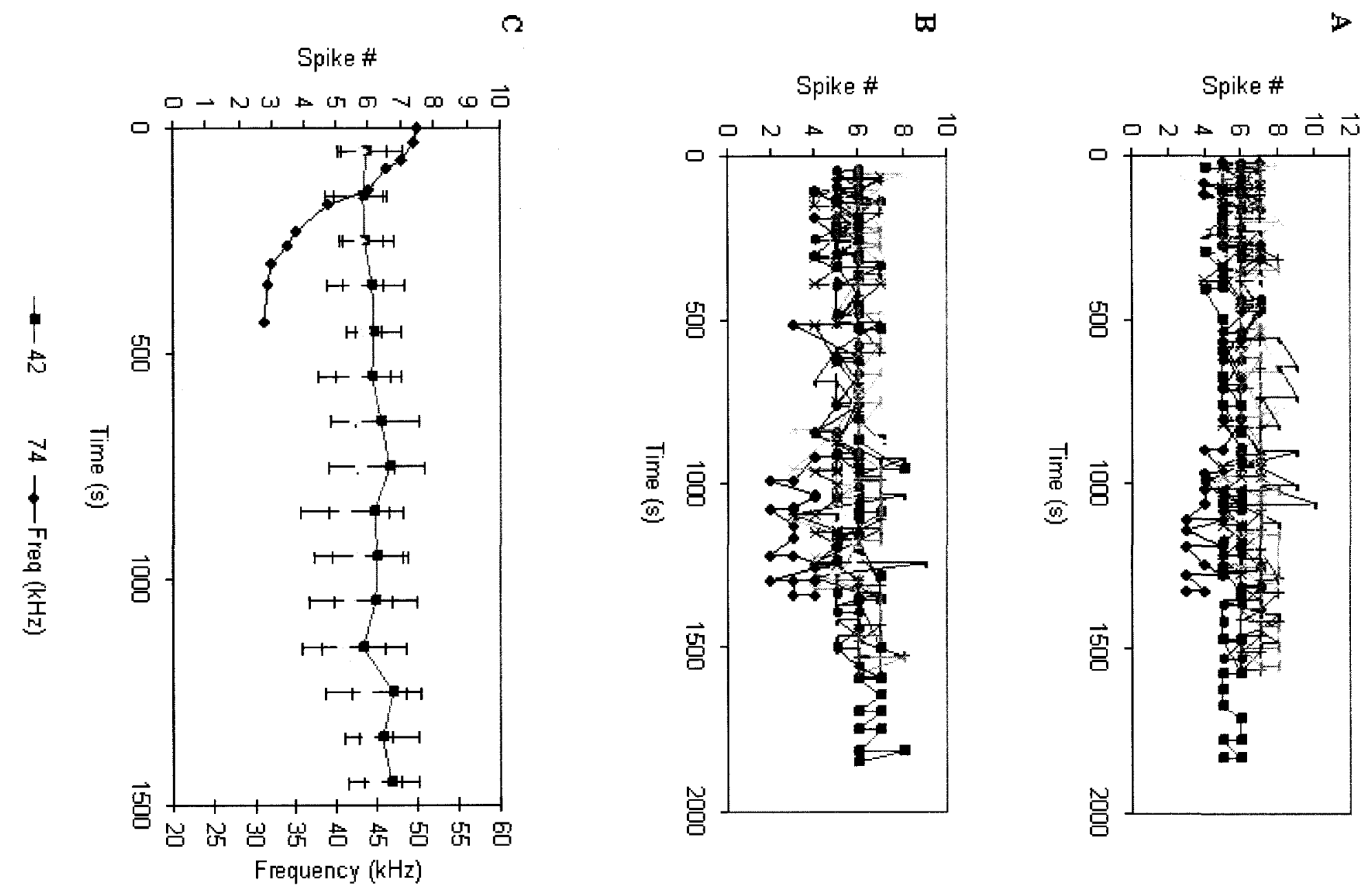
Table 3. Regression statistics for $N$. pronuba CUT indicating both the F-statistic and $p$ values. Yellow boxes indicate statistical significance and the Binom column gives Binomial test statistic as the likelihood of achieving X-number of significant values across the total sample size. 
\# Sig Total binom

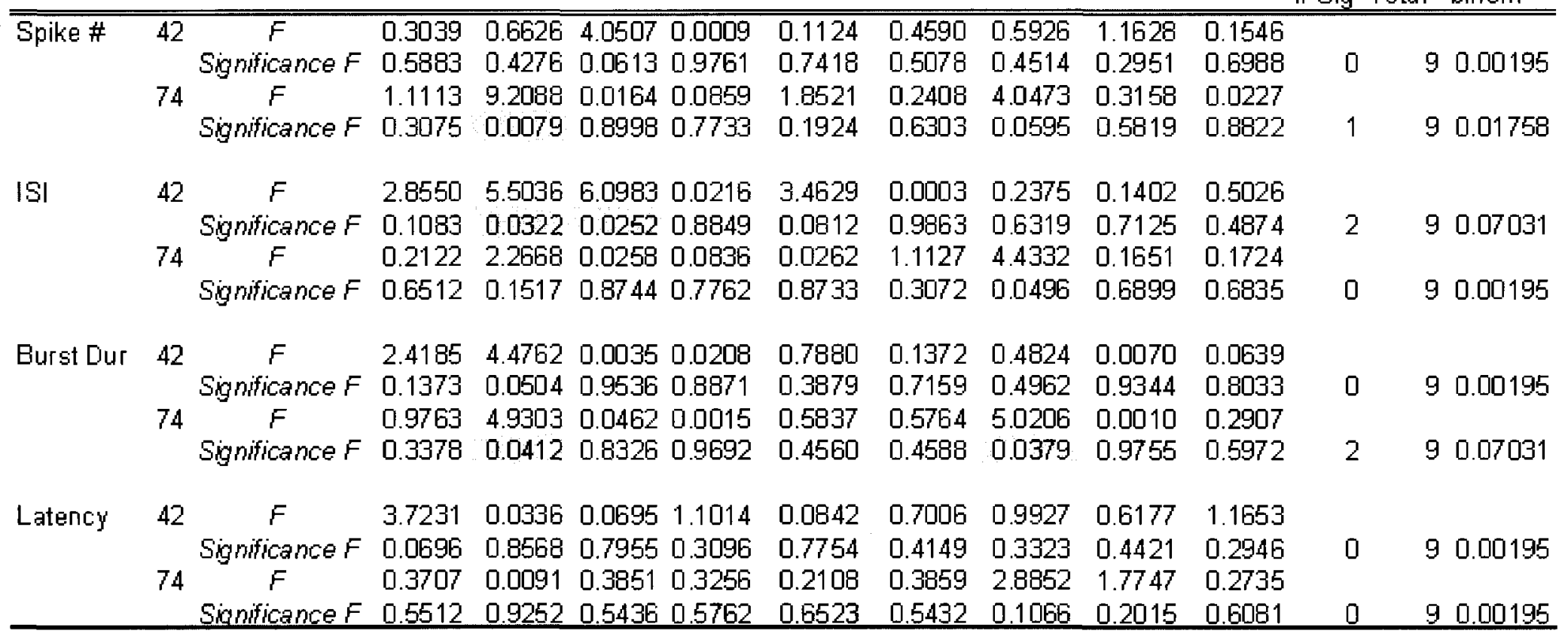




\section{Amphypyra pyramidoides}

Data for $A$. pyramidoides $(\mathrm{n}=5)$ is given in the form of scatterplots and, when possible, graphed against Windmill as 100 second bins. No response values were obtained for a number of stimulus bursts following high intensity stimulation. This resulted in blank values for interspike interval, burst duration, and latency and as a result large standard deviations about the mean as ISI and latency values had to be ignored (no number could be assigned to these bursts). Graphical representation of spike number is given in Fig. 12 (ISI, burst duration and latency graphs in Appendix 3: Fig. 22). Linear regressions conducted over the first 500 seconds of testing yielded a statistically significant positive slope for the data. Moths that initially showed no response and recovered were considered significant in terms of a regression test. Complete regression statistics are given in Table 4. 
Figure 12. Time series data for spike number in $A$. pyramidiodes trials. Three graphs are given: (A) scatter plot showing probe stimulus responses for all moths at $42 \mathrm{kHz}$ and (B) $74 \mathrm{kHz}$, in addition to times series data (C) placed into 100 second bins and plotted over tympanal velocity data from Windmill et al. (2006) (bars are mean (+/- SD)). Data for $42 \mathrm{kHz}$ and $74 \mathrm{Khz}$ test pulses with time values greater than 1100 seconds account for the $\mathrm{RE}$ portion of the trial. 

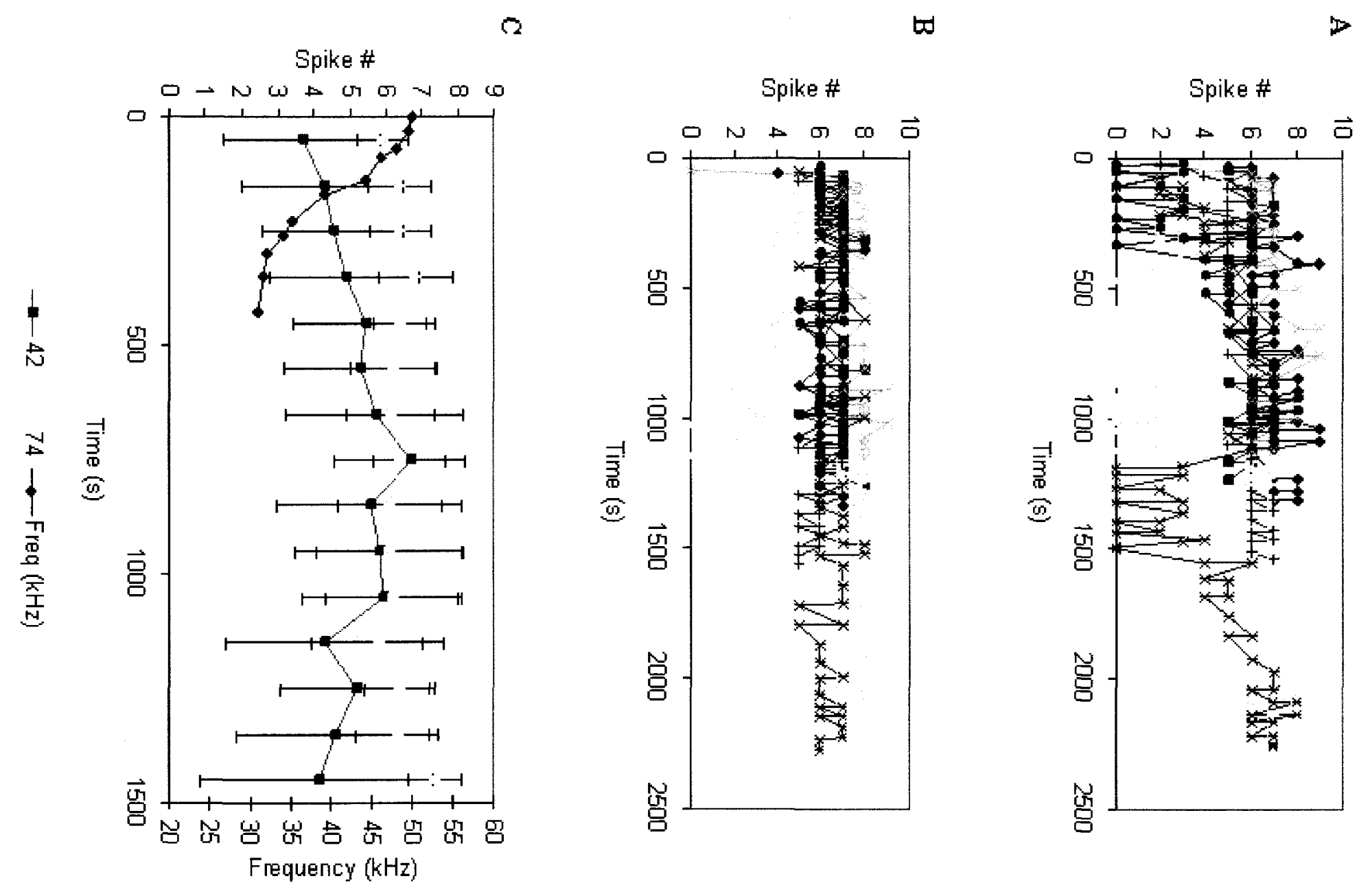
Table 4. Regression statistics for $A$. pyramidoides indicating both the F-statistic and $p$ values. Yellow boxes indicate statistical significance and the Binom column gives Binomial test statistic as the likelihood of achieving X-number of significant values across the total sample size. 
\# Sig Total binom

\begin{tabular}{|c|c|c|c|c|c|c|c|c|c|c|c|c|}
\hline Spike \# & 74 & $\begin{array}{c}F \\
\text { Significance } F \\
F \\
\text { Significance } F\end{array}$ & $\begin{array}{l}2.6026 \\
0.1241 \\
0.6744 \\
0.4223\end{array}$ & $\begin{array}{l}1.0236 \\
0.3251 \\
0.0144 \\
0.9058\end{array}$ & $\begin{array}{r}10.8074 \\
0.0041 \\
12.6989 \\
0.0022\end{array}$ & $\begin{array}{l}10.0008 \\
0.0049 \\
4.3763 \\
0.0494\end{array}$ & $\begin{array}{r}57.4141 \\
0.0000 \\
11.4567 \\
0.0024\end{array}$ & $\begin{array}{l}7.9570 \\
0.0097 \\
1.3698 \\
0.2544\end{array}$ & $\begin{array}{l}6.8334 \\
0.0176 \\
2.8298 \\
0.1098\end{array}$ & 3 & 7 & 0.2734 \\
\hline ISI & 42 & $\begin{array}{c}F \\
\text { Significance } F \\
F \\
\text { Significance } F\end{array}$ & $\begin{array}{l}0.2725 \\
0.6080 \\
0.0027 \\
0.9588\end{array}$ & $\begin{array}{l}0.5327 \\
0.4749 \\
0.1252 \\
0.7276\end{array}$ & $\begin{array}{l}0.4150 \\
0.5276\end{array}$ & & $\begin{array}{l}0.2803 \\
0.6018\end{array}$ & $\begin{array}{l}0.3835 \\
0.5427\end{array}$ & $\begin{array}{l}2.5516 \\
0.1276 \\
0.2236 \\
0.6420\end{array}$ & & & $\begin{array}{r}0.7734 \\
0.0547\end{array}$ \\
\hline Burst Dur & 74 & $\begin{array}{c}F \\
\text { Significance } F \\
F \\
\text { Significance } F\end{array}$ & $\begin{array}{l}0.1092 \\
0.7449 \\
0.2363 \\
0.6328\end{array}$ & $\begin{array}{l}0.0521 \\
0.8220 \\
0.0046 \\
0.9465\end{array}$ & $\begin{array}{l}0.8177 \\
0.3778\end{array}$ & & $\begin{array}{l}1.8323 \\
0.1896\end{array}$ & $\begin{array}{l}0.5930 \\
0.4503\end{array}$ & $\begin{array}{l}0.0009 \\
0.9770 \\
1.7120 \\
0.2072\end{array}$ & & 7 & $\begin{array}{l}0.7734 \\
0.0547\end{array}$ \\
\hline Latency & 42 & $\begin{array}{c}F \\
\text { Significance } F \\
F \\
\text { Significance } F\end{array}$ & $\begin{array}{l}0.0216 \\
0.8847 \\
0.8784 \\
0.3610 \\
\end{array}$ & $\begin{array}{l}4.4071 \\
0.0502 \\
0.5372 \\
0.4730 \\
\end{array}$ & $\begin{array}{l}0.1151 \\
0.7383 \\
\end{array}$ & & $\begin{array}{r}4.9135 \\
0.0373 \\
\end{array}$ & $\begin{array}{l}1.0597 \\
0.3156 \\
\end{array}$ & $\begin{array}{l}6.2555 \\
0.0223 \\
0.3716 \\
0.5498 \\
\end{array}$ & 2 & 7 & 0.7734 \\
\hline
\end{tabular}


Other species

Linear regression data for Acronicta americana $(\mathrm{n}=2)$, Xestia dolosa $(\mathrm{n}=5)$, and Catocala ultronia $(\mathrm{n}=1)$ yielded no significant differences over the first 500 seconds of testing. Complete regression/binomial test statistics are given in Table 5 (Appendix 2).

Data is plotted against Windmill et al.(2006) time series data for all aforementioned mentioned species. All regression analysis data is given in Appendix 3: Fig. 23.

B cell

Instantaneous B-cell spike frequency is plotted both between species and within species depending on whether or not the trial had a Re-tune segment. Data was adjusted to include only up to 1149 seconds of the EL portion of the trial and up to the first 314 seconds of the R portion. No significant change (t-test) in B-cell spike rate was observed as a result of either the high intensity tune up stimuli or the probe stimuli in any species of moth when the firing rate for the first 10 seconds before a tune up stimulus was compared to the first 10 seconds after for $N$. pronuba (t-test, $\mathrm{p}=0.607), N$. pronuba CUT+RE (t-test, $\mathrm{p}=0.80$ ), and A. pyramidoides (t-test, $\mathrm{p}=0.95$ ). B-cell firing rate did not proceed in a consistent linear fashion for some moth groups (Fig. 13). 
Figure 13. Instantaneous $\mathrm{B}$-cell firing rate $(\mathrm{Hz})$. Data is given as an average across specific groups of moths. Grey symbols refer to a specific group and colored lines give a polynomial line of best fit for the group. Data shown with time values over 1200 seconds refers to RE test data. 


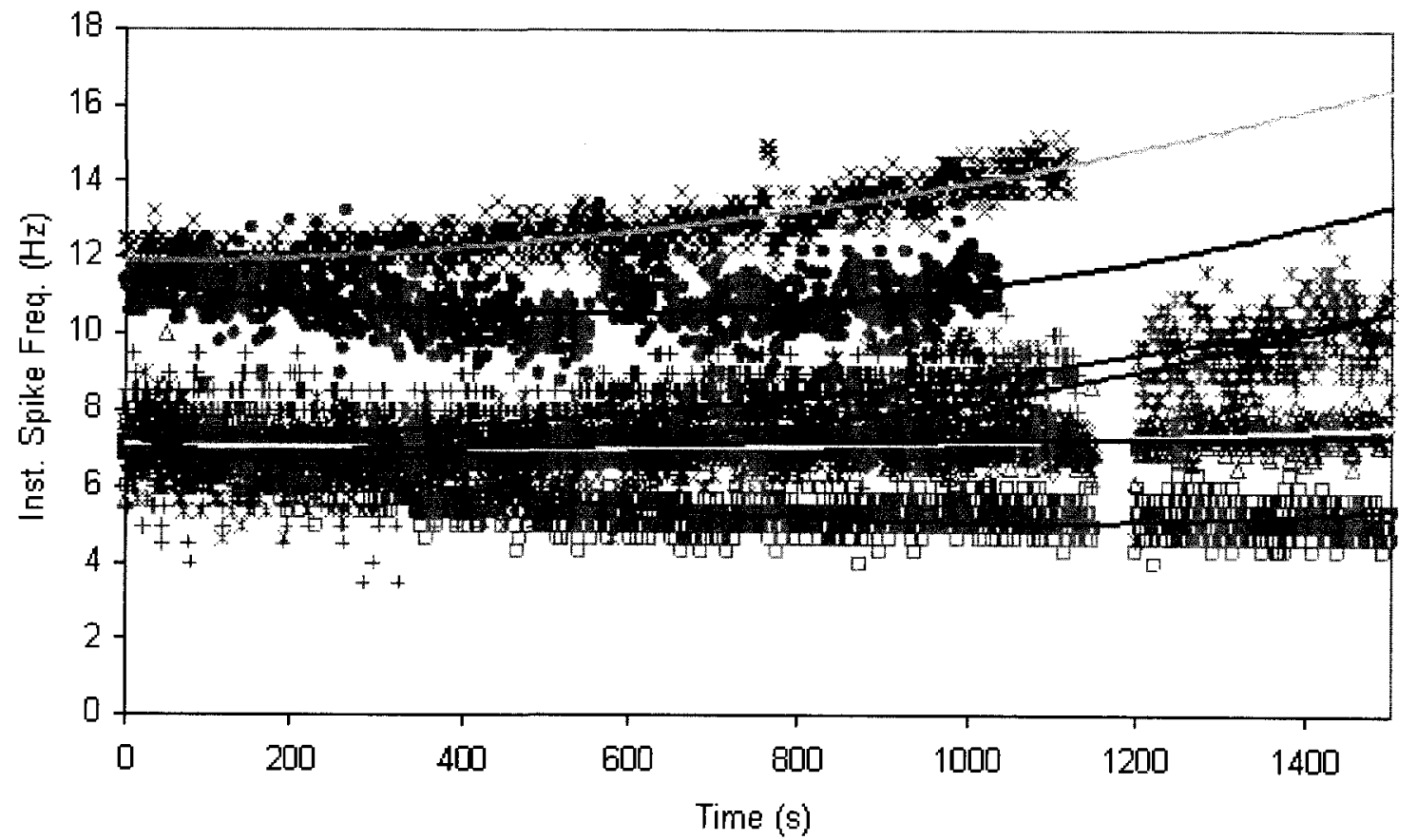

CUT

- CUT+RE

$\triangle$ N pronuba NEW

$\times$ A pyramidoides

$x$ A pyramidoides $+R E$

- X dolosa

+ A americana Poly. (A pyramidoides)

- Poly. (X dolasa)

-Poly. (A americana)

—Poly. (A pyramidoides + RE)

Poly. (N pronuba NEW)

-Poly. (CUT+RE)

- Poly. (CUT) 
Discussion

Findings by Windmill et al. (2006) showed that the noctuid moth, Noctua pronuba, is capable of actively altering the mechanical characteristics of its tympanic membrane in order to more acutely listen for the echolocation calls of bats. Specifically, they found that when the moth was presented with high intensity acoustic stimuli, the membrane would shift its resonant frequency from $42 \mathrm{kHz}$ to $74 \mathrm{kHz}$ with an increase in sensitivity at both frequencies. This "tune up" response was dependent only on the amplitude of the stimulus and was hysteretic in that it would last for an average of 7.5 minutes after which it was capable of being "Re-tuned up". In discussion "tuning up" refers to an increase in sensitivity which would be evident as an increase in spike number and burst duration, and a decrease in interspike interval and latency; the opposite is true for "tuning down". In attempting to confirm a neurological basis to the mechanical shift in the resonant frequency of the tympanic membrane this study finds that there is no time dependent neurological differences as a result of high intensity stimulation. Linear regressions indicate that time resolved afferent responses to probe pulses (given after a high intensity "tune up" stimulus) do not deviate from a zero-slope linear relationship over the same time period used by Windmill et al. (2006).

Such drastic mechanical modifications of a sound stimulus as those shown in Windmill et al. (2006) would imply a corresponding affect on the physiological system responsible for analyzing these signals. At a given frequency, as the intensity of a sound stimulus is increased, the noctuid moth auditory afferents respond with variations in a combination of neurolophysiological characteristics. These include reduced latency to 
response onset, reduced interspike interval times, and increased number of action potentials per stimulus response (Roeder, 1964). The noctuid moth, $N$. pronuba, by actively manipulating the tension of its tympanal membrane, can effectively increase the velocity of its tympanal response from about $7 \mu \mathrm{m} / \mathrm{s}$ to about $25 \mu \mathrm{m} / \mathrm{s}$ at $42 \mathrm{kHz}$ and from $2 \mu \mathrm{m} / \mathrm{s}$ to about $200 \mu \mathrm{m} / \mathrm{s}$ at $74 \mathrm{kHz}$. Given this data, it is reasonable to hypothesize that an increase in membrane velocity produced by tuning the membrane up should result in a corresponding effect at the afferent level. Therefore a hysteretic increase in membrane velocity should result in auditory afferents reacting more strongly to stimuli of equal amplitude for some period of time. In this experiment no time dependent shift in afferent activity was observed implying that afferent response is only affected by stimulus amplitude at a particular frequency and not receptor velocity. This is not surprising in that as the tension placed on a membrane is increased its resonant frequency also increases. This is seen in Windmill et al. (2006). But, for a simple membrane, as tension increases response amplitude to a standard stimulus decreases, therefore, assuming that response intensity of the auditory receptor cells is dictated by the amplitude of the tympanal vibrations, there should not be an increase in receptor cell response but instead there should be a decrease (See General Discussion for the proposed ramifications of this effect).

Noctua pronuba with intact nervous systems showed significant down tuning for both ISI and latency when EL stimulus responses were compared at $74 \mathrm{kHz}$. This result is expected in the context of Windmill et al. (2006) as the membrane gradually shifts downward in resonant frequency as it detunes. When we attempted to tune the 
membrane up for a second time no upward shift in tuning was observed, in fact, even stronger down tuning was observed for ER comparisons including: ISI for $1^{\text {st }}$ three spikes at $42 \mathrm{kHz}$ and ISI, ISI for $1^{\text {st }}$ three spikes, and latency at $74 \mathrm{kHz}$. For late vs. re-tune comparisons no effect was observed where one would expect a significant jump upward in sensitivity across categories for both $42 \mathrm{kHz}$ and $74 \mathrm{kHz}$ stimulus pulses.

Experiments where the auditory nerve branch (IIIN1) was cut were intended to elucidate whether or not afferent activity was responsible for initiating the tuning up of the membrane or if the motor neurons responsible for tuning the membrane are activated by some other mechanism. If an effect was observed it would imply that there may be a mechanism independent of auditory stimulation responsible for shifting membrane resonance and if not it that there is either no physiological effect as a result of a membrane shift or afferent input is required. Results show that afferent activity remains unchanged after transection of the auditory nerve. In fact only spike number showed a significant tuning effect in the upward direction at $42 \mathrm{kHz}$ for EL trials, an unexpected result. Even though the moths were allowed to sit undisturbed for 10 minutes post cutting the nerve branch IIIN1 it is possible that the uptuning in spike number seen at $74 \mathrm{kHz}$ was a result of the neuron regressing to its normal activity after receiving some trauma via transection. No significant tuning change for cut nerve experiments would indicate that afferent activity is responsible for activating the membrane sensitivity shift, but, considering these results in combination with results for the intact moths that show no initial significant shift in afferent activity, means that there is no initial physiological basis for any of the cut-nerve assumptions. Although, should these trials have yielded 
unexpected results they would have been of definite benefit in defining yet another dimension of moth active hearing.

In addition to N. pronuba four other species of noctuid moth were also tested: (1) Amphipyra pyramidoides, (2) Xestia dolosa, (3) Acronicta americana and (4) Catocala ultronia. The most interesting results were obtained from $A$. pyramidoides. When presented with an intense tune-up stimulus $A$. pyramidoides actually shows a significant decrease in sensitivity at both $42 \mathrm{kHz}$ and $74 \mathrm{kHz}$, so much so that in 2 of the 5 moths tested the auditory response was actually completely abolished for up to 5 minutes after intense stimulation. After this time period the moth would gradually regain sensitivity and slowly return to a response consisting of 6 to 8 spike bursts. These results are interesting in that they show the opposite effect to that proposed by Windmill et al. (2006). Some moths even failed to respond whatsoever to the probe pulses (threshold intensity $+5 \mathrm{~dB}$ ) for a period of time after intense stimulation. Similar results to these were obtained by Fullard et al. (2003) who proposed that there is little auditory selection pressure on moths to accurately process echolocation calls projected by a bat that is so close that only a well executed "last chance" escape maneuver would save it from being eaten. Alternatively, they also suggest that the reduced response could be a result of the bat manipulating the spectral characteristics of its calls to make it less apparent during its approach. Where Fullard et al. (2003) observed reduced firing, this study, in $40 \%$ of $A$. pyramidoides tested, shows a complete absence of neural firing for some moths in response to low intensity sound. This suggests a physiological mechanism by which the moth is rendered either less sensitive at a particular frequency or deaf for a period of 
time. Should the noctuid moth, $A$. pyramidoides, be "turning off" its auditory circuitry in favor of other "last chance for escape" circuitry it would imply a mechanism capable of directly affecting afferent response. This could be accomplished by (1) muscles directly affecting the membrane in such a way that it is no longer able to elicit the same degree of response in auditory afferents. Such as stretching it to such a great tension that only very high intensity stimulation will initiate vibrations with the necessary range of displacement to elicit responses, or (2) the afferents being actively inhibited by some CNS process.

Noctua pronuba experiments show that afferent activity is amplitude dependent. Perhaps, in A. pyramidiodes, the tension of the membrane is altered by intense stimulation resulting in a conformational change. If the membrane were to become more tense as a result of either some muscle related active stretching, or just a general increase in tension of the body wall that surrounds it, as a result of intense stimulation it could result in the membrane not being able to vibrate at as great an amplitude as it would in a relaxed state. As is the case with $N$. pronuba lower response amplitude could equal less intense response. Whatever mechanism it may be, $A$. pyramidoides will prove an ideal specimen for future research of the auditory periphery, auditory afferents, and central nervous system processes including those that may be taking place at the level of the motor efferents.

B-Cell activity was assessed for all species of moth tested. As expected, no statistically significant responses over the time periods following intense stimulation were observed. Lechtenberg (1971) was first to suggest that the B-Cell may play an 
auditory role. However, this finding was refuted by Fullard et al. (2003) who showed that discrepancies in B-Cell firing rates as a result of auditory stimulation were probably due to the use of unnaturally intense stimuli. These stimuli most likely oversaturated the system resulting in conformational changes in the exoskeleton thereby affecting the physiological characteristics of the B-cell as the accepted evolutionary origins of the cell are those of a proprioceptor (Treat and Roeder, 1959; Yack and Fullard, 1990). The nonlinear relationship seen over the 25 minute trial periods are most likely due to slight alterations in the quality of the restraints used to pin the moth's wings down during experimental investigation. Auditory thresholds were tested both before and after experimentation to ensure degradation of the preparation was not taking place. Therefore, the key finding is that there is no correlation between firing rates and intense stimulus presentation.

In assessing the biological basis of tuning up proposed by Windmill et al. (2006) some discrepancies between the relevance of active tuning and observations for wild bat behavior become apparent. Windmill et al., (2006) proposed that N. pronuba is shifting the best frequency of its tympanic membrane, which is between 15 and $25 \mathrm{kHz}$ (Waters and Jones, 1996), up in order to better anticipate the higher echolocation frequencies used by bats as they attack their prey. The best frequency given in Waters and Jones (1996) may be a bit on the low side as other studies have predicted average best hearing frequencies of typical noctuid moths to be between $20-40 \mathrm{kHz}$ (Fullard, 1988). Previous studies (Surlykke and Moss, 2000) indicate that while bats do increase the repetition rate of their echolocation pulses as they approach a source of prey they do not 
alter the frequency content of these pulses as suggested in Windmill et al. (2006). Instead of broadening the frequency content bats decrease the bandwith of their calls, narrowing the frequency content, thereby omitting some of the high frequencies found in search phase echolocation pulses (Surlykke and Moss, 2000) (Fig. 4B). While a hysteretic response would give the moth a better chance of detecting low intensity search phase calls for a period of time following an encounter with an attacking bat this would seem irrelevant in that the previously attained audiograms (Waters and Jones, 1996) already show more than sufficient sensitivity in search call frequency ranges (Fig. $4 A \& B)$

This begs the question: Is there a biological need for $N$. promuba to increase its overall frequency sensitivity when it is already such a sensitive moth (Fullard, personal communication) compared to most other noctuids? Results of this study indicate while there may be complex mechanical characteristics present at the auditory periphery of $N$. pronuba they serve no physiological function. As we did not attain any physiological evidence for an effect of active tuning on afferent coding it leads us to conclude that the membrane response shown in Windmill et al. (2006) may be epiphenomenal in its functioning. In the case of $N$. pronuba it is stimulus amplitude alone and not a shift in receptor velocity that affects afferent activity. 


\section{Literature Cited}

Coro, F. and Kössl, M. (1998). Distortion-product otoacoustic emissions from the tympanic organ in two noctuid moths. J. Comp. Physio.l A. 183: $525-531$.

Coro, F. and Kössl, M. (2001). Components of the 2f1-f2 distortion-product otoacoustic emission in a moth. Hear. Res. 162: $126-133$.

Fielden, A. (1960). Transmission through the last abdominal ganglion of the dragonfly nymph, Anax imperator. J. Exp. Biol. 37: 832 - 844.

Fullard, J.H. (1987). Sensory ecology and neuroethology of moths and bats: interactions in a global perspective. In Recent Advances in the Study of Bats (ed. M. B.

Fenton, P. A Racey and J. M. V. Rayner). 244-272. Cambridge University Press, Cambridge.

Fullard, J.H. (1988). The tuning of moth ears. Experientia. 44: $423-428$.

Fullard, J.H. (1998). Sensory coevolution of moths and bats. In Comparative Hearing: Insects. (ed. Hoy, R.R., Popper, A.N. and Fay, R.R. eds). 279-326. Springer Handbook of Auditory Research Springer-Verlag, New York.

Fullard, J. H. and Dawson, J. W. (1999). Why do diurnal moths have ears?. Naturwissenschaften. 86: $276-279$.

Fullard, J.H., Dawson, J.W. and Jacobs, D.S. (2003). Auditory encoding during the last moments of a moths life. J. Exp. Biol. 206: 281-294.

Gibson, G. and Russell, I. (2006) Flying in tune: sexual recognition in mosquitoes. Curr. biol. 16: $1311-1316$. 
Göpfert, M.C. and Robert, D. (2001). Active auditory mechanics in mosquitoes. Proc. $R$. Soc. Lond. B. 268: 333 - 339.

Göpfert, M.C. and Robert, D. (2001a). Turning the key on Drosophila audition. Nature. 411: 908 .

Göpfert, M.C. and Robert, D. (2002). The mechanical basis of Drosophila audition. $J$. Exp. Biol. 205: 1199-1208.

Göpfert, M. C. and Robert, D. (2007). Active processes in insect hearing. In Active processes and otoacoustic emissions in hearing (ed. G. A. Manley et al.). Springer Science +Business Media. New York.

Jackson, J. C. and Robert, D. (2006). Nonlinear auditory mechanism enhances female sounds for male mosquitoes. PNAS. 103: $16734-16739$.

Kim, J., Chung, Y.D., Park, D.Y., Choi, S., Shin, D.W., Soh, H., Lee, H.W., Son, W., Yim, J., Park, C.S., Kernan, M.J. and Kim, C. (2003). A TRPV family ion channel required for hearing in Drosophila. Nature. 424: 81 - 84 .

Kössl, M. and Boyan, G.S. (1998). Acoustic distortion products from the ear of a grasshopper. J. Acoust. Soc. Am. 104: $326-335$.

Kössl, M. and Boyan, G.S. (1998a). Otoacoustic emissions from a nonvertebrate ear. Naturwissenschaften. 85: $124-127$.

Kössl, M., Coro, F., Seyfarth, E-A. and Nässig, W.A. (2007). Otoacoustic emissions from insect ears having just one auditory neuron. J. Comp. Physio.l A. 193: $909-915$.

Kössl, M., Mockel, D. and Weber, M. (2008) Otoacoustic emissions from insect ears: evidence of active hearing? J. comp. physiol. A. 194: 597 - 609 . 
Lechtenberg, R. (1971). Acoustic response of the B cell in noctuid moths. J. Insect Physiol. 17: 2395-2408.

Robert, D. and Hoy, R.R. (2007). Auditory systems in insects. In Insect neurobiology (ed G. North and R. J. Greenspan), pp. 155 - 184. Cold Spring Harbour Laboratory Press, New York.

Roeder, K.D. (1962). The behaviour of free flying moths in the presence of artificial ultrasonic pulses. Anim. Behav. 10: $300-304$.

Roeder, K.D. (1964). Aspects of the noctuid tympanic nerve response having significance in the avoidance of bats. J. Insect Physiol. 10: $529-546$.

Roeder, K.D. (1967). Turning tendency of moths exposed to ultrasound while in stationary flight. J. Insect Physiol. 13: $873-888$.

Roeder, K.D. (1969). Nerve Cells and Insect Behaviour. Harvard University Press, Cambridge.

Roeder, K.D. (1975). Neural factors and evitability in insect behaviours. J. exp. Zool. $194,75-88$.

Roeder, K.D. and Treat, A.E. (1957). Ultrasonic reception by the tympanic organ of noctuid moths. J. Exp. Zool. 134: 127 -157.

Surlykke, A. and Moss, C. F. (2000). Echolocation behaviour of big brown bats, Eptesicus fuscus, in the field and laboratory. J. Acoust. Soc. Am. 108: $2419-$ 2429.

Treat, A. and Roeder, K. D. (1959). A nervous element of unknown function in the tympanic organ of moths. J. Insect Physiol. 3: 262 - 270. 
Waters, D. A. and Jones, G. (1996). The peripheral auditory characteristics of noctuid moths: responses to search phase echolocation calls of bats. J. Exp. Biol. 199: $847-856$.

Windmill, J.F.C., Göpfert, M.C. and Robert, D. (2005). Tympanal travelling waves in migratory locusts. J. Exp. Biol. 208: 157 - 168.

Windmill, J.F.C., Jackson, J.C., Tuck, E.J. and Robert, D. (2006). Keeping up with bats: dynamic auditory tuning in a moth. Curr. Biol. 16: 2418 - 2423.

Windmill, J.F.C., Fullard, J.H., Robert, D. (2007). Mechanics of a simple ear: tympanal vibrations in noctuid moths. J. Exp. Biol. 210: $2637-2648$.

Yack, J.E., Fullard, J.H. (1990). The mechanoreceptive origin of insect tympanal organs: a comparative study of similar nerves in tympanate and atympanate moths. $J$. Comp. Neurol. 300: 523 - 534. 


\section{CHAPTER 3}

Intracellular Investigation of Auditory Processing in the Noctuid Moth, Noctua pronuba

Introduction

To be a successful member of a specific environment all living organisms must react adaptively to a number of complex sensory stimuli. Adaptive reactions include those that involve: first, detecting and encoding a stimulus using some specialized sensory system, second, creating a neural representation of that stimulus (in the form of action potentials), and third, determining through some central nervous system (CNS) process whether or not the stimulus warrants an adjustment to be made to some ongoing motor pattern. This concept can be broadly defined as sensorimotor integration: the combination of sensory information for adaptive motor planning.

The noctuid moth is an ideal model system for the study of sensory motor integration (Roeder, 1969; Fullard, 1998) because it is highly specialized in its processing capabilities. Specifically, the noctuid auditory system has evolved exclusively to detect the echolocation calls of its foremost predator, the bat (Fullard, 1998; Fullard and Dawson, 1999). Amazingly, in this type of moth, sensory detection of complex bat calls is completed using only two sensory cells, labeled Al and A2. Both cells are tuned to a broad range of frequencies ( 5 to over $50 \mathrm{kHz}$ ) with the main difference between the cells being that $\mathrm{A} 2$ is about $20 \mathrm{~dB}$ less sensitive than $\mathrm{A} 1$ (Roeder, 1964). This system, as a result of its serving only one purpose, yields an excellent opportunity to draw direct inferences about the cause and effect of highly complex behaviors resulting from the activity of just two sensory cells. 
In moths, the majority of neurophysiological and neuroanatomical research to date has focused on the activity of afferents during acoustic stimulation (i.e. extracellular recordings from the auditory nerve), the structure of the ear (tympanic membrane and associated air sacs), and the evolution of the ear from pre-cursor sensory structures (See reviews by Roeder, 1963; Roeder, 1966; Yager, 1999; Waters, 2003; Mason \& Faure, 2004; Yack, 2004). Central projections of noctuid moth auditory afferents A1 (Paul, 1973), and A1, A2, and B (Surlykke and Miller, 1982) have been identified using procion yellow and $\mathrm{CoCl}_{2}$ backfill techniques respectively. The $\mathrm{B}$ cell is a third cell found in the auditory periphery that is thought to serve no auditory function (Fullard et al., 2003). It is believed that the axonal projections of A2 are isolated to the dorsal side of the pterothoracic (fusion of the meso and meta) ganglion ipsilateral to the auditory nerve. The B cell is thought to project ipsilateraly in both the anterior direction without entering the abdominal connectives and posterior direction as far as the prothoracic ganglion. These studies are purely speculative as to the true identities of the cells in question in that the physiological activity of the afferents was not taken into consideration upon filling. The only auditory afferent to be identified both morphologically and physiologically is Al (Boyan et al., 1990) which exhibits projection patterns that are similar to those proposed for the B cell. Previous studies have also identified interneurons involved in the auditory pathway of moths (Boyan \& Fullard, 1986; Boyan \& Fullard, 1988; Boyan et al., 1990), although, compared to other insects, very little intracellular physiological research has been completed. From these studies, and similar ones examining locusts, crickets, bushcrickets and other tympanate insects, it has been noted that auditory 
afferents, with one exception (preying mantids), project to the same area in the CNS (Yager, 1999) - the medial ventral association centre (mVAC). Since the organization of the moth thoracic ganglia is similar to that of locusts, crickets, bushcrickets and other tympanate insects (i.e. they share the same groundplan), parsimony suggests that auditory processing mechanisms may also be similar.

Processing in the auditory periphery and the central nervous system has been shown to give the moth the ability to distinguish the "what" and "where" of an auditory stimulus, or in other words, the ability to identify a sound source as a bat (Roeder and Payne, 1966) and to distinguish the direction from which the bat is approaching (Coro and Perez, 1993). Directional responsiveness has been shown at the afferent level as increased afferent activity on the side of the moth ipsilateral to the sound source. There is little information pertaining to the processing of directional information in the moths CNS. Although, one could speculate to the use of contralateral inhibition, a topic thoroughly studied in crickets (Faulkes and Pollack, 2000), or some similar mechanism, as a means of sharpening the moths directional acuity. Contralateral inhibition occurs when the neurons ipsilateral to the sound source actively inhibit the sensory neurons on the contralateral side as a means of increasing their influence on higher level processing. In considering pattern recognition in noctuid moths one must first consider the anatomy of a stereotypical bat echolocation call. As an insectivorous bat approaches a moth it progresses through three stereotyped phases of echolocation call production (recently Surlykke and Moss (2000) broke the third, or terminal phase, into two sub phases). The first phase is known as the search phase where the bat is making calls at 
about 10 pulses per second (pps). During the search phase the bat has not located a moth, it is simply investigating its environment for potential food sources. When the bat locates a potential source of prey it switches to the approach phase where it increases the pulse rate (to about 50pps), in addition to the bandwidth of its calls. Once the bat verifies that the potential prey source is in fact a moth it begins the terminal phase of its approach where it further increases the pulse rate of its calls to about $100-200 \mathrm{pps}$. The A1 cell is capable of responding to bat echolocation pulses with instantaneous spike rates of up to 1 $\mathrm{kHz}$ (Perez and Coro, 1984). This is much faster than the maximum instantaneous firing rates found in many other invertebrate sensory systems (Boyan and Fullard, 1988). Activity at auditory afferents must be further broken down by primary auditory interneurons. noctuid moths are unique in this respect as the two auditory receptor neurons diverge to activate approximately seven auditory interneurons (Boyan and Fullard, 1986), surely a conservative estimate. In most animals, especially vertebrates, large numbers of auditory receptor neurons converge, connecting with a lesser number of interneurons projecting to higher centers responsible for feature extraction. This is also the case for many insects, for example, the ratio of auditory receptors to interneurons in crickets and grasshoppers are 10:1 and 3:1 to 5:1 respectively (Gerhardt and Huber, 2002). Intracellular studies of both unidentified and identified interneurons have shown that these cells tend to copy the response of the A1 cell (Boyan and Fullard, 1988) hence; they are commonly referred to as repeater cells (Roeder, 1966a). Until the studies of Boyan and Fullard $(1986,1988)$ researchers were unable to draw inferences to the integration of the information relayed by Al afferent at the synaptic level. Their research 
has given the first hints to the mechanism by which noctuid moths are processing auditory information, although, more work remains to be done.

Four distinct possibilities for temporal pattern recognition are outlined in Bush and Schul (2006) and are labeled as follows: (1) autocorrelation, (2) band-pass filtering, (3) resonant neuron hypothesis, and (4) cross-correlation. The first hypothesis states that the CNS performs an autocorrelation by comparing the incoming auditory signal with a delayed copy of the auditory signal at a coincidence detector (Reiss, 1964). If the delay represented in the neural network of the animal produces a match with the time-shifted signal, then a motor response is produced. In other words, a moth might consider the source of the stimulus to be from a bat (approaching or tracking). A second method, the high/low pass model (Schildberger, 1988), uses two filters (a high pass and a low pass filter) to deduce whether the afferent pulse rate is high or low enough. The output of the two filters converge on a neuron acting as an AND gate only allowing a response when both conditions are met. The third model, the resonance model, predicts that pulse rate must match the resonance frequency of a particular neuron to elicit a response (Bush and Schul, 2006). Resonance can be broadly defined as the ability of a neuron to respond selectively to inputs at preferred frequencies (for a more in-depth discussion of resonance see Hutcheon and Yarom, 2000). In addition to the previously mentioned models, a fourth, the cross correlation model, has been proposed (Hennig et al., 2004) where the pulse rate is compared to an internal template and a coincidence detector responds depending on the degree to which the incoming signal matches the template. 
In addition to auditory interneurons, both motor and pre-motor interneurons have been characterized and identified in moths (Rind, 1983; Madsen \& Miller, 1987) but their connections with auditory interneurons and/or auditory afferents are unknown.

In Locusts, two models have been proposed that account for how sensory information (visual or auditory) may be integrated with an ongoing flight motor pattern for effecting a steering response. First, Reichart and Rowell $(1985 ; 1986)$ proposed that deviation from a straight flight path is detected by the eyes and ocelli and conducted to multimodal thoracic interneurons by deviation detector neurons (DDN's). The thoracic interneurons, in addition to receiving input from DDN's carrying visual information, also receive input from the ears. The role of the thoracic interneurons is to selectively gate sensory information to premotor interneurons and motor neurons at the appropriate phase of the flight rhythm for effecting a steering maneuver. These multimodal thoracic interneurons can be viewed as having a global effect over the flight motor centers in that they elicit a coordinated, total shift, in flight motor output. As an alternate approach, it has been proposed that auditory input may affect wing specific oscillators (Comer \& Robertson, 2001) directly producing a change in flight motor output. Evidence in support of this comes from observations that locusts are able to produce a flight rhythm when their thoracic ganglia are bisected and hemisected (Ronacher et al., 1988). This would imply that auditory input merely shifts the timing of the neuronal ensemble relative to the contralateral side. These two hypotheses are not mutually exclusive. Given the scarcity of information regarding the connections of interneurons with the flight CPG in both moths and locusts (and other insects) it will be a long time before the complete 
organization of the neural circuits controlling the flight musculature are known. However, determining if auditory afferents make direct connections with flight motor neurons, and determining how acoustically active interneurons make connections with the flight CPG will provide further information. If moth auditory afferents were to make direct connections with flight motor neurons then moths may make rapid escape maneuvers by directly altering the output of the flight CPG, whether it is a hemioscillator or a distributed circuit in design. The benefit here would be revealed as a decrease in the latency of the moths response to adverse stimuli by effectively skipping the circuitry responsible for conventional steering in favor of a more rapidly produced motor response. If afferents are only found to make connections with multimodal interneurons of the flight CPG, then moths may control their flight in much the same way that locusts do. To gain as much information about the processing capabilities of a neuron as possible the neuron must be identifiable. To positively identify a neuron a researcher must characterize both its physiological behavior to a controlled stimulus and its morphological characteristics. This study will seek to identify and characterize at a cellular and synaptic level: (1) how moths are using interneurons to aid in computation of the direction of an incoming stimulus, (2) if auditory afferents or interneurons are making direct connections with flight motorneurons or interneurons, and (3) to determine how auditory interneurons are discriminating temporal characteristics of acoustic stimuli. 
Materials and Methods

Animals

Wild caught Noctua pronuba (noctuidae) were collected from Port Sydney, Ontario, Canada (45.220518,-79.270324) through the months of June 2007 - August 2007 and were used to establish a breeding colony that was maintained through one generation post wild caught moths, September 2007 - February 2008 . Wild caught moths were stored in $50 \mathrm{~cm}^{3}$ plastic container with sheets of wax paper hanging from the lid inside the container. All adult moths were fed a diet of sugarwater Ad libitum (3 tablespoons sugar in $300 \mathrm{~mL}$ DI water). The breeding colony was composed of about 300 eggs attained from a single female and the caterpillars that emerged were reared on wheat grass seedlings (C\&M Seeds) until pupation. Pupa were kept in a moist environment at room temperature until adult moths emerged. Lab bred moths were also kept in $50 \mathrm{~cm}^{3}$ plastic containers in groups of 15 - 30 individuals of both sexes and were given a steady supply of fresh sugar water. Adult wild caught moths were used within two weeks of capture and lab reared moths were used within two months post emergence. All neurophysiological recordings were preformed at Carleton University, Ottawa, Ontario, Canada.

\section{Dissection}

The moth pterothoracic ganglion (= fusion of meso- and meta-thoracic ganglia) was exposed using a modified dorsal dissection (Roeder and Treat, 1957). Moths were first restrained by laterally pinning the wings to a block of modeling clay using staples, after which the scales were carefully removed from the dorsal portion of the thorax with a 
fine paintbrush and the dorsal dissection was completed. After dissection the body cavity was immediately flooded with saline $(7.5 \mathrm{~g} \mathrm{NaCl}, 0.1 \mathrm{~g} \mathrm{KCl}, 0.2 \mathrm{~g} \mathrm{CaCl}, 0.2 \mathrm{~g} \mathrm{NaHCO}$, distilled $\mathrm{H}_{2} \mathrm{O}$ to $1000 \mathrm{ml}$ (Fielden, 1960)). Moths were then positioned on a platform and a custom made stainless steel spoon was carefully positioned under the pterothoracic ganglia to aid in immobilizing it over the duration of the neurophysiological recordings.

\section{Auditory Stimulation}

Auditory stimuli were generated using a waveform generator (Tabor electronics, WW5061) which fed into a pulse shaper (Coulbourn, 584-04) that allowed for the presentation of pulses of varying rise/fall durations, pulse length and interpulse duration. A custom made amplifier was used to control stimulus amplitude. Shaped stimulus pulses were sent to an oscilloscope (Tektronix, TDS 2014), data acquisition unit (Axon Instruments, Digidata 1322A), and a speaker (Motorola KSN1078A 2" Cone Tweeter) located within the experimental enclosure.

Cells were stimulated with a standard $35 \mathrm{kHz}$ repeating pulse $(10 \mathrm{~ms}$ width and $0.5 \mathrm{~ms}$ rise/fall times) with a $0.5 \mathrm{~s}$ interpulse interval at $80 \mathrm{~dB}$.

\section{Neurophysiological recording}

An experimental enclosure was created that consisted of the following: (1) a base support consisting of stacked cement blocks separated by dense foam padding, (2) a large faraday cage lined with sound attenuating foam placed atop the base support, (3) a self leveling antivibration table (MICRO-g, 2536-516-4-BTPE), and (4) a steel plate placed 
atop the anitvibration table into which screws could be inserted and magnetic stands could be attached.

A platinum reference electrode was first inserted into the abdomen of the moth followed by the recording electrode into the thoracic cavity. The recording electrode was connected via a headstage probe to a Neuroprobe Amplifier (A-M Systems, Inc., Model 1600). Amplifier output was routed to: (1) a digital oscilloscope (Tektronix, TDS 2014) that was used to measure electrode resistance, DC potential, AC potential, and waveform characteristics during the experiment and (2) a digital data acquisition unit (Axon Instruments, Digidata 1322A). AxoScope ver. 9.2 software was used to record both AC neural activity and auditory stimulus characteristics simultaneously and store output for future analysis $(20 \mathrm{kHz}$ sampling rate). A laser based microelectrode puller (Sutter, p2000) was used to create recording electrodes (Sutter, QF 100-50-7.5) which were filled with $2 \mathrm{M}$ potassium acetate $(\mathrm{KAc})$.

A manual micromanipulator was used to position the electrode over the pterothoracic ganglia at the point of entry of the IIIN1 nerve branch. The electrode was then slowly advanced toward the ganglion until it struck and penetrated the ganglionic sheath. Upon penetration of the sheath (through a combination of manually tapping the micromanipulator and mechanically "buzzing" the electrode using the amplifier function) a drop in potential was observed $(15-80 \mathrm{mV})$. Only those recordings showing electrode resistances over $25 \mathrm{M} \Omega$ post penetration of the sheath were used (electrode resistance ranged between $20 \mathrm{M} \Omega$ and $100 \mathrm{M} \Omega$ for most recordings). 
Intracellular staining

Upon completion of a physiological recording constant hyperpolarizing current (1-5nA) was injected for $10-15 \mathrm{~min}$ resulting in a preloaded intracellular dye (Alexa Fluor 488, A10436 or Alexa Fluor 568, A10437) being pushed into the cell. The whole ganglia was then dissected, fixed for about 30 minutes in $4 \%$ paraformaldehyde in phosphate buffer (Appendix 1), dehydrated, and cleared in methyl salicylate. Ganglia were then visualized using a florescence microscope (Carl Zeiss, Axioplain 2ie MOT) and z-stacked photographs were taken (Axiovision 4.6) to show neural architecture.

\section{Statistical Analysis}

All instantaneous spike rates were calculated using Spike 2 software analysis package. Regression analysis was used to predict linear trends while basic correlation analysis was used to predict any relationships between pre and post stimulus presentation values. Possible B-cell tests for significant differences were preformed using a standard 2-tailed t-test. 
Results

Two neurons were successfully recorded from using intracellular recording techniques.

\section{Cell 1: Possible B-Cell}

Intracellular staining with Alexa fluor 488 revealed a cell that projects both anteriorally and posteriorly (Fig. 14). Posterior projections terminate in the metathoracic portion of the pterothoracic ganglion while anterior projections can be seen in the prothoracic-mesothoracic connective suggesting that the neuron branches at least as far anteriorally as the prothoracic ganglion. It is difficult to tell from the fluorescent images obtained where the neuron enters the CNS, and, as simultaneous extracellular recordings were not obtained, spike delay times between the two recording electrodes cannot be compared to conclusively confirm that this cell is a primary afferent. On close inspection of the cells shown in Fig. 14 what appears to be fluorescent branching into the auditory nerve branch IIIN1 can be seen, although, they are not bright enough to confirm with absolute confidence that they belong to the cell in question. All branching is confined to the side of the ganglionic midline ipsilateral to the suspected point of entry into CNS (IIIN1). 
Figure 14. Pterothorascic ganglion containing possible noctuid moth B-cell (A and C) stained by ionophoretic injection of Alexa Fluor 488 (A10436) and viewed under a fluorescent microscope. (B) shows suspected B-cell structure when stained using colbalt chloride backfill technique (Taken from Surlykke and Miller, 1982). Please note that the proposed B-cell is located on the opposite half of the ganglion as that depicted in the diagram taken from Surlykke and Miller (1982). 


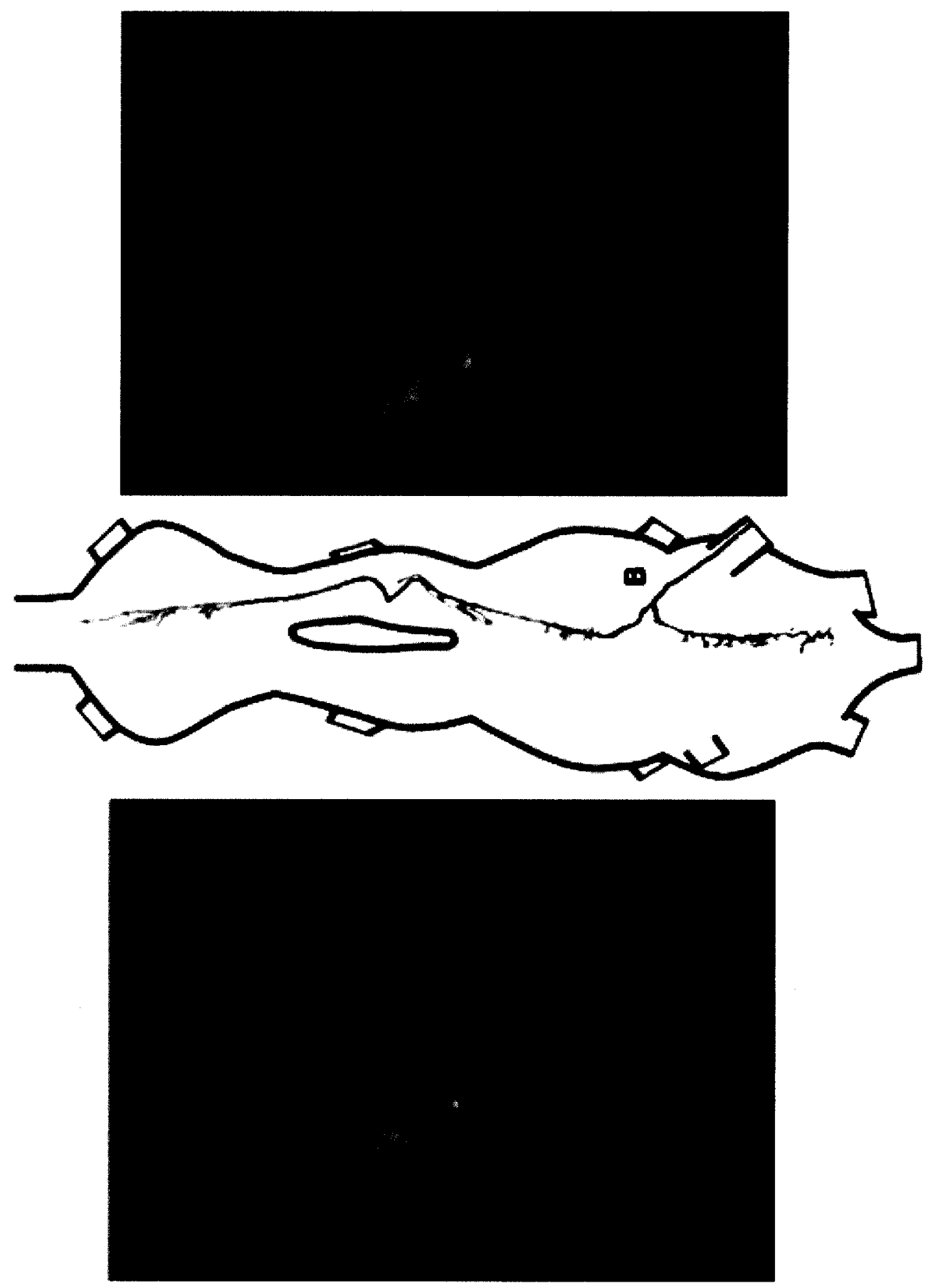


Physiologically, this cell showed consistent spiking activity with an average instantaneous spike rate of $30.78 \mathrm{~Hz}$ over 150 seconds of recording with a standard deviation of only $1.29 \mathrm{~Hz}$. Regression analysis confirmed consistent spiking activity over the duration of the recording $(\mathrm{p}=0.28)$ (Fig. 15). Figure 16 shows a section of spiking activity from the intracellular recording.

Please note that the apparently high average firing rates used for pre/post comparison are due to data export sampling frequency constraints within the data analysis software and are simply a scaled version of the true firing rate of $30.87 \mathrm{~Hz}$. When spike bursts before (average duration $=0.067 \mathrm{~s}$ ) and after (average duration $=0.082 \mathrm{~s}$ ) stimulus presentation were compared in terms of average frequency of each burst across the whole trial (both before and after stimulus statistics consisted of 328 observations) a 2 tailed ttest assuming equal variances showed statistical significance $\left(p=1.6 \times 10^{-7}\right)$ in that the average prestimulus spike frequency was lower $(\operatorname{avg}=44.75 \mathrm{~Hz}$, stdev $=4.72)$ than the average post stimulus frequency $($ avg $=46.69 \mathrm{~Hz}$, stdev $=4.76 \mathrm{~Hz})$. 
Figure 15. Intracellular instantaneous firing rate $(\mathrm{Hz})$ for a possible noctuid moth B-Cell. Grey dots indicate firing rate values while the black line is a polynomial line of best fit. 


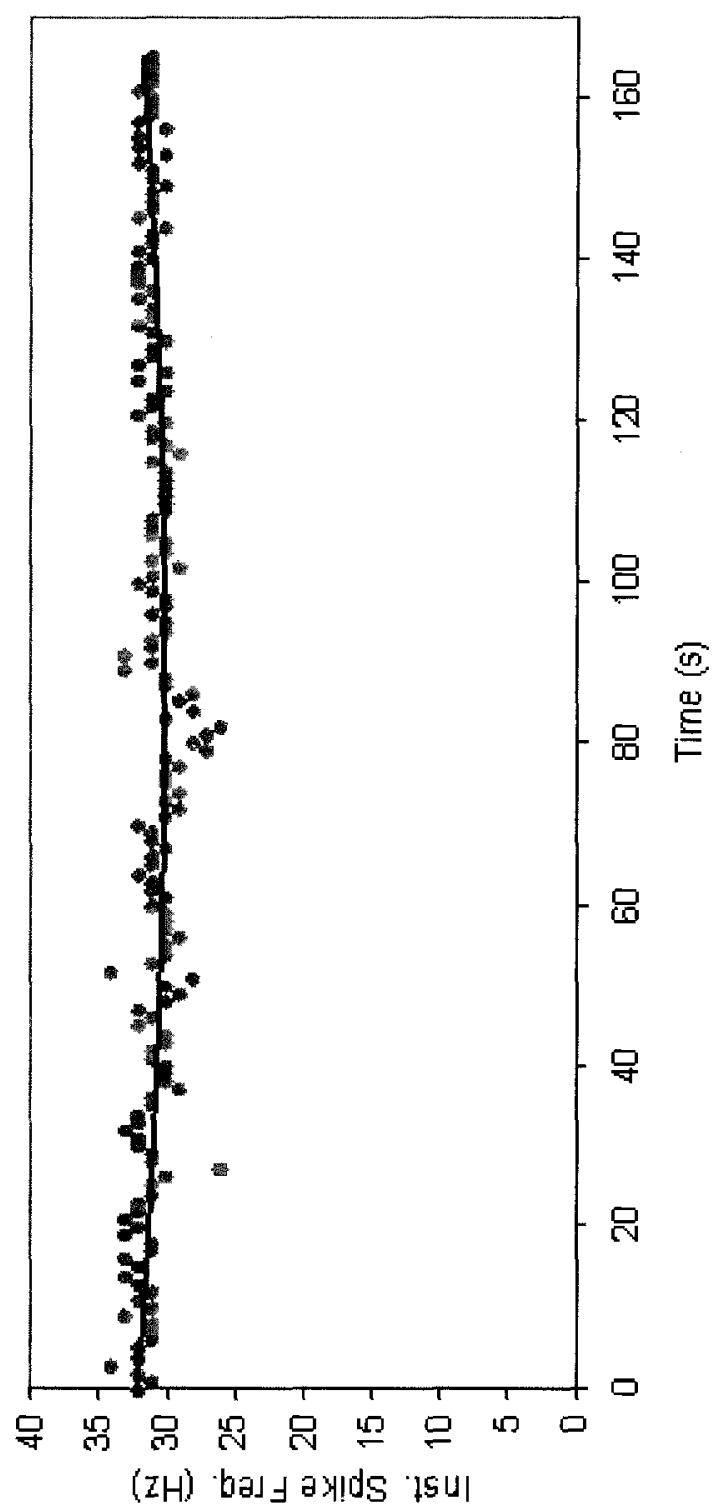


Figure 16. Intracellular trace of possible noctuid moth B-cell. (A) shows extended timescale while $(B)$ is the highlighted portion of $(A)$ magnified. 
A

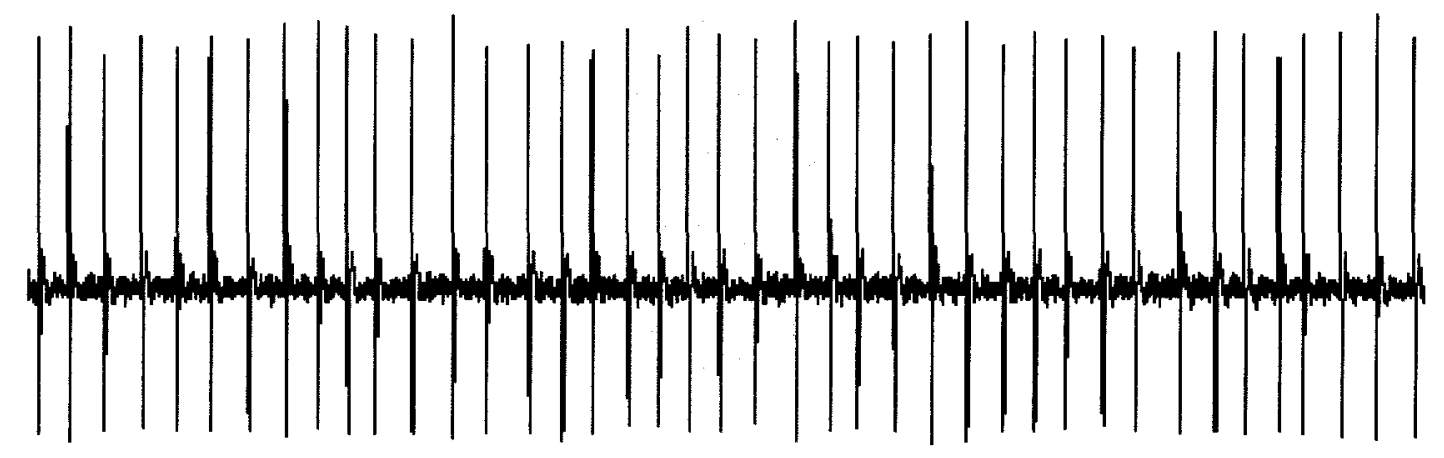

$0.2 \mathrm{~s}$

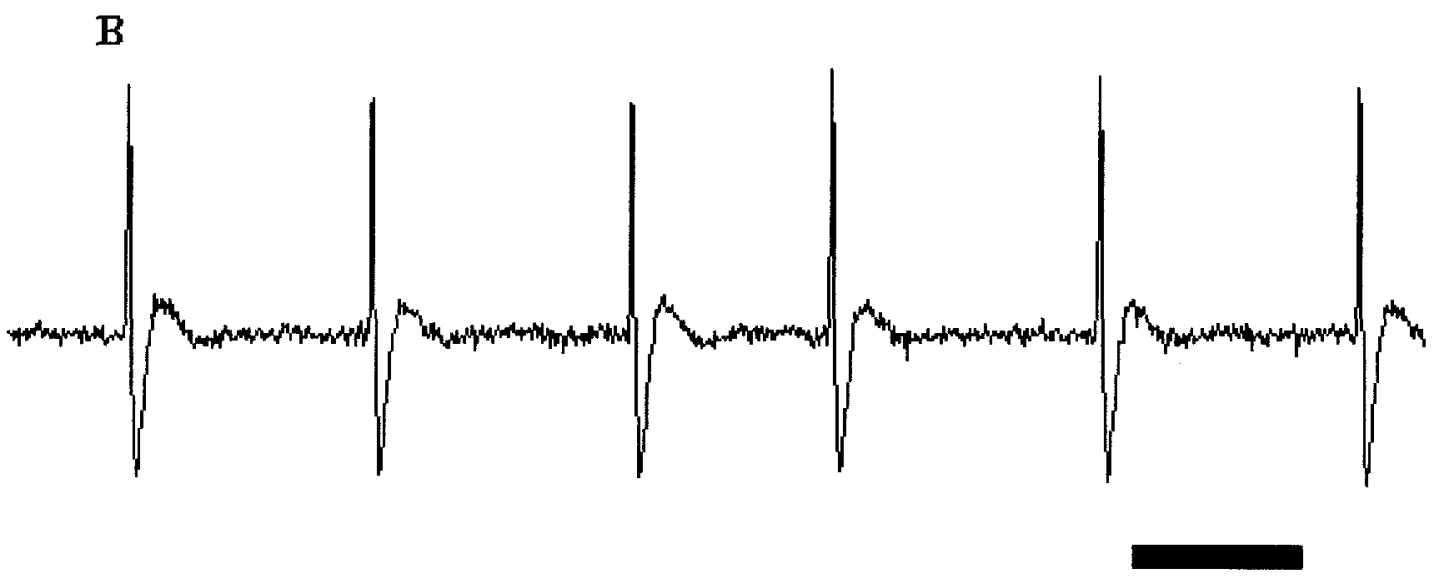

$0.02 \mathrm{~s}$ 
Cel1 2: Possible motor neuron showing auditory influence

Intracellular confirmation of neural morphology was not completed for this cell.

Figure 17 shows example auditory responses from the intracellular recording.

Physiologically this cell exhibited constant spiking at a rate of $46.75 \mathrm{~Hz}$ (standard

deviation $4.91 \mathrm{~Hz}$ ). Upon presentation of a standard auditory stimulus spiking rate would increase to $94.72 \mathrm{~Hz}$ (standard deviation $15.56 \mathrm{~Hz}$ ) over a preset stimulus burst time of 0.03 seconds post stimulus onset (Fig. 18). Pre and post stimulus spiking frequency was significantly different $(\mathrm{p}<0.0001)$ while there was not a significant correlation between slight deviations seen in pre stimulus spike rate and post stimulus spike rate $(p=0.14)$. The average latency to burst onset was 0.0117 seconds (stdev $=0.0063 \mathrm{sec}$ ) suggesting that this neuron is either a $3^{\text {rd }}$ or $4^{\text {th }}$ order (assuming a synaptic delay of $2-3 \mathrm{~ms}$ ) in terms of neural layers of separation from the primary auditory afferent. Latency values ranged between $0.00025-0.023 \mathrm{sec}$ (Fig. 19). 
Figure 17. Intracellular recording from possible noctuid moth motorneuron showing auditory influence. (A) shows intracellular trace (top) and auditory stimulus (bottom). (B) is a magnified version of the highlighted portion in (A). 
A

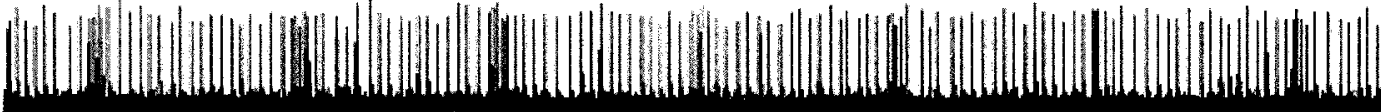

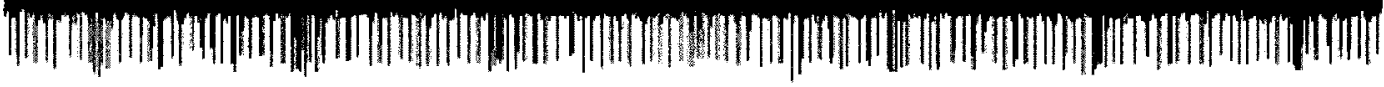

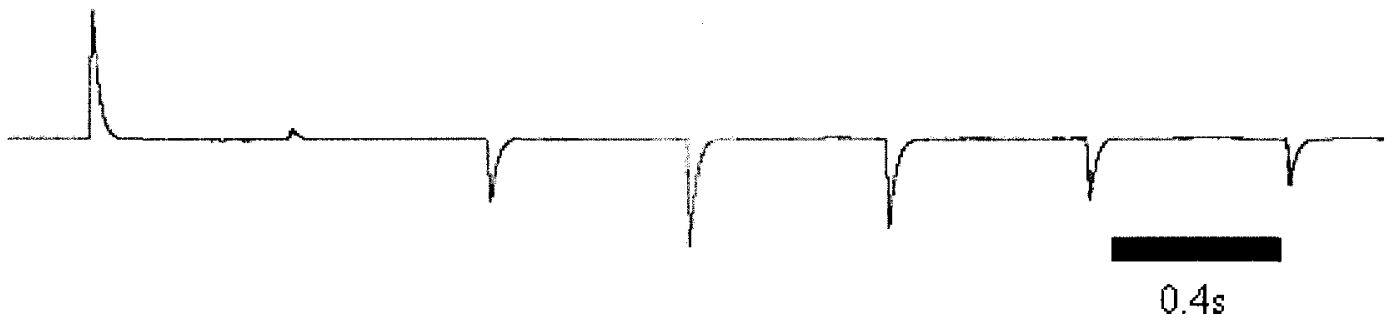

B

$\left|\int\right| \ln \mid$

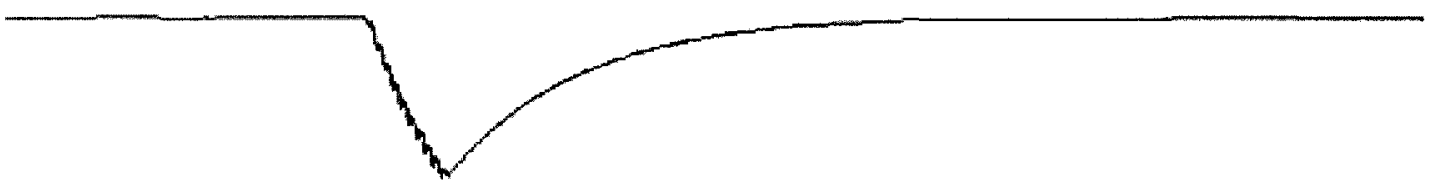

$$
0.02 \mathrm{~s}
$$


Figure 18. Intracellular instantaneous firing rate for a possible noctuid moth motor neuron showing auditory influence. Black squares refer to firing rate $(\mathrm{Hz})$ in response to auditory stimulation while grey diamonds refer to firing rate $(\mathrm{Hz})$ immediately before stimulus presentation. Error bars indicating standard deviation over the 80 second trial are given for both pre and post stimulus data points. 


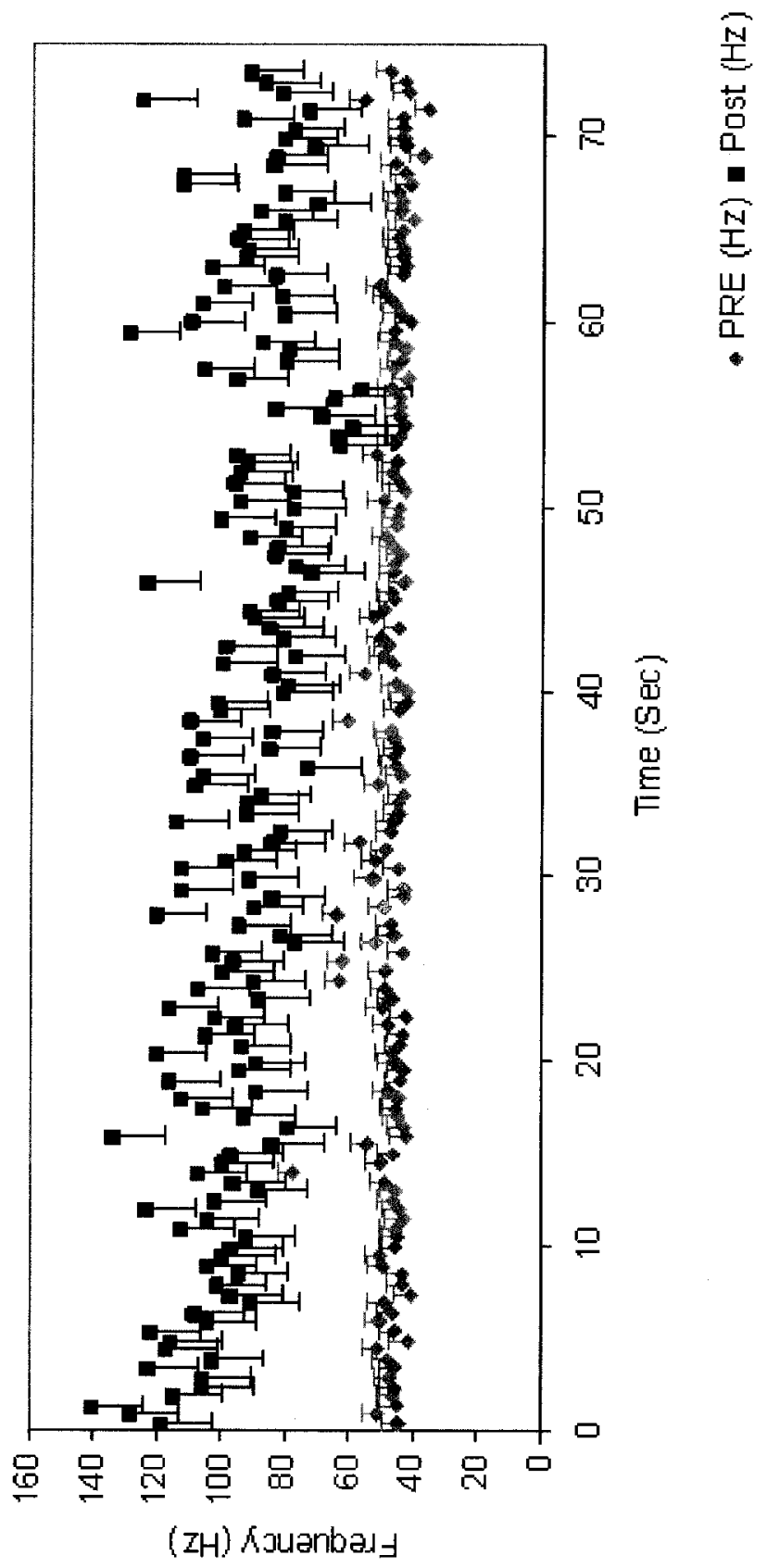


Figure 19. Intracellular latency (s) values for a possible noctuid moth motor neuron showing auditory influence over an 80 second recording. Black line represents line of best fit for the data in question. 


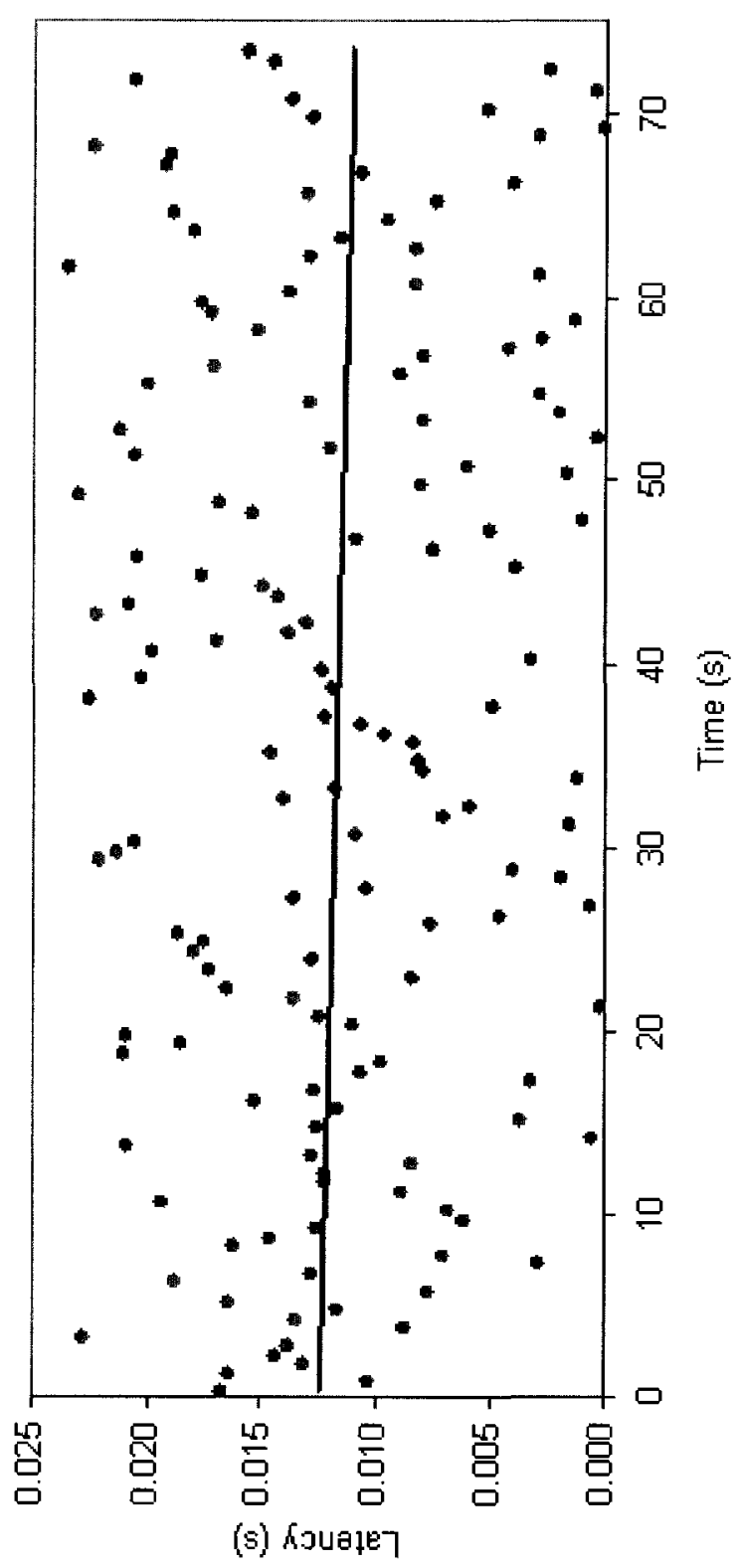


Discussion

Neuron 1: Possible B-Cell

Neural architecture was very similar to that described in Surlykke and Miller (1982) with branching being confined to the side of the pterothoracic ganglia ipsilateral to the proposed point of entry into the ganglion, nerve IIIN1, and not crossing the ganglionic midline. Posterior projections ceased before entering abdominal connectives while anterior projections continued to at least the prothoracic ganglia. The cell exhibited consistent spiking activity at about $30 \mathrm{~Hz}$ over a 150 second recording period with a standard deviation of about $1.3 \mathrm{~Hz}$. Lichtenberg (1971) reported a range of $10-30 \mathrm{~Hz}$ for a general sample of noctuid moth B-cell firing rates while the moth is at rest (this rate would decrease in active insects), while Fullard et al. (2003) reported firing rates of up to 12Hz. In either case the cell in question is firing in the high range of reported B-cell spike rate values. These can also be compared to results presented in Chapter 2 of this thesis where instantaneous B-cell spike rates averaged within species did not exceed 16 spikes per second. Only one specific moth in chapter two of this study, X. dolosa (July 5), exceed instantaneous firing rates of $16 \mathrm{~Hz}$ with an average instantaneous firing rate of 23.26Hz. B-cell firing may have been affected by the dissection or the restraint system used in this experiment as cuticular deformation is known to affect firing rates.

Although results did show a statistical difference between mean firing rate values before and after auditory stimulation across 328 stimulus presentations one must still question whether or not a mean difference of just $2 \mathrm{kHz}$ (pre $=44.76$, post $=46.69)$ is biologically significant or simply an artifact of statistical analysis. 


\section{Neuron 2: Possible motor neuron showing auditory influence}

Although no morphological characteristics were extracted from this cell it is possible to draw strong inferences about its function within the moth CNS. Upon initial observation it is quite apparent that this cell is influenced by the auditory system of the moth (Fig. 17). The most obvious characteristic of this neuron is that it is regularly spiking in the absence of auditory stimulation. Across 147 observations this cell fired at an average frequency of $46.75 \mathrm{~Hz}$ with a standard deviation of $4.91 \mathrm{~Hz}$. Of the previously identified auditory interneurons none have shown such firing characteristics (Boyan and Fullard, 1986; Boyan and Fullard 1988; Boyan et al. 1990; Boyan and Miller, 1991). In terms of unidentified auditory neurons Roeder (1975) has described two general classes; repeater and pulse-marker neurons. Repeater neurons follow the sound stimulus in a more or less 1:1 ratio while pulse-markers fire a single spike per stimulus pulse. The neuron under investigation fits neither of the previous descriptions as auditory stimuli simply alter the frequency of an ongoing rhythmic process. In investigating repeated presentations of auditory stimuli this cell yields a distinct firing pattern that consists of two characteristics: (1) the ongoing neural pattern is altered by the introduction of auditory stimulation and (2) upon removal of the auditory stimulus the system resumes its original pattern of activity. These observations are characteristic of the activity of central pattern generators (Marder and Calabrese, 1996).

Comparing this cell to identified motor neurons in Madsen and Miller (1987) gives strong clues to its physiological identity. In their study 5 out of 28 cells showed similar rhythmic activity during intracellular physiological recordings. Specifically their 
cells gave consistent firing frequencies of 14 to $19 \mathrm{~Hz}$, values that are similar to the wing beat frequency of the moths they tested. When presented with an auditory stimulus they found that cells either responded with an increased spike rate or a cessation of spiking and that both responses seemed to be randomly elicited within a single cell. In addition, they found that auditory stimulation could initiate rhythmic flight activity in a non responding cell and that response latencies were quite variable ranging from 10 to 100 milliseconds.

While the cells described in Madsen and Miller (1987) responded with a single spike per wing beat cycle this cell responds at approximately double that rate. Given auditory stimulation Madsen and Miller's (1987) cells responded by firing 2 spikes per wingbeat cycle, in effect doubling the frequency, while in this cell's case an average spike rate of $94.72 \mathrm{~Hz}$ was observed, also approximately double the initial firing rate. Latencies for this cell ranged between $0.25 \mathrm{~ms}$ and $23 \mathrm{~ms}$ with the average latency being about $11 \mathrm{~ms}$. The difficulty in isolating the first spike in a stimulus response for a rhythmically active cell is a challenge in that the experimenter must use their own judgment to reliably differentiate between the first spike and a stimulus response and a spike that is simply part of the cells ongoing rhythmic activity, thus probably resulting in minimum response latency estimates being slightly low. Nevertheless, this cell does show an average latency of $11.7 \mathrm{~ms}(\mathrm{stdev}=6.3 \mathrm{~ms})$; quite a short period of time in terms of neural layers (this value corresponds to about $3-4$ layers) that an auditory signal must travel through to affect ongoing motor patterns. 
In Locusts, precise motor patterning of flight information and selective gating of sensory information pertinent to successful flight is dependent on the central flight oscillator (Reichert et al., 1985; Reichert and Rowell, 1985; 1986). While motor neuron responses can be activated in the absence of the central flight oscillator, those that are intended to affect flight rhythms in a reliable and adaptive way must be selectively gated by the oscillator and presented to specific motor neurons during the appropriate phase of the wing beat cycle. Two important differences between auditory input to motorneurons in moths and locusts include: (1) maximum latencies for locust motor neuron activation is about 30ms (Boyan, 1985), about three times longer than those observed in moths, and (2) auditory input to Locust flight motor neurons routinely produces predictable changes to body kinematics and wing beat patterns (Robert and Rowell, 1992; 1992a).

The combination of a wide range of unpredictable and short response latencies suggest that this cell is a flight motorneuron receiving direct input from both the moth's central flight oscillator and the auditory system. While prestimulus firing frequency shows a consistent firing rate of $46.75 \mathrm{~Hz}(\mathrm{stdev}=5 \mathrm{~Hz}$ ) poststimulus firing frequency is quite variable ranging between 60 and $140 \mathrm{~Hz}$ with an average of $94.72 \mathrm{~Hz}$ (stdev $=$ $15.56 \mathrm{~Hz})$. This could account for the apparent randomness of looping and diving maneuvers seen in the moths rapid escape response (Roeder, 1975). In addition, it would be advantageous for the moth to skip the central flight oscillator in triggering a rapid escape response as this would give the moth the best chance of evading the bat, which, at the time of detection by the moth's auditory system, is already an immediate threat. The fewer layers of neural circuitry an auditory signal has to pass through the faster a 
response can be produced and the more random a response the more difficult it is to predict an outcome; both major advantages for a moth in eluding its foremost predator, the bat. 


\section{Literature Cited}

Boyan, G.S. (1985). Auditory input to the flight system of the locust. J. Comp. Physiol. A. 156: $79-91$.

Boyan, G.S. and Fullard, J.H. (1986). Interneurons responding to sound in the tobacco budworm moth Helios virescens (noctuidae): morphological and physiological characteristics. J. Comp. Physiol. A. 190: $581-600$.

Boyan, G.S. and Fullard, J.H. (1988). Information processing at a central synapse suggests a noise filter in the auditory pathway of the noctuid moth. J. Comp. Physiol. A. 164: $251-258$.

Boyan, G.S., Miller, L.A. (1991). Parallel processing of afferent input by identified interneurones in the auditory pathway of the noctuid moth Noctua pronuba (L.). J. Comp. Physiol. A. 168:727-738.

Boyan, G.S., Williams, L. and Fullard, J.H. (1990). Organization of the auditory pathway in the thoracic ganglia of noctuid moths. J. Comp. Neurol. 295: 248 - 267.

Bush, S.L. and Schul, J. (2006). Pulase rate recognition in an insect: evidence of a role for oscillatory neurons. J. Comp. Physiol. A. 192: $113-121$.

Comer, C.M. and Robertson, M.R. (2001). Identified nerve cells and insect behavior. Prog. Neurobiol. 63: $409-439$.

Coro, F. and Perez, M. (1993). Threshold and suprathreshold responses of the auditory receptors in an arctiid moth. Experientia. 49: 285 - 290 .

Faulkes, Z. and Pollack, G.S. (2000). Effects of inhibitory timing on contrast enhancement in audtory circuits of crickets. J. Neurophysiol. 84:1247 - 1255. 
Fielden, A. (1960). Transmission through the last abdominal ganglion of the dragonfly nymph, Anax imperator. J. Exp. Biol. 37: 832 - 844.

Fullard, J.H. (1998). Sensory coevolution of moths and bats. In Comparative Hearing: Insects. (ed. Hoy, R.R., Popper, A.N. and Fay, R.R. eds). 279-326. Springer Handbook of Auditory Research Springer-Verlag, New York.

Fullard, J.H. and Dawson, J.W. (1999). Why do diurnal moths have ears?. Naturwissenschaften. 86: $276-279$.

Fullard, J.H., Dawson, J.W. and Jacobs, D.S. (2003). Auditory encoding during the last moment of a moths life. J. Exp. Biol. 206: 281-294.

Gerhardt, H.C. and Huber, F. (2002). Acoustic communication in insects and anurans: common problems and diverse solutions. Chicago: The University of Chicago Press.

Hennig, R.M., Franz, A. and Stumpner, A. (2004). Processing of auditory information in insects. Microsc. Res. Tech. 63: $351-374$.

Hutcheon, B. and Yarom, Y. (2000). Resonance, oscillation and the intrinsic frequency preferences of neurons. Trends Neurosci. 23: 216-222.

Lechtenberg, R. (1971). Acoustic response of the B cell in noctuid moths. J. Insect Physiol. 17: 2395-2408.

Madsen, B.M. and Miller, L.A. (1987). Auditory input to motor neurons of the dorsal longitudinal flight muscles in a noctuid moth (Barathra bassicae L.). J. Comp. Physiol. A. 160: $23-31$. 
Marder, E., Calabrese, R.L. (1996). Principles of rhythmic motor pattern production.

Physiol. Rev. 76: 687-717.

Mason, A.C. and Faure, P.A. (2004). The physiology of insect auditory afferents.

Microsc. Res. Tech. 63: $338-350$.

Paul, D.H. (1973). Centeral projections of the tympanic nerve fibres in noctuid moths. $J$. Insect Physiol. 19: $1785-1792$.

Perez, M. and Coro, F. (1984). Physiological characteristics of the tympanic organ in noctuoid moths. I. Responses to brief acoustic pulses. J. Comp. Physiol. A. 154: $441-447$

Reichert, H. and Rowell, C.H.F. (1985). Integration of nonphaselocked exteroreceptive information in the control of rhythmic flight in the locust. J. Neurophysiol. 53: $1201-1218$.

Reichert, H. and Rowell, C.H.F. (1986). Neuronal circuits controlling flight in the locust: how sensory information is processes for motor control. Trends Neurosci. 9: 281 $-283$.

Reichert, H., Rowell, C.H.F., Griss, C. (1985). Course correction circuitry translates feature detection into behavioural action in locusts. Nature. 315: $142-144$.

Reiss, R. F. (1964). A theory of resonance. In: Reiss RF (ed) Neural theory and modeling. Stanford UP, Stanford, pp 105-137

Rind, F.C. (1983). The organization of flight motorneurons in the moth, Manduca sexta. J. Exp. Biol. 102: $239-251$. 
Robert, D. and Rowell, C.H.F. (1992). Locust flight steering. I. Head movements and the organization of correctional manoeuvres. J Comp. Physiol. A. 171: 41 - 51.

Robert, D. and Rowell, C.H.F. (1992a). Locust flight steering. II. Acoustic avoidance manoeuvres and associated head movements, compared with correctional steering. J Comp. Physiol. A. 171: 53-62.

Roeder, K.D. (1963). Nerve cells and insect behaviour. Harvard University Press. Cambridge, Mass.

Roeder, K.D. (1964). Aspects of the noctuid tympanic nerve response having significance in the avoidance of bats. J. Insect Physiol. 10: $529-546$.

Roeder, K.D. (1966). Auditory system of noctuid moths. Science. 154: 1515 - 21

Roeder, K.D. (1966a). Interneurons of the thoracic nerve cord activated by tympanic nerve fibres in noctuid moths. J. Insect Physiol. 12: 1227 - 1234

Roeder, K.D. (1969). Nerve Cells and Insect Behaviour. Harvard University Press, Cambridge.

Roeder, K.D. (1975). Neural factors and evitability in insect behavior. J. Exp. Zool. 194: $75-88$.

Roeder, K.D. and Payne, R.S. (1966). Acoustic orientation of a moth in flight by means of two sense cells. Symp. Soc. Exp. Biol. 20: $251-272$.

Roeder, KD. and Treat, AE. (1957). Ultrasonic reception by the tympanic organ of noctuid moths. J. Exp. Zool. 134: 127-157. 
Ronacher, B., Wolf, H. and Reichert. (1988). Locust flight behavior after hemisection of individual thoracic ganglia: evidence for hemiganglionic pre-motor centers. $J$ Comp. Physiol. A. 163: 749 - 759.

Schildberger, K. (1988). Behavioral and neuronal mechanisms of cricket phonotaxis. Experientia. 44: 408-414.

Surlykke, A. and Miller, L. A. (1982). Centeral projections of three sensory axons from a moth ear (Agrotis segetum, noctuidae). J. Insect Physiol. 28: 357 - 364.

Surlykke, A., and Moss, C. F. (2000). Echolocation behaviour of big brown bats, Eptesicus fuscus, in the field and laboratory. J. Acoust. Soc. Am. 108: $2419-$ 2429.

Waters. D.A. (2003). Bats and moths: what is there left to learn?. Physiol. Entomol. 28: $237-250$

Yack, J.E. (2004). The structure and function of auditory chordotonal organs in insects. Microsc. Res. Tech. 63: $315-337$.

Yager, D.D. (1999). Structure, development, and evolution of insect auditory systems. Microsc. Res. Tech. 47: $380-400$. 


\section{GENERAL DISCUSSION}

As technology advances researchers gain the means to more precisely identify and characterize subtle nuances in the behavior, physiology, mechanical activity and hence the processing abilities, of their particular research subjects. As exciting and innovative as these findings may be one must be extremely careful in assigning a biological basis to them. This is apparent in Windmill et al. (2006) who suggest that, through evolution, the noctuid moth $N$. pronuba has adapted to predation by bats by being able to increase its sensitivity to their calls once it has been exposed to intense auditory stimulation. While this thesis does not refute that there may be something occurring at the auditory periphery that is altering the mechanical characteristics of the tympanal membrane it does refute the proposed biological basis of these findings. As previously stated, for an organism to devote some amount of energy to a physiological process there must be a corresponding biological need that deems it necessary. The proposed biological significance of $N$. pronuba's seemingly self imposed increase in tympanal sensitivity is that, should it be lucky enough to evade a bat on its first approach, it will be left more sensitive (for an average of 7.5 minutes) and therefore more capable of detecting the bat at greater distances, upon its possible return. At first glance this seems entirely feasible and even quite innovative in an evolutionary sense.

This study finds no significant changes in afferent activity in response to intense stimulation as a function of time. Upon close inspection of Fig. 4 (in General Introduction) one can see a moth that is already extremely sensitive in the same range as a typical bat echolocation call, whether it be search, approach, or terminal phase. This 
begs the question: What would be the point of increasing auditory sensitivity in anticipation of a bats possible return when it is more than likely that if the bat is not detected upon its initial approach the moth will already be dead? In my opinion the moth has answered this question by being sufficiently sensitive to bat echolocation calls in the absence of an active tympanal membrane. Compared to most noctuid moths $N$. pronuba is extremely sensitive in terms of auditory threshold (Fullard, personal communication).

Taking into account that there is no biological need for $N$. pronuba to actively increase the sensitivity of an already more than sufficient system we tested other less sensitive moths. No statistical differences with time were found in $X$. dolosa, $A$. Americana, or C. ultronia either. It should be noted that while sample sizes were small for these species one would expect that afferent response to an approximately $10,000 \%$ increase in receptor velocity (Fig. 3: in General Introduction, Windmill et al. 2006) would be readily detectable should it be affecting afferent activity. Considering the lack of physiological evidence for the effect of active tuning I suggest that changes in the mechanical nature of the tympanal response are most likely due to a conformational change (tensioning) of the exoskeleton surrounding the area of the tympanum as a result of high amplitude stimuli startling the moth.

Chapter 3 describes the spiking activity of a possible motorneuron and the corresponding response to auditory stimulation. This motorneuron is firing at a rate of about 2 spikes per wing beat cycle under normal conditions with a fairly variable increase in firing rate as a response to auditory stimulation. Presumably, the change in activity to intense auditory stimulation alters the moth's natural flight rhythm. Such a marked 
increase in flight rhythm in combination with short latencies in response to stimulation would result in a significant change in the physiology of a number other neurons/muscles involved in the behavior; which in this case is flight. This would result in increased stress on the body wall surrounding the area. Coincidentally, the section of the thorax containing the flight musculature also contains the auditory structures. This implies that a conformational change in the physical characteristics of the exoskeleton as a result of an increase in flight vigor could be affecting the mechanical characteristics of structures in the immediate vicinity; in this case the mechanical characteristics of the tympanic membrane.

For a basic membrane, such as that of a drum, as tension on the membrane is increased the frequency of vibration increases and the amplitude of vibration decreases. This is exactly what is seen in Windmill et al. (2006) in that the membrane's resonant or natural frequency (ie. where the membrane is in phase with incoming sound) is shifted up. Previous studies have shown that moths discriminate sounds based on amplitude alone (see Chapter 2: Introduction) and are therefore considered tone-deaf. I propose that while there is an increase in resonant frequency of the membrane possibly as a result of increased tension in the exoskeleton that surrounds it, the corresponding change in the magnitude at which the membrane vibrates is not great enough to produce a physiological effect at the afferent level and is therefore epiphenomenal.

I suggest that the increase in sensitivity proposed in Windmill et al. (2006) is a misinterpretation of the biological processes that would underlie such an effect. As previously mentioned when a membrane is stretched resonant frequency is increased and 
amplitude is decreased. In Windmill et al. (2006) an increase in resonant frequency of the membrane was interpreted as an increase in sensitivity whereas it should have been interpreted as a decrease. Tympanal receptor neurons work under the principle of motion: the greater the range of motion the receptor neuron receives the more vigorously it will fire. When Windmill et al. (2006) observed an upward shift in resonant frequency of the membrane they should have recognized that this would correlate to a decreased range/amplitude of motion for the tympanal membrane. This equates to a decrease in amount of stimulation that the auditory receptor cells receive. Thus we should see decreased afferent response in response to a tune up shift. While the change in amplitude is not significant enough to affect afferent response in $N$. pronuba we do see this effect in A. pyramidoides as an overall decrease in response intensity for a period of time following high amplitude stimulation. Therefore, I suggest that instead of increasing its sensitivity in response to high amplitude bat calls the moth is actually, at least in the case of $A$. pyramidoides, decreasing its auditory responsiveness, possibly in favor of devoting CNS processes to the production of a last ditch escape maneuver. 
APPENDIX 1 
4\% paraformaldehyde in phosphate buffer

Preparation:

(1) Prepare 4 volumes of $0.1 \mathrm{M}$ sodium phosphate dibasic $\left(\mathrm{Na}_{2} \mathrm{HPO}_{4}\right)$. $(80 \mathrm{ml}$ for $100 \mathrm{ml}$ solution)

(2) Prepare 1 volume of $0.1 \mathrm{M}$ sodium phosphate monobasic $\left(\mathrm{NaH}_{2} \mathrm{PO}_{4}\right)$. $(20 \mathrm{ml}$ for $100 \mathrm{ml}$ solution)

(3) Warm the dibasic phosphate solution to $60^{\circ} \mathrm{C}$

(4) Weigh paraformaldehide ( $4 \mathrm{~g}$ for a $100 \mathrm{~mL}$ solution)

(5) Add paraformaldehyde to the warm dibasic phosphate stirring constantly (do NOT exceed $70^{\circ} \mathrm{C}$ )

(6) When paraformaldehide has dissolved ( $\sim 5 \mathrm{~min})$ add the monobasic phosphate to the solution

(7) $\mathrm{Check} \mathrm{pH}$, if not correct then add $\mathrm{NaOH}$ or $\mathrm{HCl}$ to $\mathrm{pH} 7.4$

(8) If the solution has been heated for too long white flakes may appear. If there are too many, start again. If there are only a few, filter the solution.

(9) (OPTIONAL) Add $400 \mathrm{mM}$ sucrose (this is to adjust the osmolarity of the solution to something close to the saline's) 
APPENDIX 2 - Tables 
Table 5. Regression statistics for A. americana, $X$. dolosa, and $C$. ultronia indicating both the F-statistic and $p$ values. Yellow boxes indicate statistical significance and the Binom column gives Binomial test statistic as the likelihood of achieving $\mathrm{X}$-number of significant values across the total sample size. 
A americana \# Sig Total binom $X$ dolosa

\# Sig Total binom c ultronia \# Sig Total binom

\begin{tabular}{|c|c|c|c|c|c|c|c|c|c|c|c|c|c|c|c|c|c|c|c|}
\hline \multirow[t]{4}{*}{ Spike \# } & 42 & $F$ & 0.0260 & 1.3586 & & & & 0.7218 & 0.7132 & 0.4037 & 2.1631 & 1.3427 & & & & 0.0688 & & & \\
\hline & & Significance $F$ & 0.9736 & 0.2575 & 0 & 2 & 0.25 & 0.4098 & 0.4095 & 0.5305 & 0.1608 & 0.2636 & 0 & 5 & 0.0313 & 0.7957 & 0 & 1 & 0.5 \\
\hline & 74 & $F$ & 6.6240 & 0.0230 & & & & 1.3145 & 0.9254 & 2.4151 & 0.0576 & 2.6481 & & & & 6.8644 & & & \\
\hline & & Significance $F$ & 0.0191 & 0.8810 & 1 & 2 & 0.5 & 0.2708 & 0.3488 & 0.1318 & 0.8134 & 0.1232 & 0 & 5 & 0.0313 & 0.0164 & 1 & 1 & 0.5 \\
\hline \multirow[t]{4}{*}{$|\mathbf{S}|$} & 42 & $F$ & 0.2548 & 0.5629 & & & & 1.8888 & 0.5629 & 0.0144 & 0.1564 & 0.0330 & & & & 0.0459 & & & \\
\hline & & Significance $F$ & 0.6199 & 0.4618 & 0 & 2 & 0.25 & 0.1909 & 0.4628 & 0.9054 & 0.6977 & 0.8582 & 0 & 5 & 0.0313 & 0.8326 & 0 & 1 & 0.5 \\
\hline & 74 & $F$ & 2.3742 & 0.8644 & & & & 0.0295 & 1.3038 & 0.8361 & 9.7707 & 0.9256 & & & & 0.1109 & & & \\
\hline & & Significance $F$ & 0.1408 & 0.3636 & 0 & 2 & 0.25 & 0.8660 & 0.2685 & 0.3686 & 0.0065 & 0.3503 & 1 & 5 & 0.1563 & 0.7426 & 0 & 1 & 0.5 \\
\hline \multirow[t]{4}{*}{ Burs Dur } & 42 & $F$ & 0.6236 & 1.2831 & & & & 1.7456 & 0.1590 & 0.2231 & 0.1416 & 0.2497 & & & & 0.1145 & & & \\
\hline & & Significance $F$ & 0.4400 & 0.2707 & 0 & 2 & 0.25 & 0.2076 & 0.6948 & 0.6405 & 0.7117 & 0.6241 & 0 & 5 & 0.0313 & 0.7387 & 0 & 1 & 0.5 \\
\hline & 74 & $F$ & 6.2027 & 0.6705 & & & & 0.3871 & 1.4151 & 4.1061 & 3.9338 & 0.0238 & & & & 0.2628 & & & \\
\hline & & Significance $F$ & 0.0228 & 0.4225 & 1 & 2 & 0.5 & 0.5438 & 0.2497 & 0.0527 & 0.0648 & 0.8792 & 0 & 5 & 0.0313 & 0.6138 & 0 & 1 & 0.5 \\
\hline \multirow[t]{4}{*}{ Latency } & 42 & $F$ & 0.0233 & 0.0242 & & & & 0.1653 & 0.9716 & 0.0004 & 0.7279 & 0.5706 & & & & 0.3962 & & & \\
\hline & & Significance $F$ & 0.8804 & 0.8780 & 0 & 2 & 0.25 & 0.6905 & 0.3373 & 0.9837 & 0.4062 & 0.4610 & 0 & 5 & 0.0313 & 0.5362 & 0 & 1 & 0.5 \\
\hline & 74 & $F$ & 0.0512 & 0.7456 & & & & 0.2712 & 0.3315 & 0.0518 & 0.8119 & 1.0223 & & & & 7.1761 & & & \\
\hline & & Significance $F$ & 0.8236 & 0.3981 & 0 & 2 & 0.25 & 0.6107 & 0.5719 & 0.8216 & 0.3809 & 0.3270 & 0 & 5 & 0.0313 & 0.0144 & 0 & 1 & 0.5 \\
\hline
\end{tabular}


APPENDIX 3 - Figures 
Figure 20. Time series data for spike number (pg. 144) and burst duration (pg. 145) in $N$. pronuba trials. Three graphs are given: (A) scatter plot showing probe stimulus responses for all moths at $42 \mathrm{kHz}$ and (B) $74 \mathrm{kHz}$, in addition to times series data (C) placed into 60 second bins and plotted over tympanal velocity data from Windmill et al. (2006) (bars are mean ( $+/-\mathrm{SD})$ ). Data for $42 \mathrm{kHz}$ and $74 \mathrm{Khz}$ test pulses with time values greater than 1000 seconds account for the Re portion of the trial. 
Spike \#
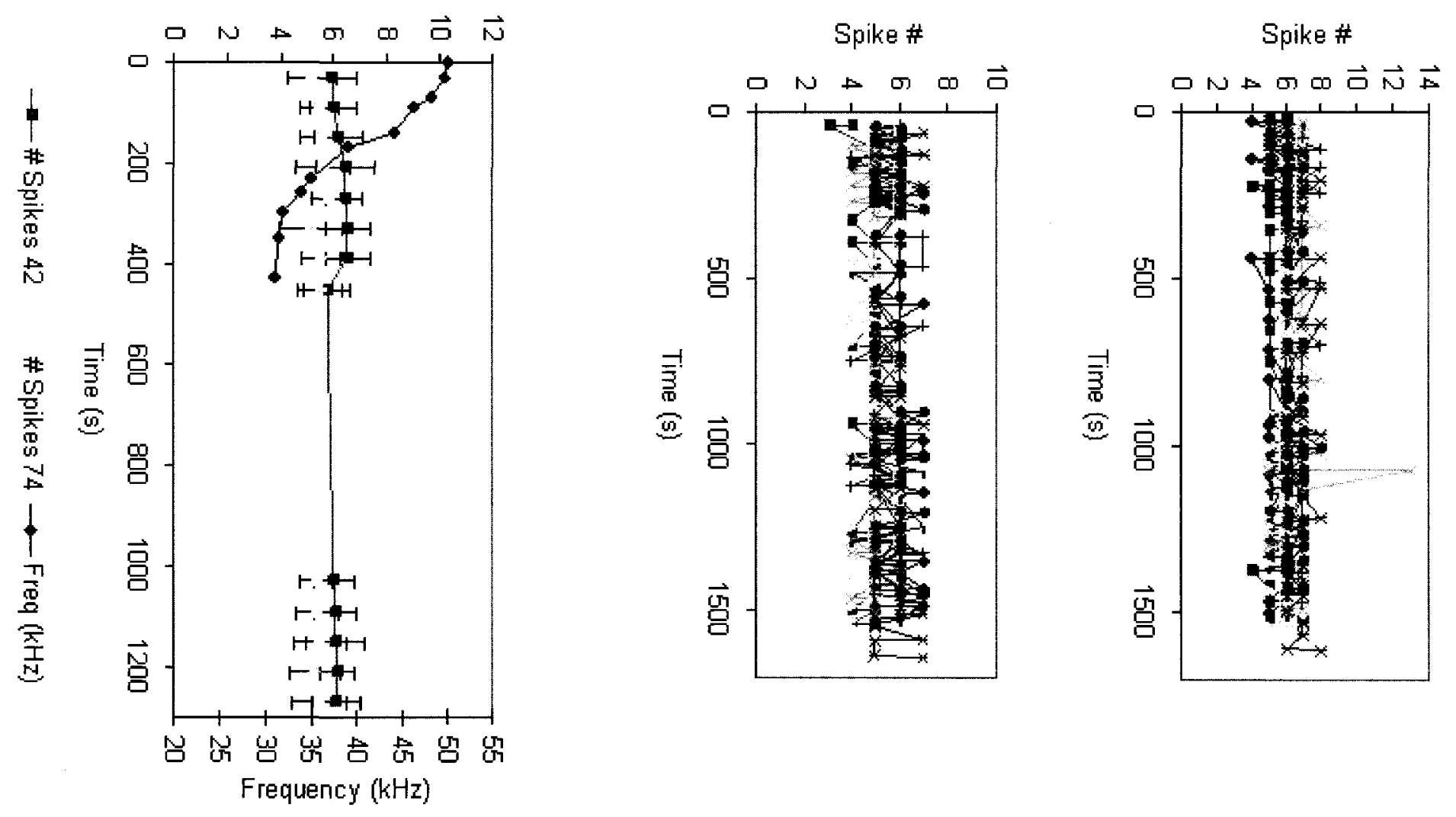

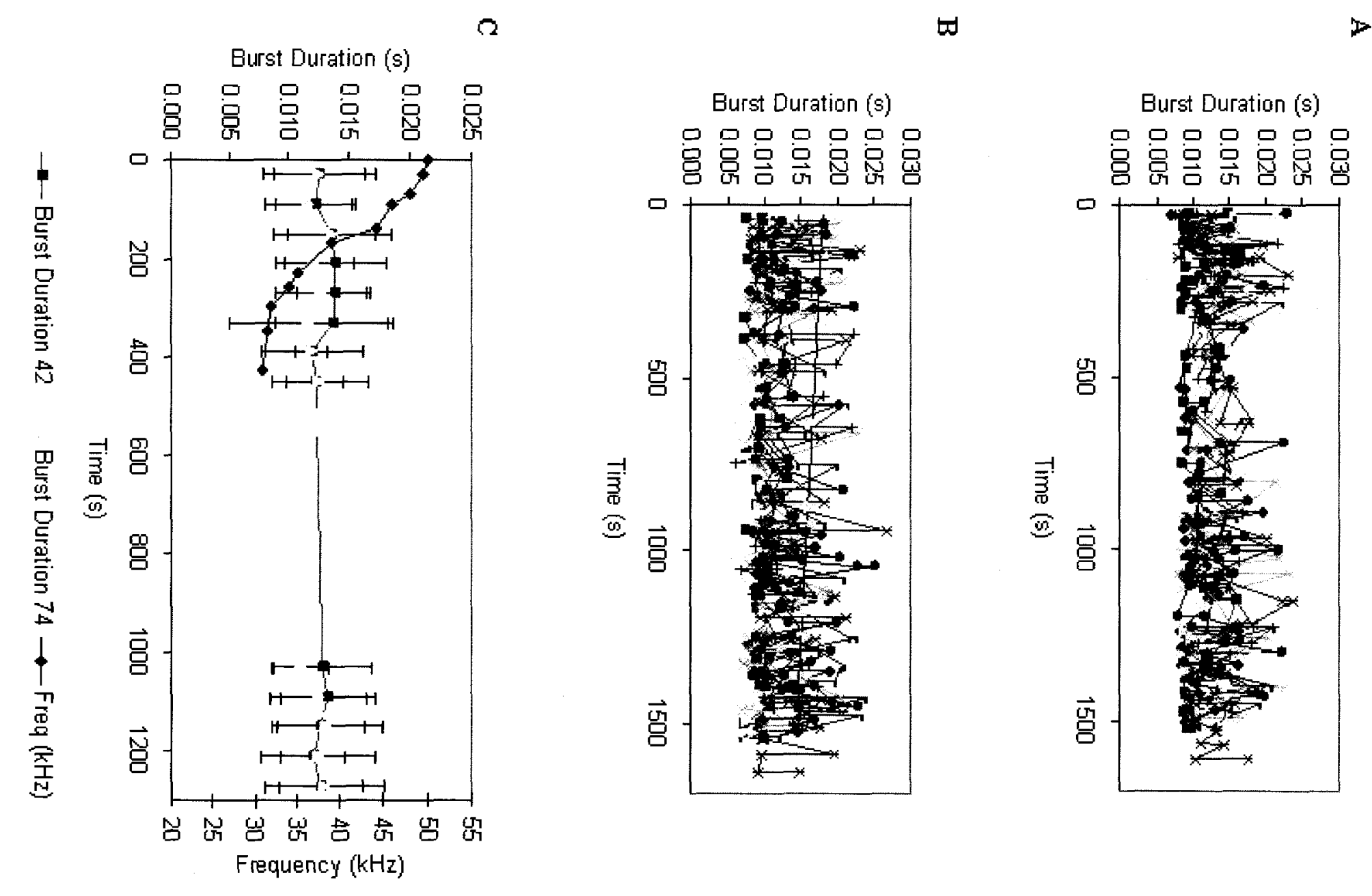
Figure 21. Time series data for interspike interval (pg. 147), burst duration (pg. 148) and latency (pg. 149) in N. pronuba CUT trials. Three graphs are given: (A) scatter plot showing probe stimulus responses for all moths at $42 \mathrm{kHz}$ and (B) $74 \mathrm{kHz}$, in addition to times series data (C) placed into 100 second bins and plotted over tympanal velocity data from Windmill et al. (2006) (bars are mean (+/- SD)). Data for $42 \mathrm{kHz}$ and $74 \mathrm{Khz}$ test pulses with time values greater than 1200 seconds account for the Re portion of the trial. 
A

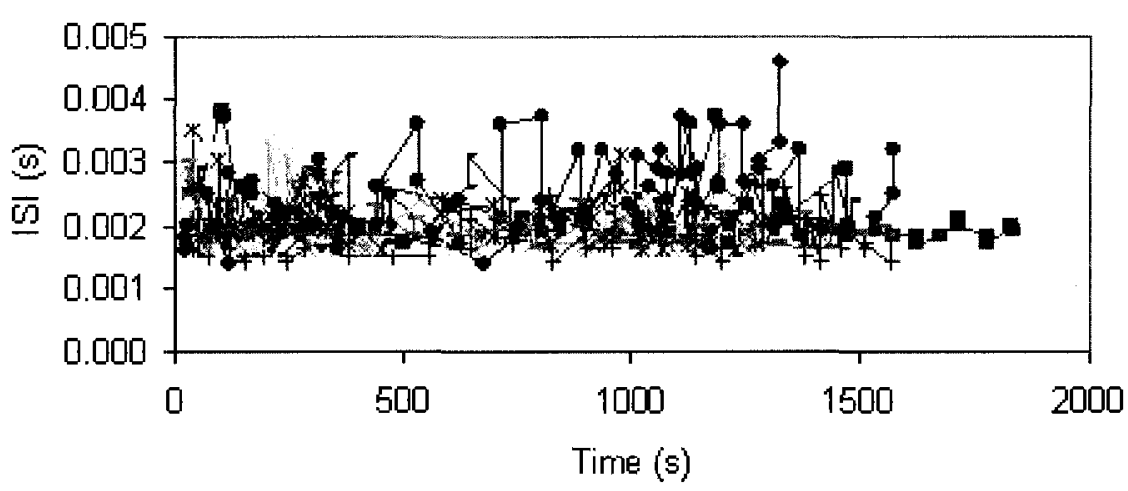

B

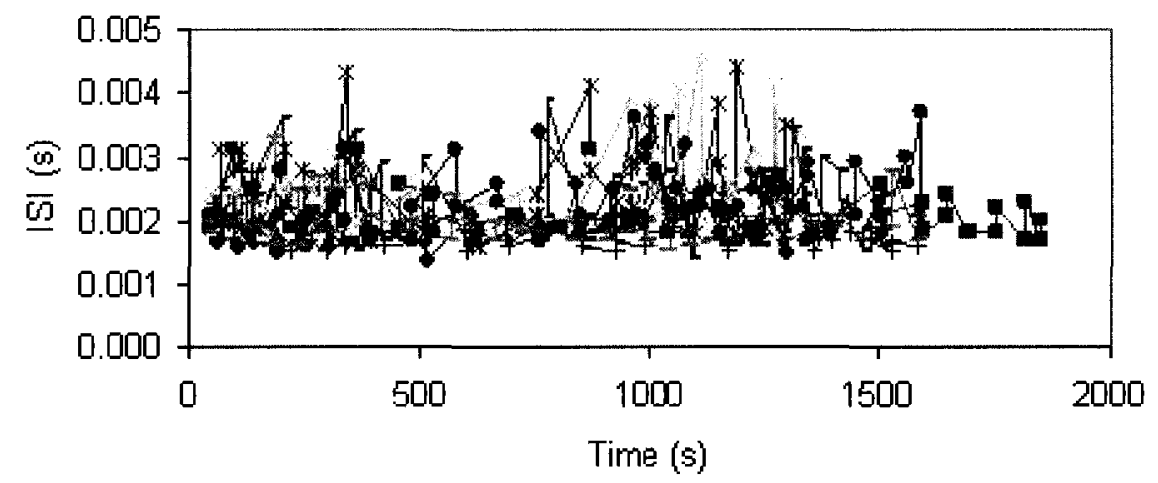

c

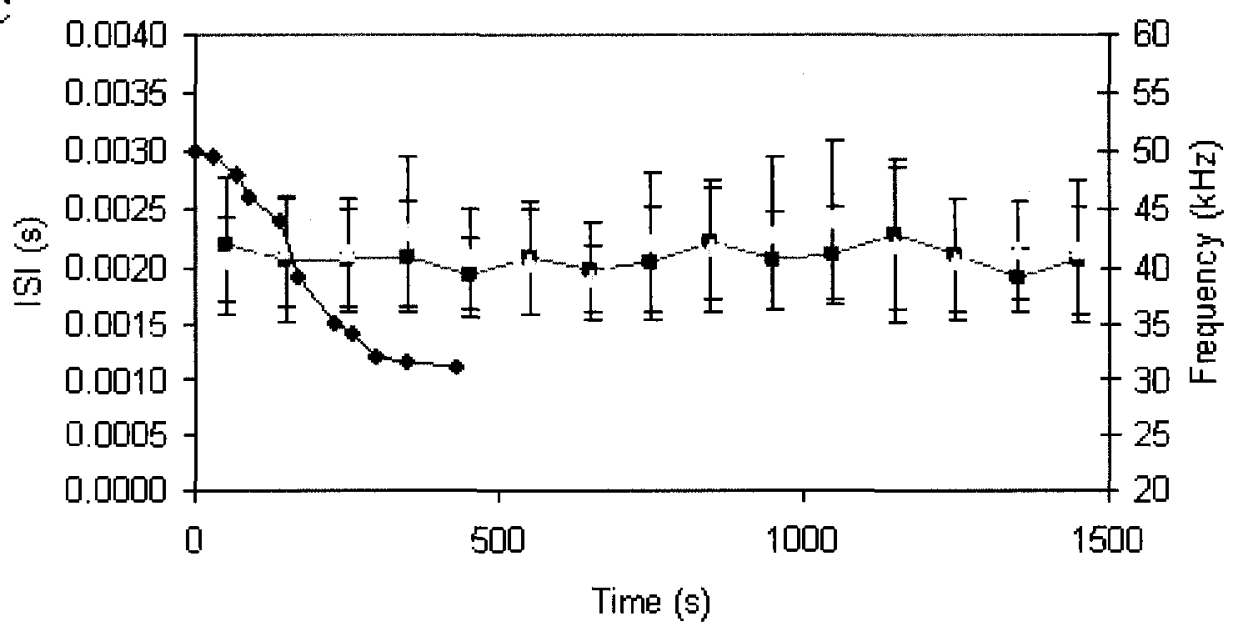

$\rightarrow-42 \quad 74 \rightarrow-$ Freq $(\mathrm{kHz})$ 

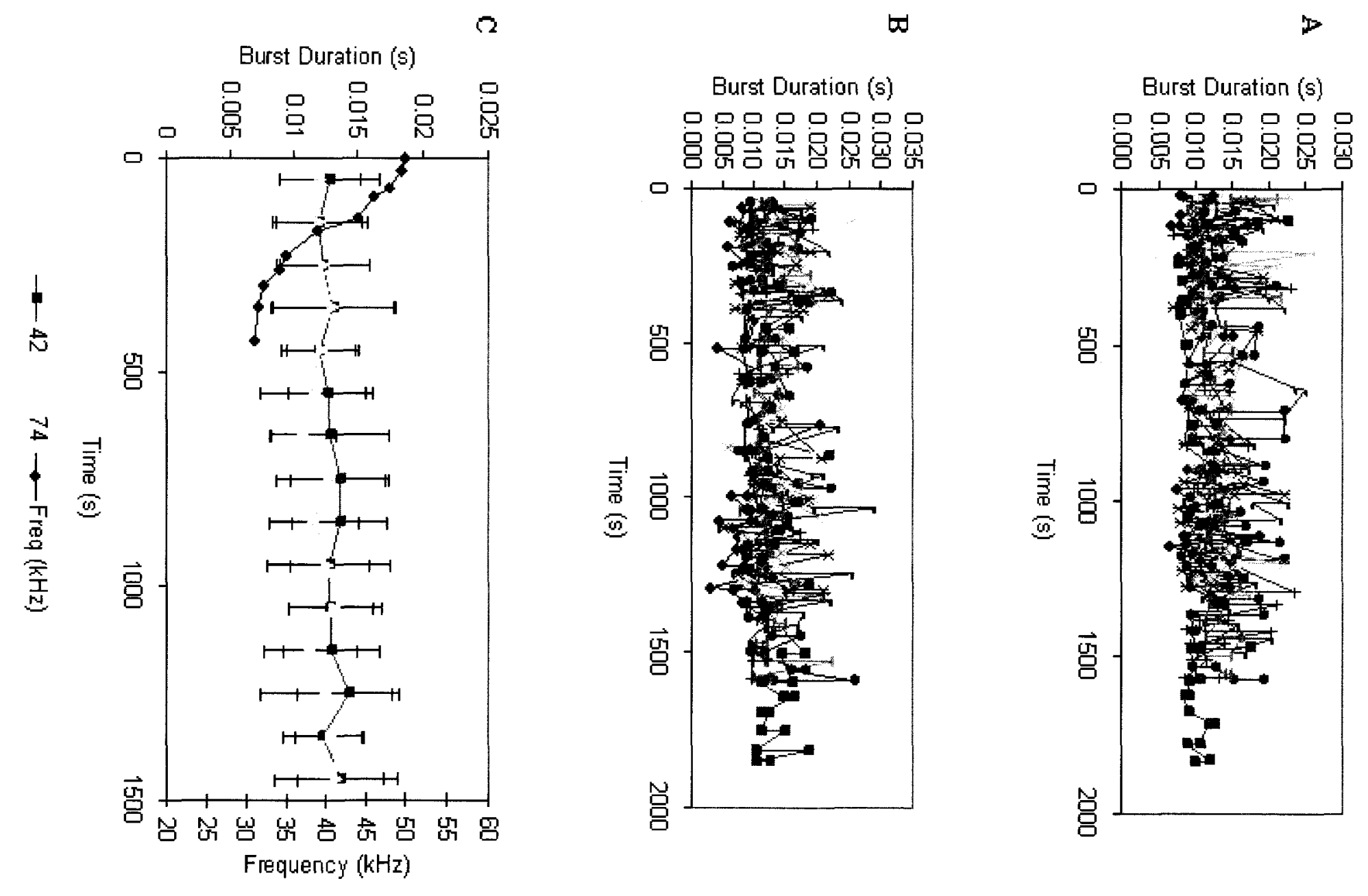
$\Omega$

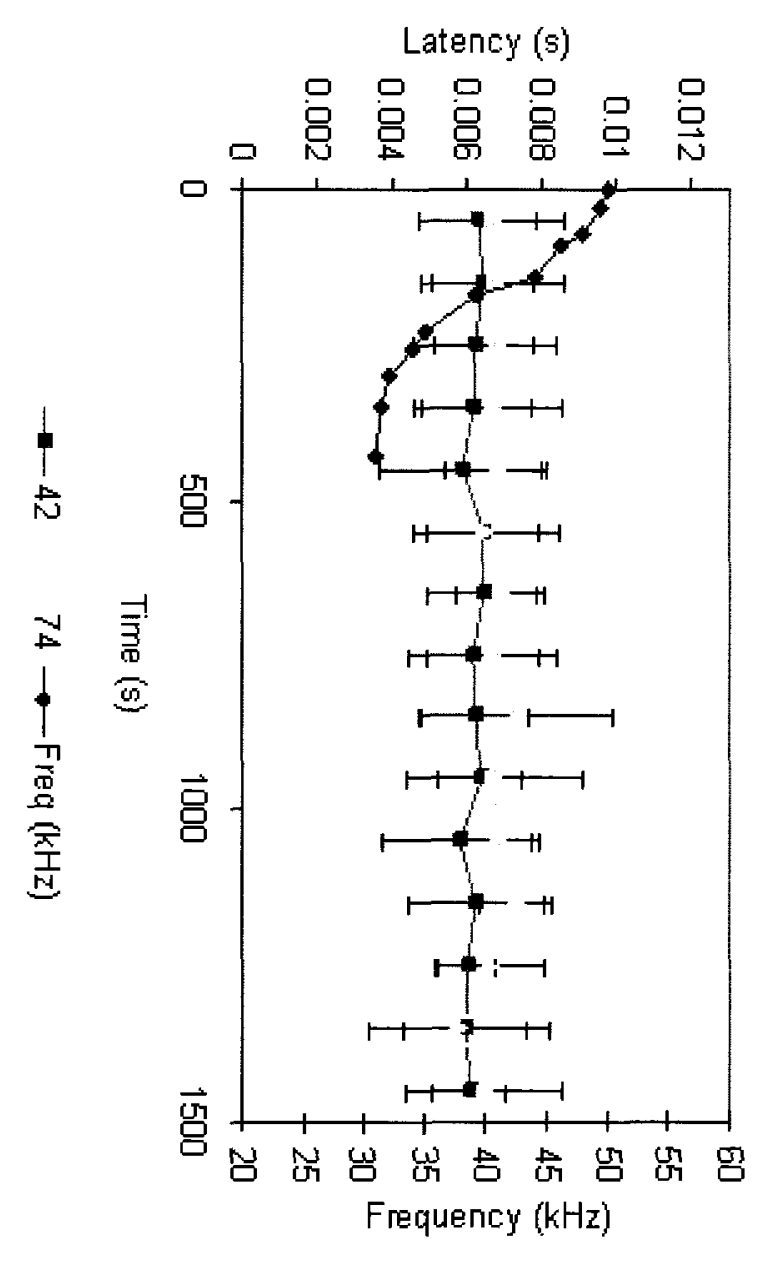

$\infty$

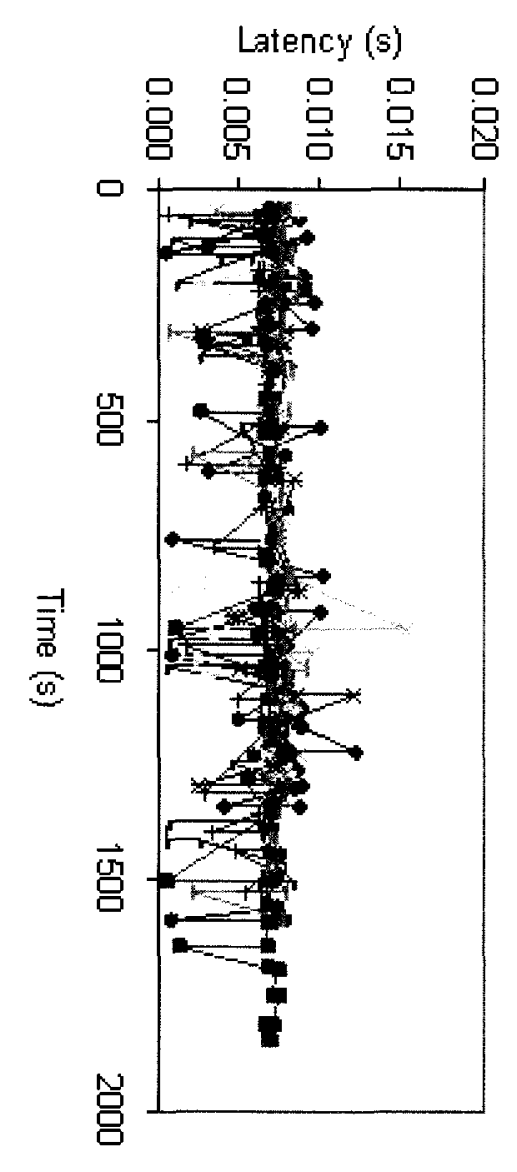

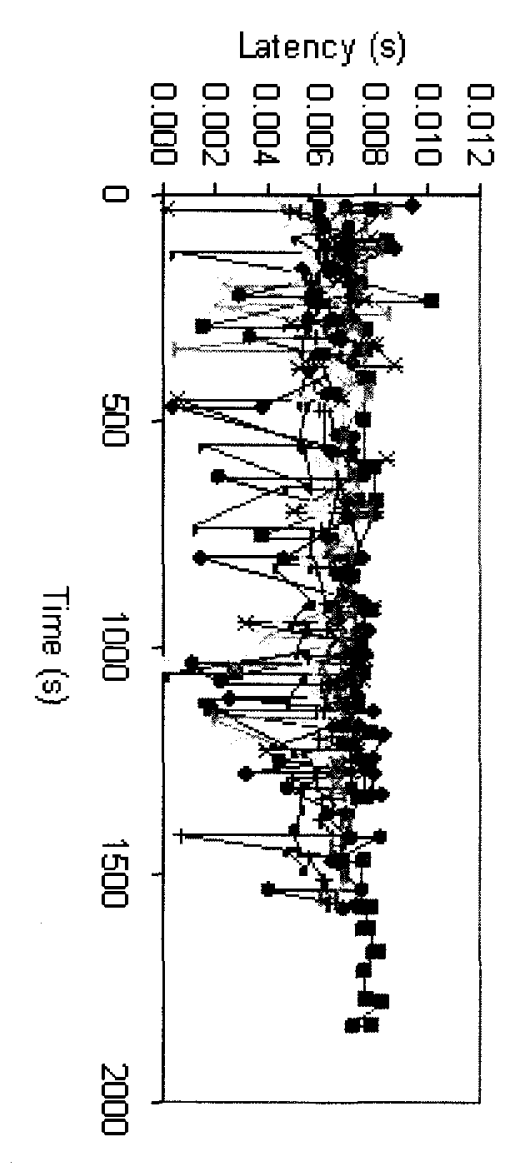


Figure 22. Time series data for interspike interval (pg. 151), burst duration (pg.152) and latency (pg. 153) in A. pyramidiodes trials. Three graphs are given: (A) scatter plot showing probe stimulus responses for all moths at $42 \mathrm{kHz}$ and (B) $74 \mathrm{kHz}$, in addition to times series data (C) placed into 100 second bins and plotted over tympanal velocity data from Windmill et al. (2006) (bars are mean (+/-SD)). Data for $42 \mathrm{kHz}$ and $74 \mathrm{Khz}$ test pulses with time values greater than 1100 seconds account for the Re portion of the trial. 

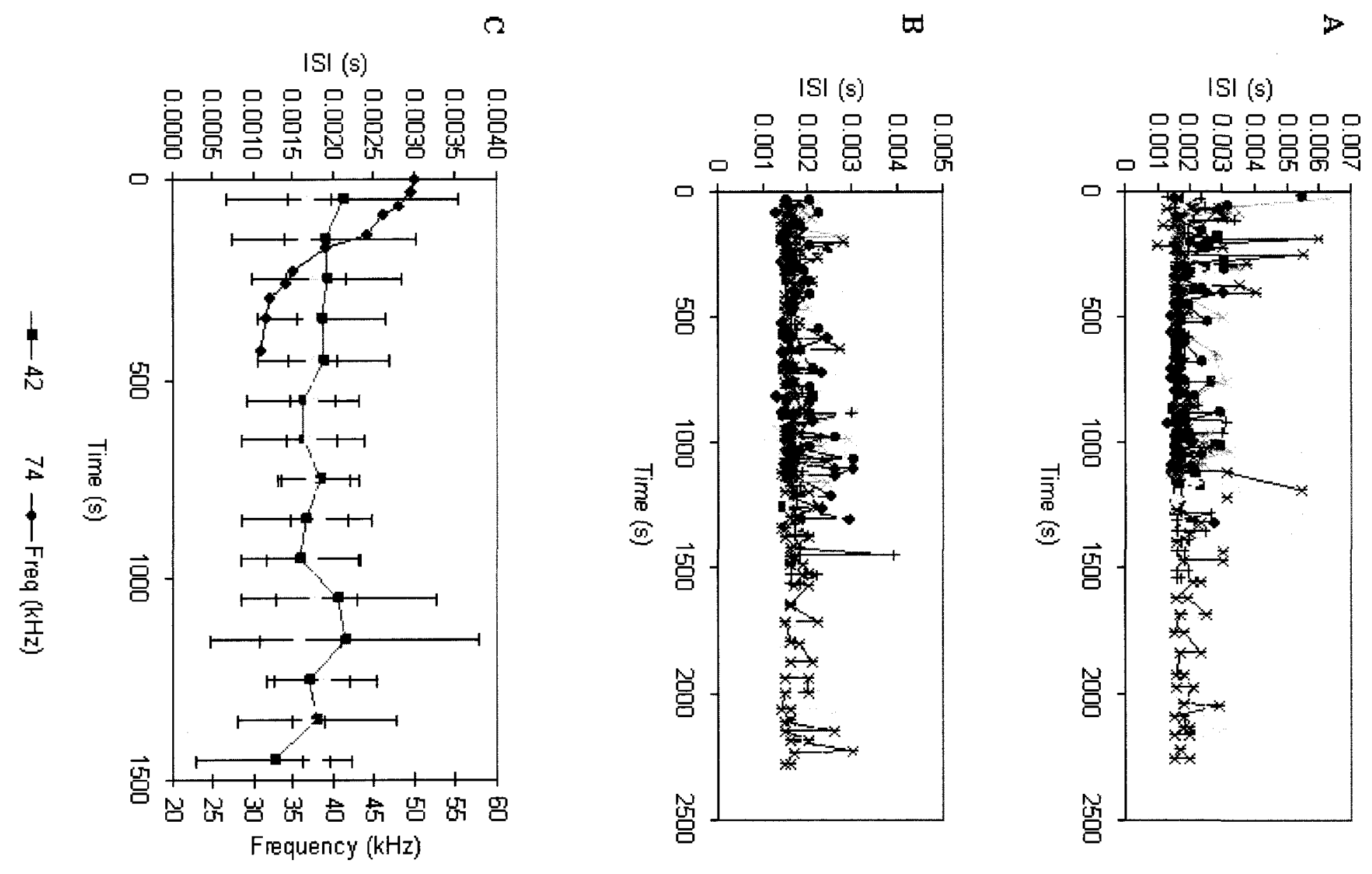


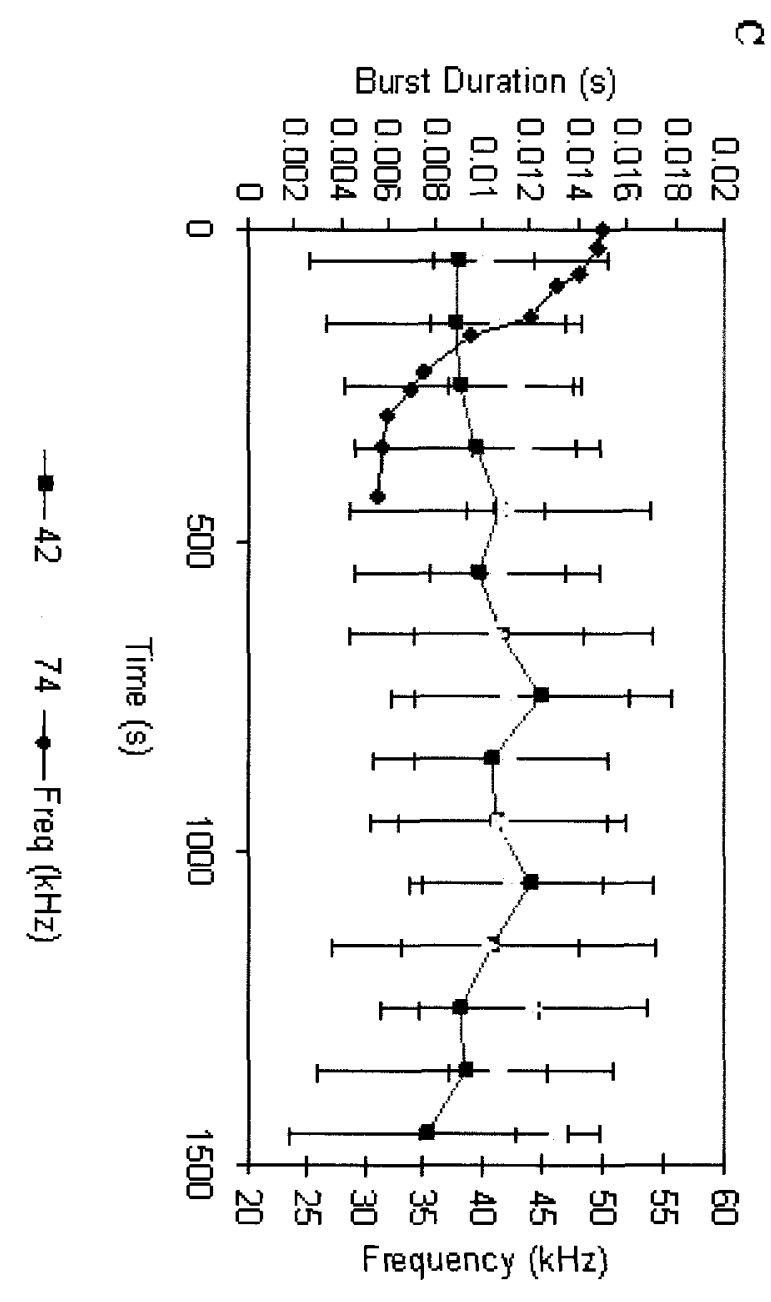

bo
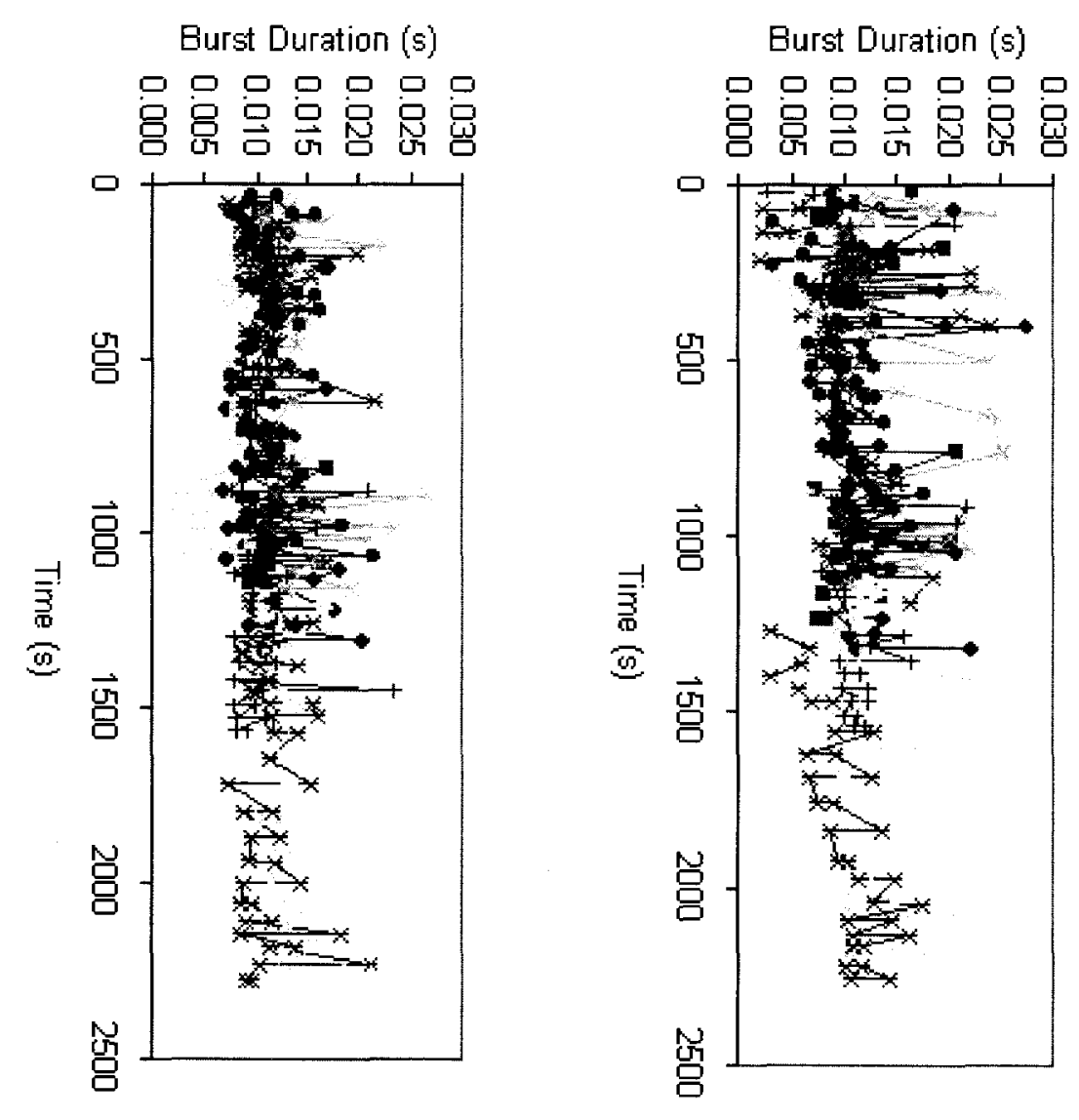
A
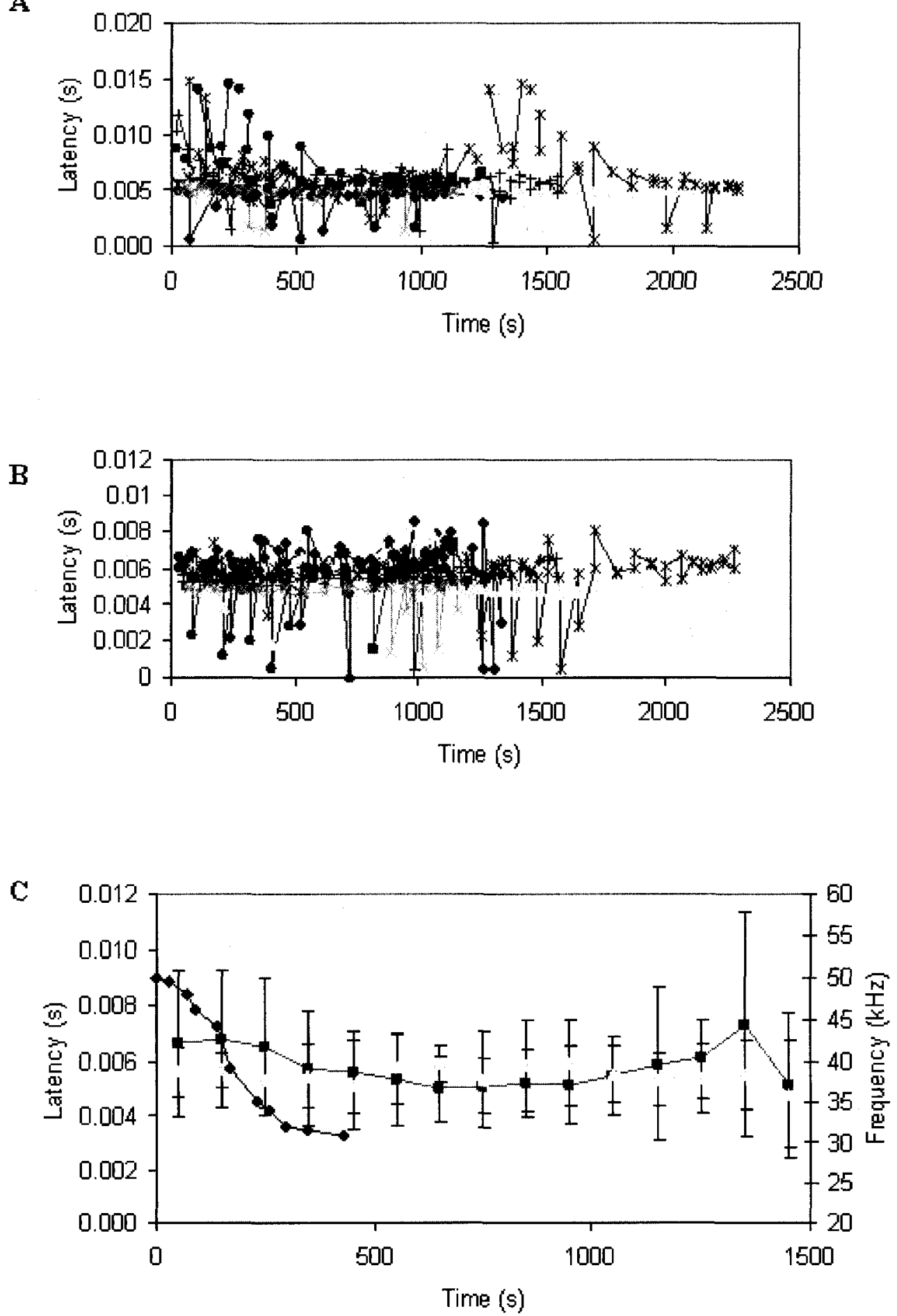

$\rightarrow-4274 \rightarrow$ Freq $(\mathrm{kHz})$ 
Figure 23. Time series data for spike number (pg. 155), interspike interval (pg. 156), burst duration (pg. 157) and latency (pg. 158) in A. americana, X. dolosa, and C. ultronia trials. Five graphs are given: (A) scatter plot showing probe stimulus responses for all moths at $42 \mathrm{kHz}$ and (B) $74 \mathrm{kHz}$, in addition to times series data for A. americana (C), $X$. dolosa (D), and C. ultronia (E) placed into 100 second bins and plotted over tympanal velocity data from Windmill et al. (2006) (bars are mean (+/-SD)). 

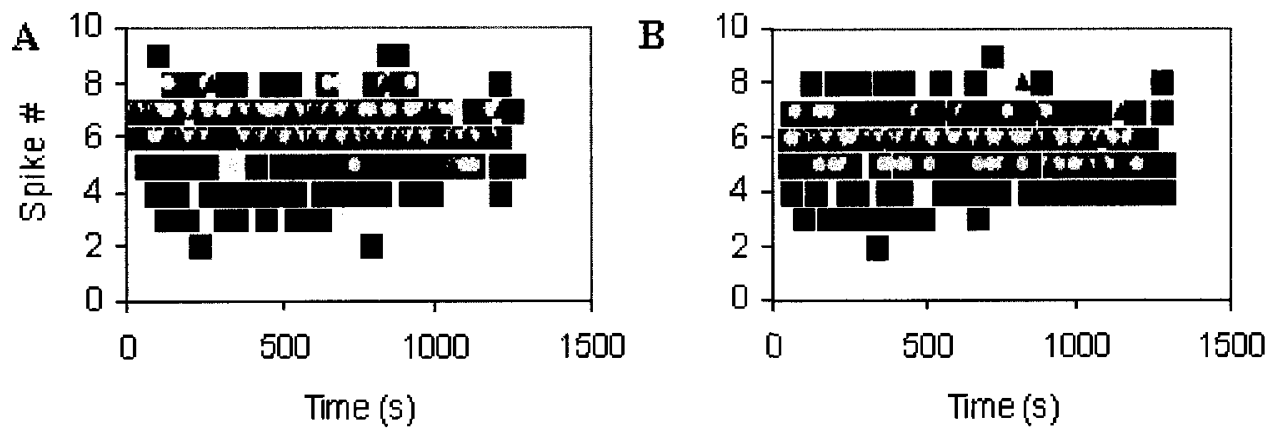

X dolosa A americara ^Catocala ultronia

$\mathrm{C}$

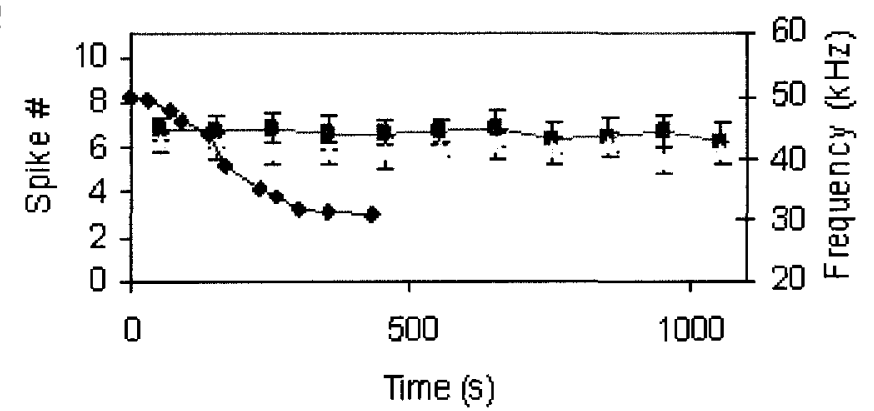

D

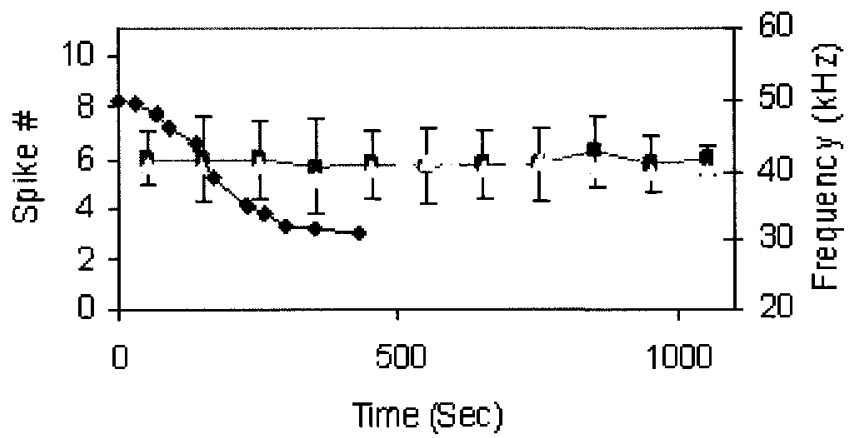

E

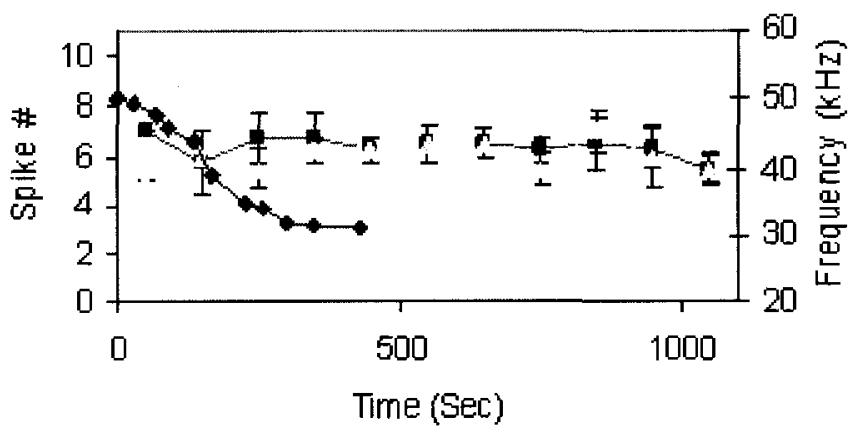

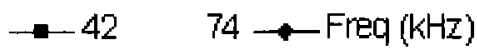



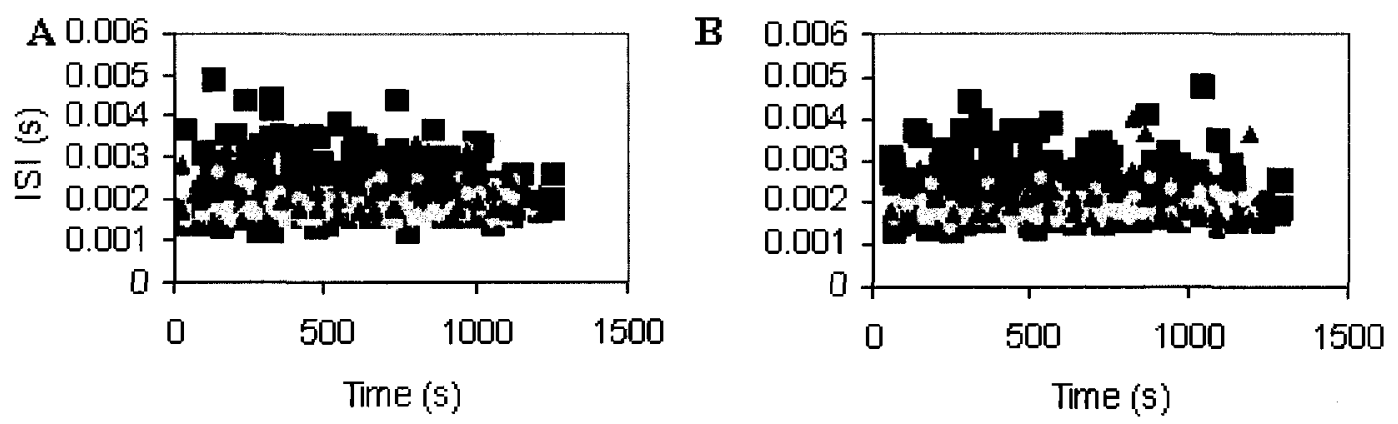

X dolasa A americana ^Catocala ultronia

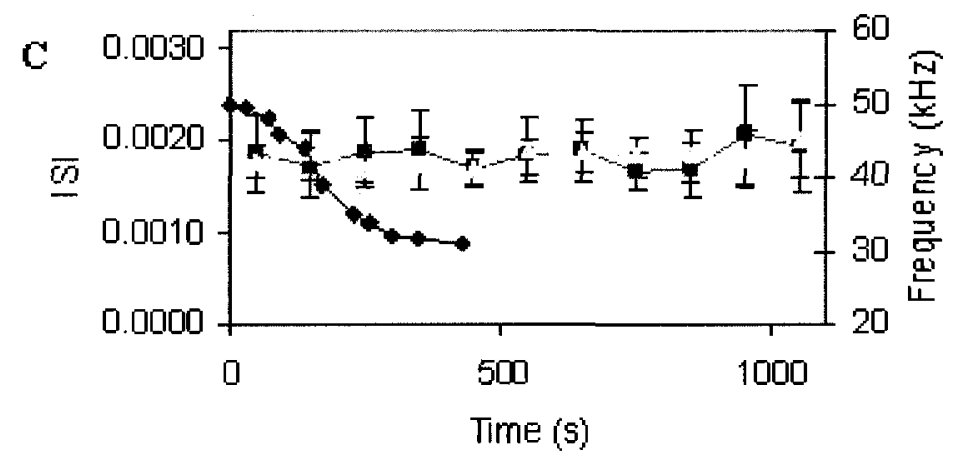

D

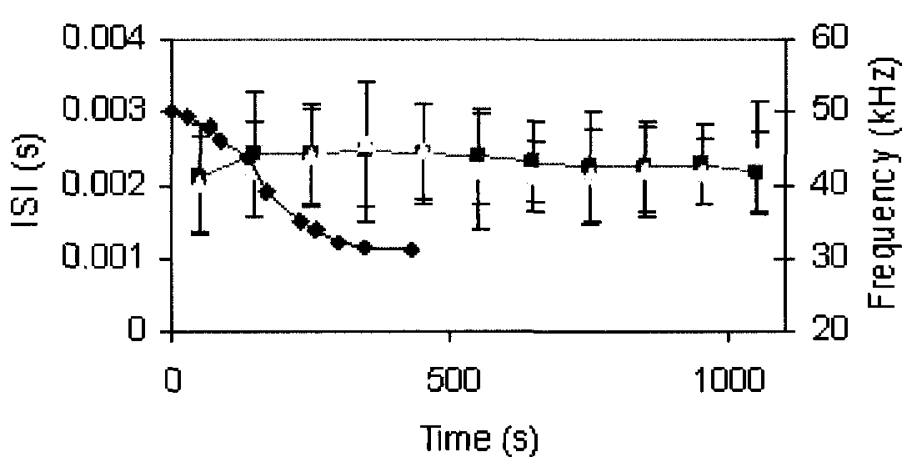

E

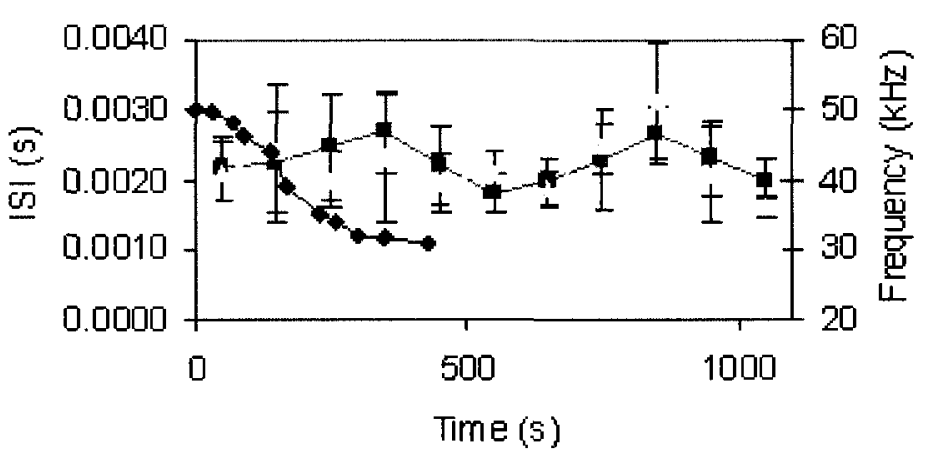

$\rightarrow-4274 \rightarrow$ Freq $(\mathrm{kHz})$ 


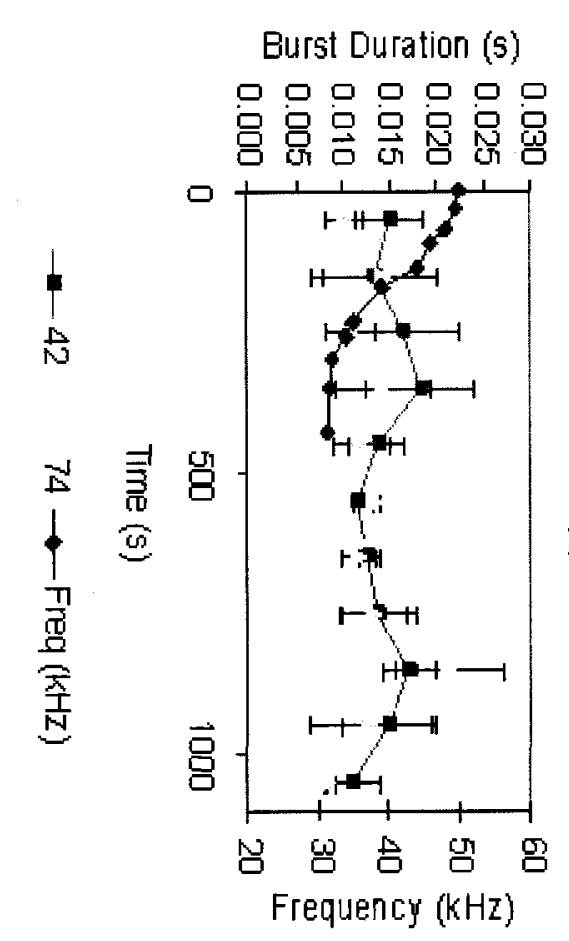

[]

$\theta$

2
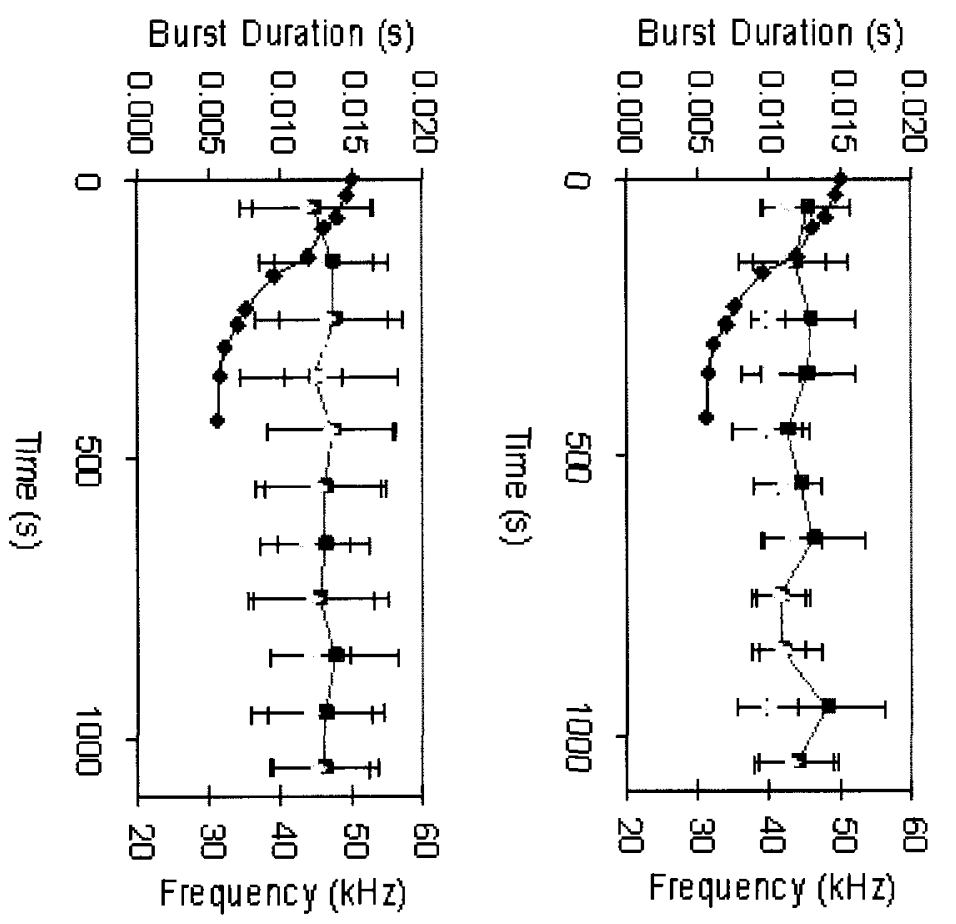

Burst Duration (5)

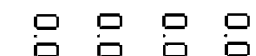

言言号皓

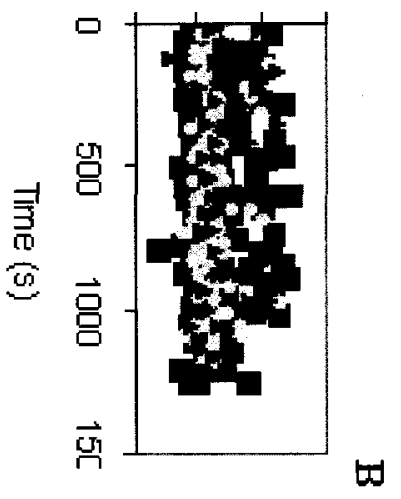




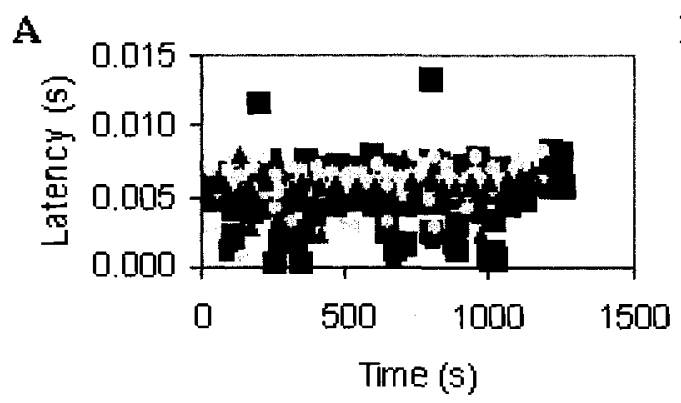

B

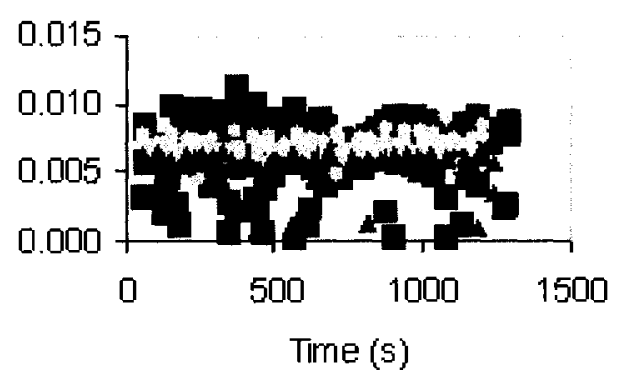

- Xdolosa A americana ^Catocala ultronia

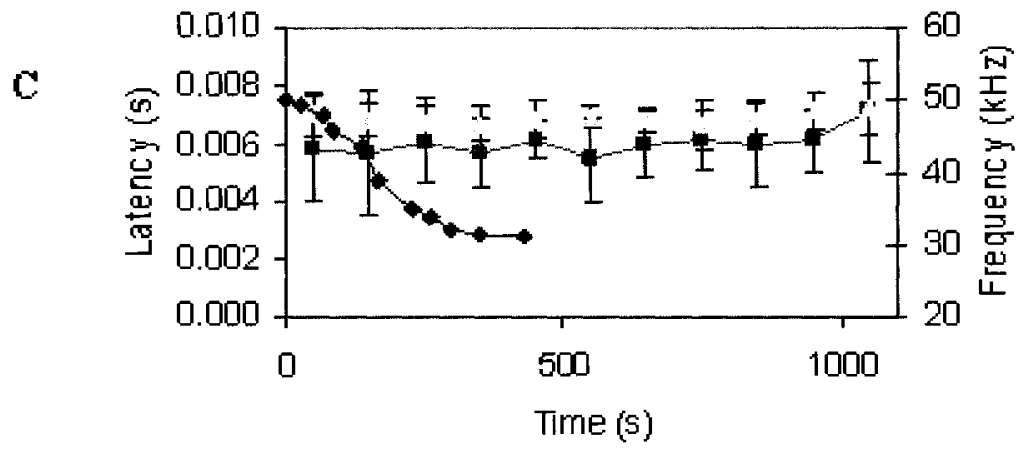

D

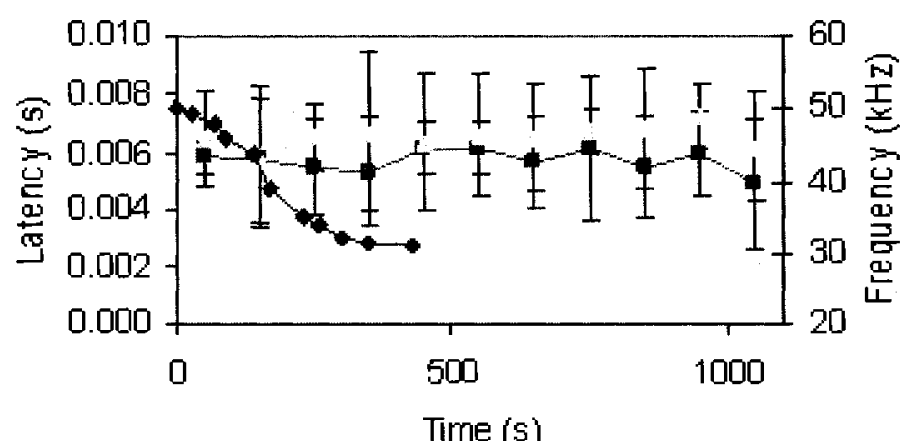

$\mathbf{E}$

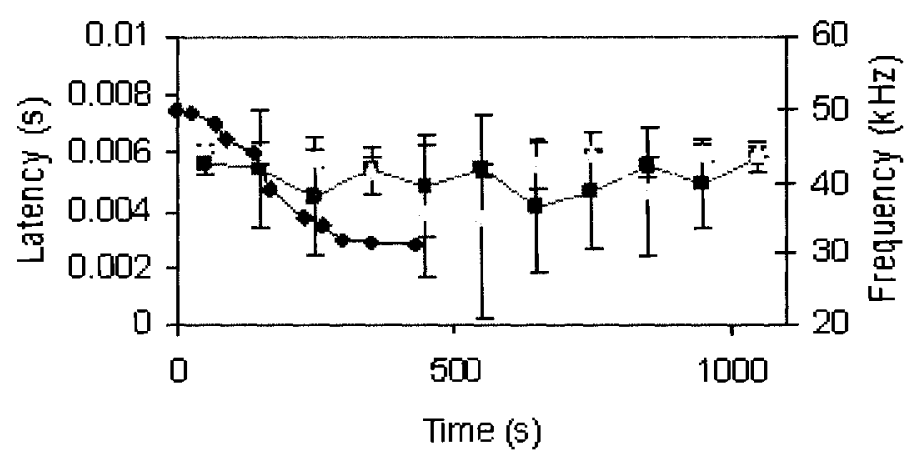

$\rightarrow-42 \quad 74 \rightarrow-$ Freq $(\mathrm{kHz})$ 